Aus der Abteilung Herz- und Kreislaufphysiologie

(Prof. Dr. med. D. M. Katschinski)

im Zentrum Physiologie und Pathophysiologie

der Medizinischen Fakultät der Universität Göttingen

\title{
Chemoresistenz als Folge einer Inhibition der zellulären Sauerstoffsensoren (Prolyl-4-Hydroxylase-Domäne)
}

\section{INAUGURAL - DISSERTATION}

zur Erlangung des Doktorgrades

der Medizinischen Fakultät der

Georg-August-Universität zu Göttingen

vorgelegt von

Nils Brökers

aus

Mettingen

Göttingen 2010 
Dekan:

I. Berichterstatterin:

II. Berichterstatter/in:

III. Berichterstatter/in:

Tag der mündlichen Prüfung: $\quad$ 13.12.2010
Prof. Dr. med. C. Frömmel

Prof. Dr. med. D. M. Katschinski

Prof. Dr. med. Gerald Wulf 


\section{Inhaltsverzeichnis}

Abbildungsverzeichnis

Tabellenverzeichnis vii

Abkürzungsverzeichnis viii

1 Einleitung 1

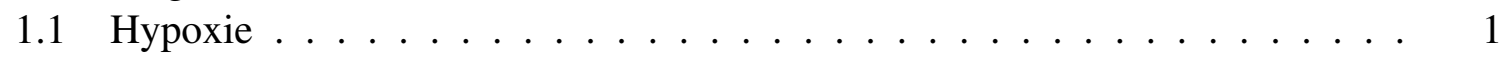

1.2 Hypoxie-induzierbarer Faktor $1(\mathrm{HIF}-1) \ldots \ldots \ldots . \ldots 2$

1.2 .1 Aufbau von HIF-1 . . . . . . . . . . . . . . . . 2

1.2 .2 Regulation von HIF-1 . . . . . . . . . . . . . . . . . . . . . . 4

1.3 Zelluläre Sauerstoffsensoren . . . . . . . . . . . . . . . . . 5

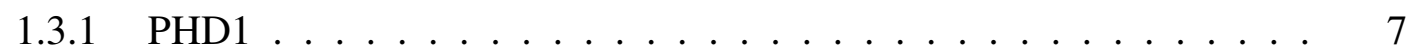

1.3 .2 PHD2 $\ldots \ldots \ldots \ldots \ldots$

1.3 .3 PHD3 $\ldots \ldots \ldots \ldots \ldots \ldots$

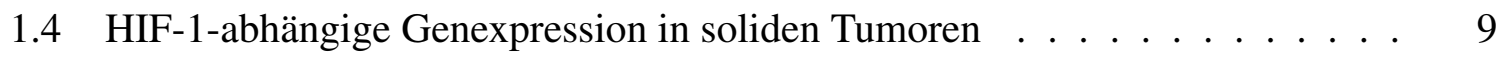

1.4 .1 HIF-1-Akkumulation in soliden Tumoren . . . . . . . . . . . . . . 9

1.4 .2 Die Bedeutung von HIF-1 für die Angiogenese . . . . . . . . . . . . . . 10

1.4 .3 Die Bedeutung von HIF-1 für den Metabolismus . . . . . . . . . . . 11

1.4 .4 Die Bedeutung von HIF-1 für die Metastasenbildung . . . . . . . . . . 11

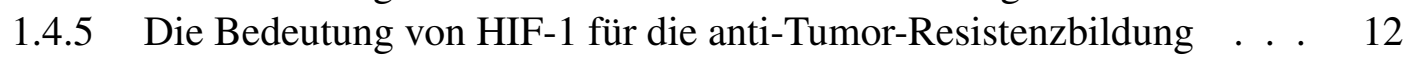

1.4.6 Die Bedeutung der PHDs für das Tumorwachstum und die anti-Tumor-

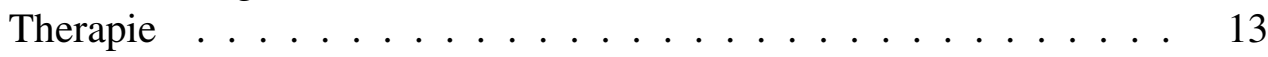

1.5 Regulation der PHDs $\ldots \ldots \ldots \ldots \ldots \ldots \ldots$

1.5.1 Regulation der PHDs durch Protein-Protein-Interaktion. . . . . . . . . 15

1.5 .2 Regulation der PHDs durch kleine Moleküle . . . . . . . . . . . . . . . . . 16

1.5 .3 PHD-Inhibitoren . . . . . . . . . . . . . . . . . . . . . 16

$1.6 \quad$ Fragestellung und Zielsetzung der Arbeit. . . . . . . . . . . . . . . . 18

2 Material und Methoden 20

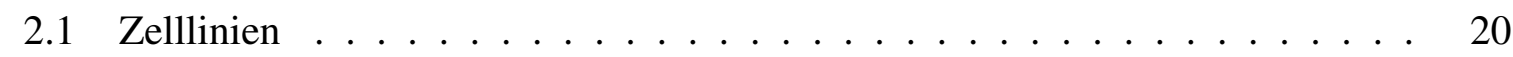

2.1 .1 HeLa-Zellen . . . . . . . . . . . . . . . . . . . . . . . . . . .

2.1 .2 T-REx-HeLa-Zellen . . . . . . . . . . . . . . . . 20

2.1 .3 PHD2- und PHD3-knock-down-Zellen . . . . . . . . . . . . 20

2.1 .4 HIF-1 $\alpha$-knock-out-Zellmodelle . . . . . . . . . . . . 22

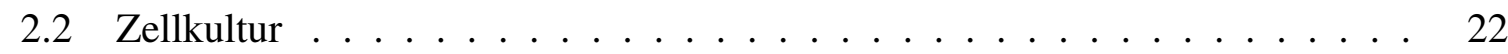


Inhaltsverzeichnis

2.3 Bestimmung der Zellzahl und Zell-Vitalität . . . . . . . . . . . . . . 23

2.4 Zytotoxizitätsnachweis durch MTT-Assay . . . . . . . . . . . . . . . . . . . 24

2.5 MTT-unabhängige Bestimmung der Zytotoxizität . . . . . . . . . . . . . . . 25

$2.6 \quad$ Bestimmung der Caspase-3/7-Aktivität. . . . . . . . . . . . . . . . . 26

2.7 Zellzyklusanalyse . . . . . . . . . . . . . . . . . 27

2.8 Bestimmung der Transporteraktivität . . . . . . . . . . . . . . . . . . . 27

2.8.1 Bestimmung des Etoposid-Influx . . . . . . . . . . . . . . . . 27

2.8 .2 Bestimmung des MDR-1-Efflux . . . . . . . . . . . . . . . . 28

2.9 Spezifischer Proteinnachweis . . . . . . . . . . . . . . . . . . . . . . . 29

2.9 .1 Proteinextraktion . . . . . . . . . . . . . . . . . . . . . . . . . . . . . . . 29

2.9 .2 Protein-Gelektrophorese . . . . . . . . . . . . . 30

2.9 .3 Western Blot . . . . . . . . . . . . . . . . . . . . 30

2.10 Nachweis spezifischer mRNA-Transkripte mittels RT-PCR . . . . . . . . . . 31

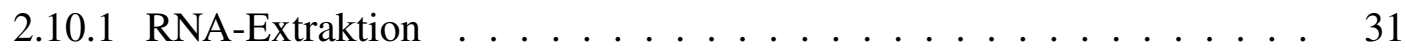

2.10 .2 Reverse Transkription . . . . . . . . . . . . . . . 32

2.10 .3 Polymerase-Ketten-Reaktion (PCR) . . . . . . . . . . . . . . . . . . . . 32

2.10 .4 Agarose-Gelelektrophorese . . . . . . . . . . . . . . . . . . 33

2.11 Statistische Auswertung . . . . . . . . . . . . . . . . . 33

3 Ergebnisse 35

$3.1 \quad$ Behandlung von HeLa-Zellen mit dem PHD-Inhibitor DMOG führt zu erhöhter Chemoresistenz gegenüber Etoposid, nicht aber Carboplatin . . . . . . . . 35

3.2 Die Resistenzzunahme gegenüber Etoposid in Anwesenheit von DMOG ist

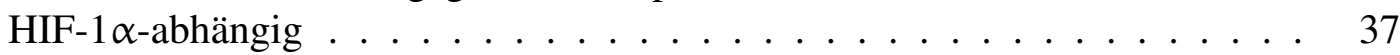

3.3 Charakterisierung einer PHD2- und PHD3-knock-down-Zelllinie . . . . . . . 40

3.3.1 Ein PHD2- bzw. PHD3-knock-down hat keinen Einfluss auf die Proliferation ..................... 40

3.3.2 Ein PHD2-knock-down hat keinen Einfluss auf den Zellzyklus . . . . 43

3.3.3 Ein PHD2- bzw. PHD3-knock-down hat keinen Einfluss auf die Zellvitalität ........................ 44

3.4 Ein PHD2-knock-down führt zur Resistenzzunahme gegenüber Etoposid, nicht aber Carboplatin . . . . . . . . . . . . . . . . . . 45

$3.5 \quad$ Gesteigerte Vitalität nach PHD2-knock-down in Anwesenheit von Etoposid . 47

3.6 Ein PHD3-knock-down hat keinen Einfluss auf die Etoposid-induzierte Zyto-

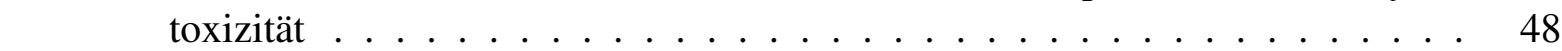

3.7 Der Anstieg der aktiven Caspase 3/7 nach Behandlung mit Etoposid ist PHD2-

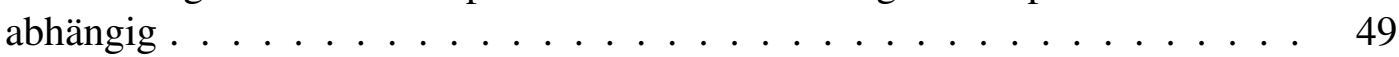

3.8 Charakterisierung der PHD2-abhängigen Transportkapazität . . . . . . . . . 51

3.8.1 Ein PHD2-knock-down und eine DMOG-Behandlung haben keinen Einfluss auf die Aufnahme von Etoposid. . . . . . . . . . . . 51

3.8.2 Ein PHD2-knock-down führt zu einer Resistenzzunahme gegenüber den MDR-1-Substraten Vinblastin und Doxorubicin . . . . . . . . 53 
Inhaltsverzeichnis

3.8.3 Die Resistenzzunahme infolge eines PHD2-knock-downs ist MDR-1-

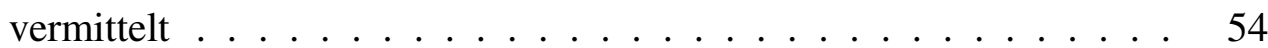

3.9 Behandlung von Zellen mit DMOG führt HIF-1 $\alpha$-abhängig zu einer erhöhten Expression und Aktivität von MDR-1 . . . . . . . . . . . . . . . . 57

$\begin{array}{lll}4 & \text { Diskussion } & 60\end{array}$

\begin{tabular}{lll}
\hline 5 & Zusammenfassung & 73
\end{tabular}

\begin{tabular}{lll}
\hline 6 & Literaturverzeichnis & 74
\end{tabular}

\begin{tabular}{lll}
\hline 7 & Publikation & 88
\end{tabular} 


\section{Abbildungsverzeichnis}

1.1 Der Aufbau des Transkriptionsfaktors HIF-1 $\alpha$. . . . . . . . . . . 3

$1.2 \quad$ Vereinfachtes schematisches Modell der zellulären Sauerstoffregulation. . . . 5

$1.3 \quad$ PHD katalysiert Prolyl-4-Hydroxylierung der $\alpha$-Untereinheit HIF-1 $\alpha$. . . . . 7

2.1 Tetrazyklin-induzierbare Expression der shRNA. . . . . . . . . . . . . . 21

2.2 Die Expression von PHD2 bzw. PHD3 der etablierten PHD2 (2.1.1-16)- bzw. PHD3 (3.3.3)-knock-down-Zelllinien ist abhängig von einer Inkubation mit

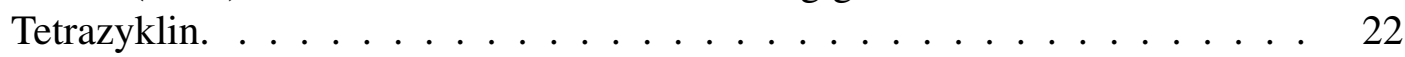

$2.3 \quad$ Das Tetrazoliumsalz MTT wird in lebenden Zellen enzymatisch gespalten. . . 25

3.1 Behandlung von HeLa-Zellen mit dem 2-Oxoglutaratanalogon DMOG führt zu einer Stabilisierung von HIF-1 $\alpha . \ldots \ldots \ldots$. . . . . . . . . . . 35

3.2 Inhibition der PHD-Aktivität mit DMOG verringert die Etoposid-induzierte Zytotoxizität, nicht aber die Carboplatin-induzierte Zytotoxizität. . . . . . . . . 36

3.3 Behandlung mit DMOG führt in MEF-Hif- $1 \alpha^{+/+}$-Zellen zu einer Stabilisierung von HIF-1 $\alpha$, nicht aber in MEF-Hif-1 $\alpha^{-1-}$-Zellen. $\ldots . . . . . . . .38$

3.4 DMOG beeinflusst die Etoposid-induzierte Zytotoxizität in Abhängigkeit von HIF-1 $\alpha$, hat aber keinen Einfluss auf das Zellüberleben nach Behandlung mit Carboplatin. ...................... 39

3.5 Behandlung von 2.1.1-16-Zellen mit Tetrazyklin führt zu einer Stabilisierung von HIF-1 $\alpha . \ldots \ldots \ldots$. . . . . . . . . . . . . . . . . 40

3.6 Die Proliferation der T-REx-HeLa-, 2.1.1-16- und 3.3.3-Zellen ist Tetrazyklin-

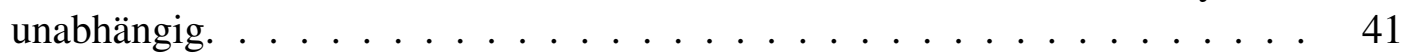

3.7 Ein PHD2-knock-down hat keinen Einfluss auf die Zellzyklusverteilung. . . . 43

3.8 Die Vitalität der T-REx-HeLa- und der 2.1.1-16- bzw. 3.3.3-Zelllinien sind Tetrazyklin-unabhängig. . . . . . . . . . . . . . . . 44 44

3.9 PHD2 beeinflusst das Zellüberleben nach Gabe von Etoposid in Normoxie und

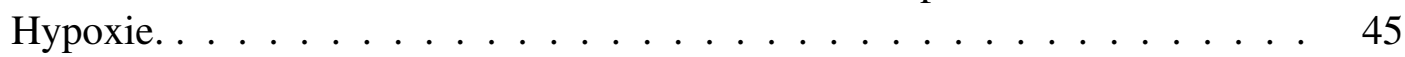

3.10 PHD2 hat keinen Einfluss auf das Zellüberleben nach Gabe von Carboplatin in Normoxie und Hypoxie. . . . . . . . . . . . . . . . . . . . . . . 46

3.11 PHD2 beeinflusst die Vitalität nach Gabe von Etoposid. . . . . . . . . . . . . 48

3.12 PHD3 hat keinen Einfluss auf das Zellüberleben nach Gabe von Etoposid in Normoxie und Hypoxie. . . . . . . . . . . . . . . . . . . . . 49

3.13 PHD2 beeinflusst die Konzentration der aktiven Caspase 3/7 nach Gabe von

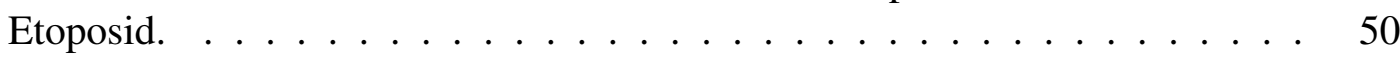


Abbildungsverzeichnis

3.14 Die Aufnahme von Etoposid wird nicht beeinflusst durch einen PHD2-knockdown oder DMOG-Behandlung. . . . . . . . . . . . . . . . 52

3.15 PHD2 beeinflusst das Zellüberleben nach Behandlung mit Vinblastin und Do-

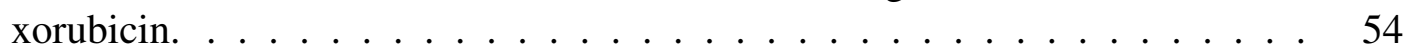

3.16 Verapamilbehandlung beeinflusst die Etoposid-induzierte Zytotoxizität nur bei den PHD2-knock-down-Zellen. . . . . . . . . . . . . . . . . 56

3.17 DMOG induziert die Expression von MDR-1 auf RNA- und Proteinebene

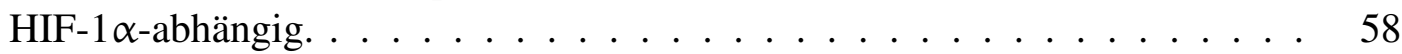

3.18 Gesteigerte Aktivität des MDR-1-Transporters durch DMOG-Behandlung. . . 59 


\section{Tabellenverzeichnis}

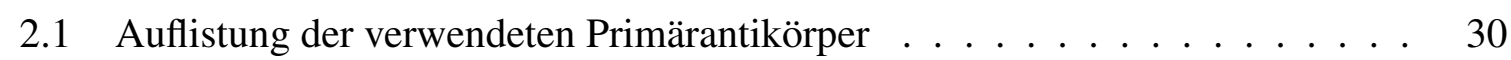

2.2 Auflistung der verwendeten Sekundärantikörper . . . . . . . . . . . . . . . . 31

2.3 Auflistung der verwendeten Primer . . . . . . . . . . . . . . . . . 33

3.1 Auflistung der zellspezifischen Wachstumsraten und Verdoppelungszeiten . . 42 


\title{
Abkürzungsverzeichnis
}

\author{
ABC $\ldots \ldots \ldots$ engl. ATP-binding cassette \\ ABCB $1 \ldots \ldots$ engl. ATP-binding cassette subfamily B \\ ARNT ......... engl. AhR nuclear translocator \\ ATCC ......... engl. American Type Culture Collection \\ ATF-4 ........ engl. activating transcription factor-4 \\ ATP .......... Adenosintriphosphat \\ Bcl-2 ........ engl. B-cell lymphoma 2 \\ bHLH $\ldots \ldots \ldots$ basische Helix-Loop-Helix \\ BSA $\ldots \ldots \ldots$ engl. bovine serum albumin \\ CBP .......... CREB-bindendes Protein \\ cDNA ......... komplementäre DNA \\ CMVP ........ Zytomegalievirus-Promotor \\ $\mathrm{CO}_{2} \ldots \ldots \ldots$ Kohlenstoffdioxid \\ CTAD ......... C-terminale transaktivierende Domäne \\ DEPC ......... Diethylpyrocarbonat \\ DEVD ......... Einbuchstabencode für Asparaginsäure-Glutaminsä ure-Valin-Asparaginsäure \\ DMEM ........ engl. Dulbecco's modified Eagle's medium \\ DMOG ........ Dimethyloxalylglycin \\ DMSO ........ Dimethylsulfoxid \\ DNA $\ldots \ldots \ldots$ engl. deoxyribonucleic acid \\ EDTA $\ldots \ldots \ldots$ Ethylendiamintetraacetat \\ EPO .......... Erythropoietin \\ et al. ......... lat. et alii; und andere \\ FACS ......... engl. fluorescence activated cell sorting \\ FIH-1 ....... engl. factor inhibiting HIF-1 \\ FKS .......... fetales Kälberserum \\ GF-AFC ....... engl. Gly-Phe-7-amino-4 trifluoromethyl coumarin \\ h ............ Stunde/n \\ H-ras ........ engl. harvey rat sarcoma virus oncogene 1 \\ HeLa-Zellen .... menschliche Epithelzellen eines Zervixkarzinoms, Ursprung: Henrietta Lacks \\ HEPES ........ 2-(4-(2-Hydroxyethyl)-1-piperazinyl)-ethansulfonsäure \\ HIF-1 ........ Hypoxie-induzierbarer Faktor 1 \\ HIF-2 ....... Hypoxie-induzierbarer Faktor 2 \\ HNO ......... Hals-Nasen-Ohren \\ HRE ......... engl. hypoxia response element \\ $\mathrm{IC}_{50} \ldots \ldots \ldots$. Dosis, bei der die Hälfte der Zellen stirbt
}




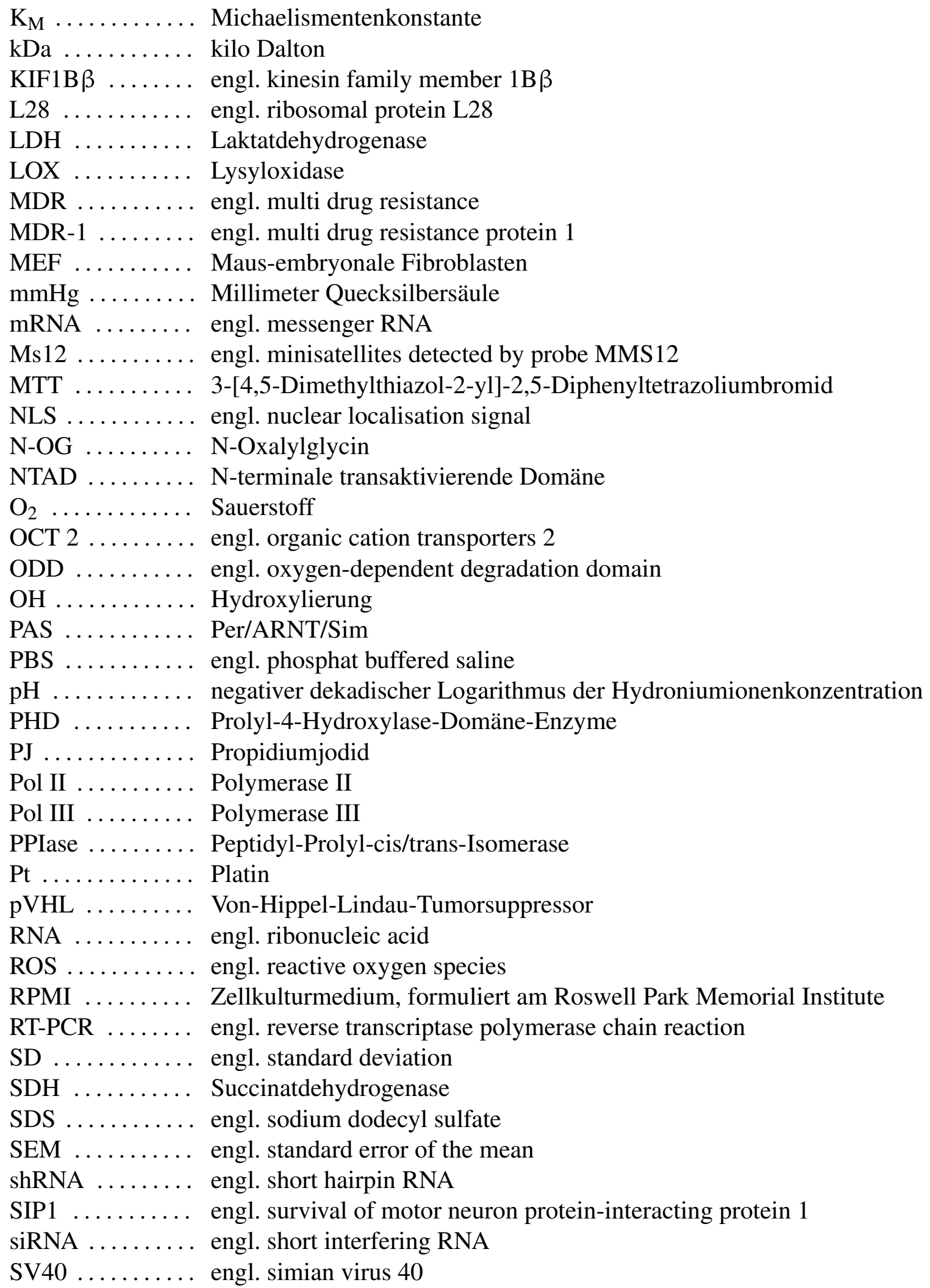


T-REx HeLa .... engl. Tetracycline-regulated expression HeLa cells

TA ........... transaktivierende Domäne

TAE .......... Tris-Acetat-EDTA-Puffer

TATA-Boy ..... Goldberg-Hogness-Box, in der Promotorregion eines Gens

TE ........... Tris-EDTA

Tet ......... Tetrazyklin

TetO ......... Tet Operator

TetR .......... Tet Repressor

Tris $\ldots \ldots \ldots \ldots$ Tris-(hydroxymethyl-)aminomethan

$\mathrm{Ub} \ldots . . \ldots . .$. Ubiquitinierung

VEGF ......... engl. vascular endothelial growth factor 


\section{Einleitung}

\subsection{Hypoxie}

Sauerstoff ist essentiell für eine effiziente zelluläre Energiegewinnung. Über die äußere Atmung wird Sauerstoff aufgenommen und erreicht über den Blutstrom vor allem als Oxyhämoglobin die einzelne Zelle, wo er als Elektronenakzeptor innerhalb der Atmungskette für die ATP-Gewinnung benötigt wird. Systemisch wird das Sauerstoffangebot fortlaufend von zentralen und peripheren Chemorezeptoren kontrolliert, die an der Regulation der Atmung beteiligt sind [Prabhakar and Kline, 2002]. Normalerweise liegt der arterielle Sauerstoffpartialdruck um 90 mmHg. Jede Änderung dieses Wertes, zum Beispiel im Rahmen einer respiratorischen Insuffizienz oder einer Hyperventilation, wird mit einer erhöhten oder erniedrigten Atemfrequenz im Sinne eines Regelkreises beantwortet. Die Abgabe des gebundenen Sauerstoffs erfolgt im Kapillarsystem, wenn ein mitochondrialer Bedarf vorhanden ist. Je nach Entfernung zwischen Blutsystem und Zelle muss eine bestimmte Diffusionsstrecke zurückgelegt werden. Problematisch ist, dass mit zunehmender Distanz der Sauerstoffpartialdruck exponentiell abfällt. Jede Zelle ist demnach mit einem unterschiedlichen Partialdruck konfrontiert, der zudem im Zeitverlauf nie konstant ist. Um Plastizität auf zellulärer Ebene zu erreichen, muss daher ein komplexes System vorhanden sein, das, vergleichbar mit den Chemorezeptoren, fortwährend das Sauerstoffangebot misst und die Genexpression der Zelle an die momentanen Bedingungen anpasst.

Sinkt das Sauerstoffangebot unter den Sauerstoffbedarf (Hypoxie), wird der Transkriptionsfaktor Hypoxie-induzierbarer Faktor 1 (HIF-1) stabilisiert [Wang GL et al., 1995]. Bis heute sind mehr als 100 Zielgene bekannt, die HIF-1-abhängig exprimiert werden und so eine Adaptation an den Sauerstoffpartialdruck ermöglichen. So werden unter anderem Angiogenese, pH-Regulation, Zellwachstum und Sauerstoffversorgung HIF-1-abhängig reguliert [Wenger, 2002]. 


\subsection{Hypoxie-induzierbarer Faktor 1 (HIF-1)}

Der Transkriptionsfaktor HIF-1 spielt eine Schlüsselrolle in der zellulären Adaptation gegenüber hypoxischen Bedingungen. HIF-1 wird in allen kernhaltigen Zellen des Organismus exprimiert und ist für die sauerstoffabhängige Regulation von mehr als 100 Genen verantwortlich, darunter Gene für Sauerstoff- und Nährstoffversorgung, Angiogenese, Zellwachstum, Zellmobilität und pH-Regulation [Wenger, 2002]. HIF-1 $\alpha$-knock-out-Mäuse sind nicht überlebensfähig und weisen Neuralrohrdefekte und kardiovaskuläre Fehlbildung auf. Diese Beobachtung deutet auf eine zentrale Bedeutung von HIF-1 während der Embryogenese hin [Iyer et al., 1998].

\subsubsection{Aufbau von HIF-1}

HIF-1, ein Heterodimer, besteht aus einer $120 \mathrm{kDa}$ großen $\alpha$ - und 91-94 kDa großen $\beta$ Untereinheit, auch bekannt als AhR nuclear translocator (ARNT) [Hoffman et al., 1991]. Die Größenangaben beziehen sich auf das posttranslational modifizierte Protein. Die $\beta$-Untereinheit wird konstitutiv exprimiert, ist im Zellkern lokalisiert und unterliegt keiner sauerstoffabhängigen Regulation. Sie dient, neben der $\alpha$-Untereinheit, als Interaktionspartner für weitere Proteine. Die $\alpha$-Untereinheit wird ebenfalls konstitutiv exprimiert, unterliegt hingegen einer sauerstoffabhängigen Regulation [Schofield and Ratcliffe, 2004].

HIF- $\alpha$ - und - $\beta$-Untereinheiten weisen eine N-terminale bHLH (basische Helix-Loop-Helix)PAS (Per/ARNT/Sim)-Domäne auf [Yang et al., 2005]. Per/ARNT/Sim sind Abkürzungen für Proteine, bei denen diese Domäne zuerst entdeckt wurde [Taylor and Zhulin, 1999]. Diese Domäne ist für die Dimerisierung zwischen der $\alpha$ - und $\beta$-Untereinheit sowie deren Bindung an die DNA-Sequenz 5'-G/ACGTG-3', der sogenannten hypoxia response element (HRE), innerhalb der Promotorregion eines Gens verantwortlich [Wang GL et al., 1995]. HIF-1 $\alpha$ wird auf der Ebene der Proteinstabilität reguliert. Unter normoxischen Bedingungen wird HIF-1 $\alpha$ 2-Oxoglutarat- und Eisen-abhängig an Prolinresten der Position 402 und 564 innerhalb seiner oxygen-dependent degradation domain (ODD) hydroxyliert und so posttranslational für den Abbau markiert. HIF-1 $\alpha$ weist zwei transaktivierende Domänen (N-terminale transaktivierende Domäne NTAD und C-terminale transaktivierende Domäne CTAD) auf. In diesen Regionen erfolgt die Regulation der transkriptionellen Aktivität von HIF-1 $\alpha$ über posttranslationale Hydroxylierung und Phosphorylierung. So verhindert zum Beispiel eine Hydroxylierung des 
Asparaginrestes an der Position 803 innerhalb des CTAD die Interaktion mit den Kofaktoren CBP (CREB-bindendes Protein) und p300 [Arany et al., 1996; Lando et al., 2002b].

Neben dem ubiquitinär exprimierten HIF- $1 \alpha$ konnten zwei weitere $\alpha$-Untereinheiten (HIF$2 \alpha$ und HIF- $3 \alpha$ ) identifiziert werden. Eine HIF- $2 \alpha$-Expression konnte während der Embryogenese in endothelialen Zellen nachgewiesen werden. Im adulten Organismus ist die Expression im Vergleich zu HIF-1 $\alpha$ restriktiver und organsspezifischer. Hohe Proteinlevel konnten für Plazenta, Lunge und Herz gezeigt werden. HIF- $2 \alpha$ dimerisiert ebenfalls mit der $\beta$ Untereinheit und ist an dem adaptiven Prozess gegenüber Hypoxie beteiligt [Ema et al., 1997].

Aufgrund seines Verhaltens nimmt HIF-3 $\alpha$ innerhalb der HIF-Familie eine Sonderstellung ein. HIF-3 $\alpha$ wird unter hypoxischen Bedingungen vor allem auf der Ebene der Transkription induziert. Seine Bedeutung hinsichtlich einer zellulären Adaptation gegenüber Hypoxie wird als gering eingeschätzt, da eine transkriptionelle Aktivität kaum nachweisbar ist. Aufgrund diverser Splicevarianten, die eine spätere Interaktion mit der DNA verhindern, wird eine Funktion als kompetitiver Inhibitor der Dimerisierung zwischen der $\beta$ - und anderen $\alpha$ Untereinheiten diskutiert [Gu et al., 1998; Maynard et al., 2003].

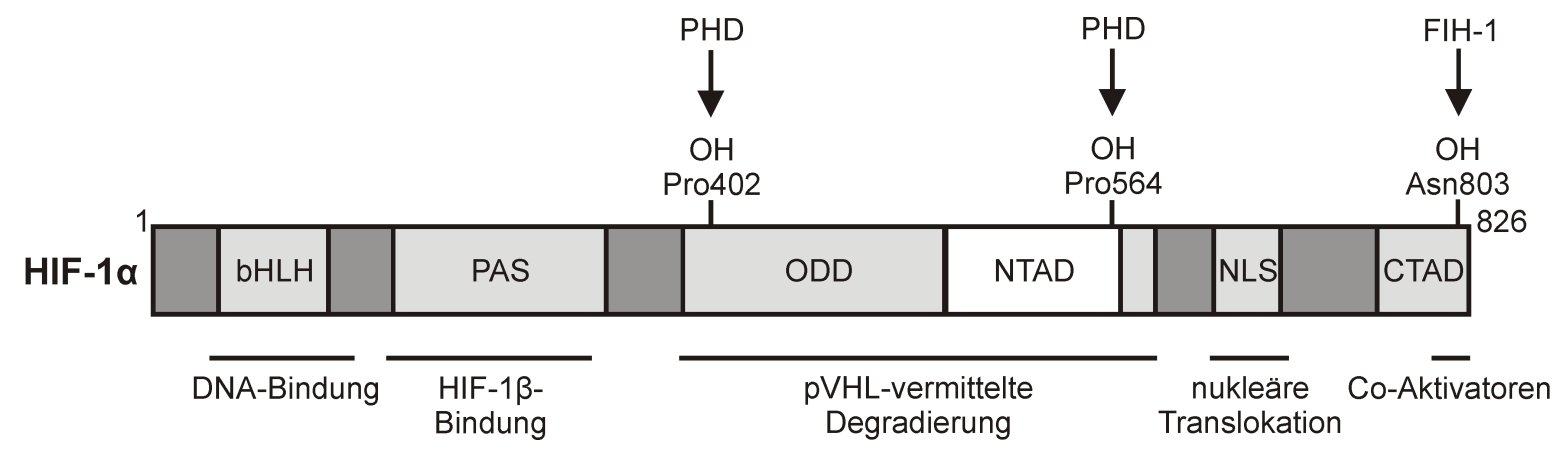

Abbildung 1.1: Der Aufbau des Transkriptionsfaktors HIF-1 $\alpha$. Das schematische Diagramm zeigt den strukturellen und funktionellen Aufbau des Transkriptionsfaktors HIF-1 $\alpha$. Die verschiedenen Boxen zeigen die unterschiedlichen funktionellen Domänen. Die posttranslationalen Modifikationen spezifischer Aminosäurereste sowie für die Reaktion verantwortliche Enzyme sind ebenfalls dargestellt. Abkürzungen: bHLH (basische Helix-Loop-Helix-Domäne), PAS (Per/ARNT/Sim)Domäne, ODD (oxygen-dependent degradation domain), NTAD (N-terminale transaktivierende Domäne), NLS (nuclear localisation signal), CTAD (C-terminale transaktivierende Domäne), PHD (Prolyl-4-Hydroxylase-Domäne-Enzyme), FIH-1 (factor inhibiting HIF-1), pVHL (VonHippel-Lindau-Tumorsuppressor), $\mathrm{OH}$ (Hydroxylierung) [modifiziert nach Rocha [2007], Seite 391] 
1. Einleitung

\subsubsection{Regulation von HIF-1}

HIF-1 wird auf der Ebene der Proteinstabilität reguliert. In Anwesenheit von molekularem Sauerstoff wird die $\alpha$-Untereinheit an den Prolinresten Pro402 und Pro564 durch Prolyl-4Hydroxylasen-Domäne-Enzyme (PHD) innerhalb der ODD hydroxyliert. Hydroxyliertes HIF$1 \alpha$ wird durch den Von-Hippel-Lindau-Tumorsuppressor (pVHL) erkannt und für den weiteren Abbau polyubiquitiniert und im Anschluss im Proteasom degradiert. Das pVHL ist eine Ubiquitin-E3-Ligase [Maxwell et al., 1999; Ivan et al., 2001; Jaakkola et al., 2001; Yu et al., 2001]. Das HIF-1 $\alpha$-Protein, das konstitutiv transkribiert und translatiert wird, ist unter Normoxie nicht nachweisbar. Inhibition des Proteasoms oder Mutationen in dem Enzym E1 führen zu einer Stabilisierung von HIF-1 $\alpha$ unter Normoxie. Diese Beobachtung zeigt, dass die Regulation von HIF-1 posttranslational erfolgt [Kallio et al., 1999; Sutter et al., 2000]. Die dafür verantwortliche Hydroxylierung ist abhängig vom Sauerstoffpartialdruck. Unter hypoxischen Bedingungen ist die Hydroxylierung von HIF-1 $\alpha$ durch einen Mangel an Sauerstoff eingeschränkt und HIF-1 $\alpha$ wird stabilisiert. HIF-1 $\alpha$ akkumuliert in der Zelle, transloziert in den Zellkern und dimerisiert mit der HIF-1 $\beta$-Untereinheit. Nach erfolgreicher Rekrutierung der Kofaktoren CBP und p300 bindet HIF-1 an die HREs und induziert die Expression zahlreicher Zielgene, die für eine zelluläre Adaptation an Hypoxie verantwortlich sind (siehe Abbildung 1.2. Seite 5).

Erst das komplexe Zusammenspiel diverser Schritte ermöglicht nach der Stabilisierung von HIF-1 $\alpha$ die Transkription des Genprodukts. Posttranslationale Proteinphosphorylisierung, nukleärer Transport, Dimerisierung, DNA-Bindung, Rekrutierung von Kofaktoren stellen jeweils für sich eine Möglichkeit der weiteren Beeinflussung der Hypoxie-induzierten Genexpression dar. So existiert, neben der PHD-vermittelten Hydroxylierung der $\alpha$-Untereinheit, mit der Hydroxylierung eines Asparaginrestes innerhalb der CTAD eine weitere sauerstoffabhängige Modifikation des Proteins [Mahon et al., 2001; Lando et al., 2002b; Lisy and Peet, 2008]. Die Hydroxylierung durch eine Asparaginhydroxylase an der Position Asp803 verhindert eine Interaktion mit den Kofaktoren CBP und p300 und führt zu einer verminderten transkriptionellen Aktivität. Daher wurde die Asparaginhydroxylase als factor inhibiting HIF-1 (FIH-1) bezeichnet [Arany et al., 1996; Lando et al., 2002a]. Die Funktion von CBP und p300 ist von diversen Interaktionen mit Transkriptionsfaktoren bekannt. Der Komplex CBP/p300 ist eine Acetyltransferase, die über eine enzymatische Reaktion Histone acetyliert und so die räumliche Struktur der DNA beeinflusst und die Zugänglichkeit für Transkriptionsfaktoren verbessert [Schiltz et al., 1999]. 


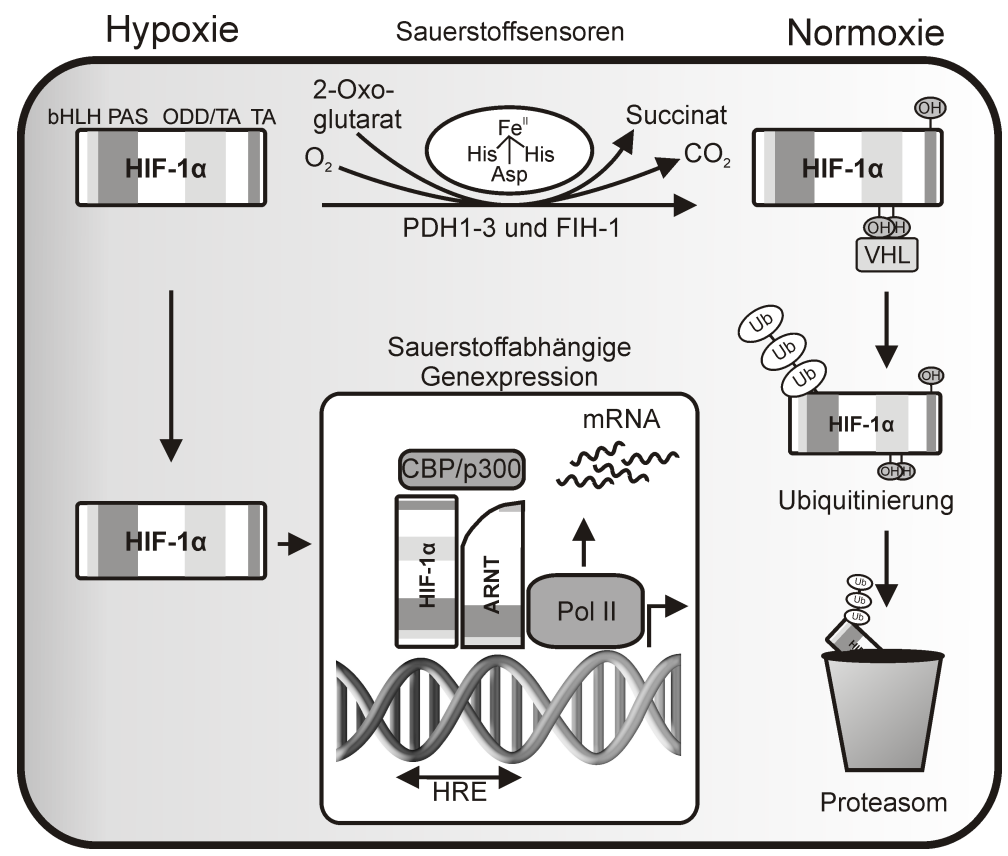

Abbildung 1.2: Vereinfachtes schematisches Modell der zellulären Sauerstoffregulation. Unter hypoxischen Bedingungen kommt es zur Akkumulation des Transkriptionsfaktor HIF-1 $\alpha$. Nach der Translokation von HIF- $1 \alpha$ in den Nukleus und der weiteren Rekrutierung von Kofaktoren kommt es zur Genexpression. Unter normoxischen Bedingungen wird HIF-1 $\alpha$ innerhalb der ODD durch die PHDs (Markierung für den pVHL-abhängigen Abbau) und innerhalb der TA durch FIH-1 (Blockierung der Interaktion mit CPB und p300) hydroxyliert. Für weitere Details siehe Text. Abkürzungen: bHLH (basische Helix-Loop-Helix-Domäne), PAS (Per/ARNT/Sim)-Domäne, ODD (oxygen-dependent degradation domain), FIH-1 (factor inhibiting HIF-1), TA (transaktivierende Domäne), OH (Hydroxylierung), Ub (Ubiquitinierung), VHL (Von-Hippel-Lindau), Pol II (Polymerase II), HRE (hypoxia response element) [modifiziert nach Wenger [2002], Seite 1157]

\subsection{Zelluläre Sauerstoffsensoren}

Die Entdeckung von HIF-1 führte zu einer intensiven Suche nach dem molekularen Mechanismus seiner sauerstoffabhängigen Regulation. Die Arbeitsgruppen von Professor Ratcliff (Oxford, England) und Professor Kaelin (Boston, USA) konnten eine enzymatisch regulierte, sauerstoffabhängige Modifikation von HIF-1 innerhalb der ODD nachweisen [Ivan et al., 2001; Jaakkola et al., 2001]. Als Modifikation konnten zwei Hydroxylierungen an den Prolinen Pro402 und Pro564 identifiziert werden, die in ihrem Reaktionsmechanismus der Prolin- 
modifikation durch die Kollagen-Prolyl-Hydroxylase (collagen prolyl hydroxylase C-P4H1) im Rahmen der Kollagensynthese ähneln [Masson et al., 2001; Yu et al., 2001]. Der genaue Mechanismus hinter der Regulation wurde mit der Identifizierung einer neuen Klasse von Dioxygenasen, den HIF-PHDs, aufgedeckt. Als Dioxygenasen benötigen die PHDs für ihre Reaktion neben 2-Oxoglutarat und Eisen molekularen Sauerstoff als Kosubstrat. Vergleichbar der Kollagensynthese wird Ascorbat für die Reaktion benötigt, um das Eisen in seiner zweiwertigen Form zu halten. Während der Reaktion wird molekularer Sauerstoff gespalten und jeweils ein Atom für die Hydroxylierung der $\alpha$-Untereinheit und der oxidativen Decarboxylierung des 2-Oxoglutarats benötigt (siehe Abbildung 1.3, Seite 7] [Schofield and Ratcliffe, 2004]. Durch die Hydroxylierung an den Prolinresten wird die $\alpha$-Untereinheit für den weiteren Abbau markiert. Obwohl sich die PHDs und C-P4H1 in ihrer Reaktion ähneln, weisen sie einen signifikanten Unterschied in ihrer Affinität gegenüber Sauerstoff auf $\left(\mathrm{K}_{\mathrm{M}}\right.$-Werte: CP4H1: $40 \mu \mathrm{M}$; PHDs zwischen 230 - $250 \mu \mathrm{M}$ ) [Myllyharju and Kivirikko, 1997; Hirsilä et al. 2003].

Die Michaeliskonstante $\mathrm{K}_{\mathrm{M}}$ gibt diejenige Substratkonzentration an, bei der die halbe Umsatzgeschwindigkeit eines Enzyms erreicht ist. Der $\mathrm{K}_{\mathrm{M}}$-Wert der PHDs liegt nur geringfügig über jener $\mathrm{O}_{2}$-Konzentration, die auf Meereshöhe gemessen werden kann. Kleine Schwankungen des Sauerstoffwertes führen daher zu einer drastischen Beeinflussung der Aktivität des Enzyms, sodass bereits auf geringe Abweichungen Einfluss genommen werden kann. FIH-1, ein Enzym, das ebenfalls an der sauerstoffabhängigen Hydroxylierung von HIF- $1 \alpha$ beteiligt ist, weist einen $\mathrm{K}_{\mathrm{M}}$-Wert von $90 \mu \mathrm{M}$ auf und liegt damit zwischen den $\mathrm{K}_{\mathrm{M}}$-Werten von C-P4H1 und den PHDs [Koivunen et al., 2004; Hirsilä et al., 2003]. Im Vergleich benötigen die PHDs eine höhere Konzentration an Sauerstoff als FIH-1, das somit eher im unteren hypoxischen Bereich für die Steuerung der HIF-1 Aktivität verantwortlich ist [Stolze et al., 2004].

Es konnten drei Isoformen der PHDs (PHD1-3) identifiziert werden [Bruick and McKnight, 2001; Epstein et al., 2001], die sich in ihrer Reaktion ähneln, sich aber im Hinblick auf ihr Expressionsprofil, zelluläre Lokalisation, weitere Proteininteraktionen und ihre Induktion unter hypoxischen Bedingungen unterscheiden. Zudem weisen die PHDs Unterschiede hinsichtlich ihrer Aktivität gegenüber den spezifischen HIF $\alpha$-Isoformen auf, die jeweils unterschiedliche Zielgene aktivieren können. Selektive Inhibitionen einzelner Isoformen der PHDs und damit spezifische Einflussnahmen auf die Stabilität einer bestimmten HIF-Isoform könnten in Zukunft neue Therapiechancen bedeuten.

Als weitere Isoform existiert PHD4, deren physiologische Bedeutung bis heute ungeklärt ist. Obwohl PHD4 große Ähnlichkeiten mit den Isoformen PHD1-3 aufweist und in der Lage 
ist, eine HIF-1 $\alpha$-Akkumulation in vitro zu unterdrücken, ist PHD4 für die Markierung der $\alpha$ Untereinheit unter physiologischen Bedingungen nicht verantwortlich [Oehme et al., 2002]. Aus diesem Grund soll die Isoform PHD4 bei der weiteren Betrachtung der PHDs ausgespart werden.

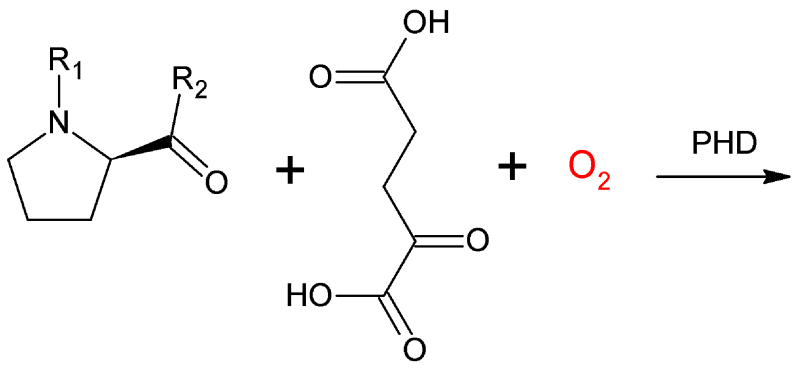<smiles>[R2]C(=O)C1C[C@@H](O)CN1[R1]</smiles>

Abbildung 1.3: PHD katalysiert Prolyl-4-Hydroxylierung der $\alpha$-Untereinheit HIF-1 $\alpha$. PHD katalysiert Prolyl-4-Hydroxylierung an den Prolinen 402 und 564 der $\alpha$-Untereinheit HIF-1 $\alpha$. Sauerstoff (rot) wird geteilt und für die Hydroxylierung der Prolinreste sowie die oxidative Decarboxylierung von 2-Oxoglutarat vewendet. Es entsteht $\mathrm{CO}_{2}$ sowie Fumarat.

\subsubsection{PHD1}

PHD1 (44 kDa) wird konstitutiv exprimiert und unterliegt, im Gegensatz zu den anderen Isoformen, keiner hypoxischen Induktion. PHD1 ist vor allem im Zellkern lokalisiert und weist ein unterschiedliches Expressionsmuster auf. Hohe Proteinlevel konnten in Hodengewebe nachgewiesen werden [Willam et al., 2006]. Durch alternatives Splicen entstehen zwei weitere PHD1 Isoformen (40 und $43 \mathrm{kDa}$; [Tian et al., 2006]). Um weiteren Einblick in die Bedeutung und Funktion der jeweiligen PHD Isoformen zu gewinnen, wurden in-vivo-Studien durchgeführt.

PHD1 $^{-/-}$-knock-out-Mäuse weisen nach Geburt keinen offensichtlichen Phänotyp im Vergleich zu Wildtypmäusen auf [Aragonés et al., 2008]. Bei weiteren Untersuchungen konnte für das Skelettmuskelgewebe insgesamt eine erniedrigte zelluläre Energiegewinnung festgestellt werden. Der PHD1-knock-out und die damit verbundene Stabilisierung von HIF-2 $\alpha$ führte zu einer erhöhten Resistenz des Muskelgewebes gegenüber ischämischen Schäden [Takeda et al. 2006]. 
1. Einleitung

\subsubsection{PHD2}

Der Isoform PHD2 (46 kDa) kommt unter normoxischen Bedingungen die größte Bedeutung für die Markierung von HIF-1 $\alpha$ zu [Berra et al., 2003]. PHD2 ist im Zytoplasma lokalisiert und weist als Reaktionspartner eine höhere Affinität gegenüber HIF-1 $\alpha$ auf [Metzen et al., 2003a; Appelhoff et al., 2004; Tian et al., 2006]. Für PHD2 konnte eine Induktion der Genexpression über Bindung von HIF-1 in seinem Promotor gezeigt werden, sodass eine verstärkte HIF-Degradierung nach Reoxygenierung möglich ist [Metzen et al., 2005]. PHD2 wird selbst auf der Stufe der Proteinstabilität sauerstoffunabhängig über eine Interaktion mit der Peptidyl-Prolyl-cis/trans-Isomerase (PPIase) FKBP38 reguliert. Die Bedeutung dieser Regulation in vivo ist allerdings noch unklar [Barth et al., 2007].

PHD2 $^{-/-}$-knock-out-Mäuse sterben zwischen Tag E 12.5 und Tag E 14.5 der embryonalen Entwicklung. Diese Beobachtung zeigt, dass die Funktion von PHD2 durch die anderen Isoformen PHD1 und PHD3 nicht kompensiert werden kann und dass PHD2 eine immense Rolle

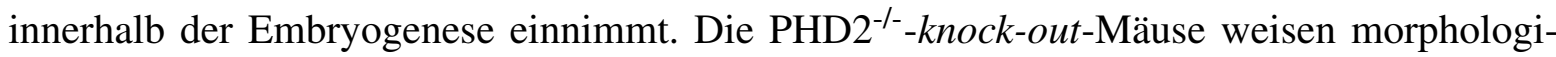
sche Veränderungen des Herzens und der Plazenta auf. Dass PHD2 innerhalb der Sauerstoffadaptation eine große Bedeutung zukommt, konnte durch somatische knock-down-Studien an Tetrazyklin-induzierbaren PHD2-/--Mäusen bestätigt werden. Im adulten Organismus führte der PHD2-knock-down zu einer Erhöhung der Angiogenese, der Erythropoese und der extramedullären Hämatopoese [Minamishima et al., 2008; Takeda et al., 2008].

\subsubsection{PHD3}

PHD3 (27,3 kDA) wird, wie auch PHD2, HIF-1-abhängig unter hypoxischen Bedingungen induziert. Unter normoxischen Bedingungen ist PHD3 kaum nachweisbar, wohingegen unter Hypoxie eine gesteigerte Proteinexpression erfolgt [Appelhoff et al., 2004]. PHD3 ist sowohl im Zytoplasma als auch im Zellkern lokalisiert [Metzen et al., 2003a]. Im Gegensatz zu PHD2 weist PHD3 eine höhere Aktivität gegenüber HIF-2 $\alpha$ auf [Chan et al., 2005] und es existieren zwei alternative Splicevarianten (17 und $24 \mathrm{kDa}$ ) [Cervera et al., 2006]. PHD1 und PHD2 hydroxylieren HIF- $1 \alpha$ an den Prolinen Pro402 und Pro564, wohingegen eine Hydroxylierung von PHD3 ausschließlich an der Stelle Pro564 festgestellt wurde.

$\mathrm{PHD}^{-/-}$-knock-out-Mäuse sind überlebensfähig. Die durch den knock-out entstehenden Beeinträchtigungen resultieren aus der Einbindung von PHD3 in Apoptosevorgänge. Beschrieben wurde der Einfluss von PHD3 auf neuronale Apoptose sowie die Verbindung zu ATF-4 und KIF1B $\beta$, beides Proteine, die Apoptosevorgänge regulieren [Lipscomb et al., 2001; Lee S 
1. Einleitung

et al., 2005; Köditz et al., 2007; Schlisio et al., 2008]. Aufgrund der Behinderung der zielgerichteten Apoptosevorgänge kommt es zu einer abnormalen Entwicklung des sympathischen Nervensystems mit daraus folgender erniedrigter Innervation der jeweiligen Zielgewebe. Dies führt zum Beispiel zu einem erniedrigten Blutdruck und Katecholaminspiegel im Blut der $\mathrm{PHD}^{-/-}$-knock-out-Mäuse [Bishop et al., 2008].

\subsection{HIF-1-abhängige Genexpression in soliden Tumoren}

Unter hypoxischen Bedingungen wird der Transkriptionsfaktor HIF-1 $\alpha$ stabilisiert und führt nach Dimerisierung mit der $\beta$-Untereinheit zu einer Induktion zahlreicher Gene. Bis heute sind mehr als 100 Zielgene bekannt und nach Schätzungen werden 2-5 \% des Genoms HIF1-abhängig reguliert [Wenger, 2002; Manalo et al., 2005]. Die Zielgene sind charakterisiert durch spezifische DNA-Sequenzen, an die HIF-1 über seine bHLH-Domäne binden kann. Diese Sequenzen sind als HREs bekannt und lokalisiert im Promotor oder Enhancer eines Gens [Pugh et al., 1991; Semenza et al., 1991; Wenger et al., 2005].

Entdeckt wurde HIF-1 im Zusammenhang mit DNA-Proteinstudien der regulierenden Elemente des Erythropoietingens [Wang GL and Semenza, 1993]. Unter Hypoxie akkumuliert HIF- $1 \alpha$ in Fibroblasten-ähnlichen Zellen der Nierenrinde und führt zu einer gesteigerten Expression von Erythropoietin (EPO), das die Proliferation und Differenziertung von erythrozytären Vorläuferzellen reguliert. Es kommt durch einen Anstieg des Hämatokrits und einer daraus resultierenden gesteigerten Sauerstoff-Bindungskapazität des Blutes zu einer besseren Versorgung des Organismus mit Sauerstoff im Sinne eines Regelkreises.

\subsubsection{HIF-1-Akkumulation in soliden Tumoren}

Eine autonome Regulation auf zellulärer Ebene kann für den Gesamtorganismus problematisch werden. 1953 wurde erstmals Tumorhypoxie von Radiotherapeuten beschrieben, die unter dieser Bedingung eine gesteigerten Resistenz gegenüber Strahlentherapie beobachteten [Gray et al., 1953]. Durch Messung des Sauerstoffpartialdrucks mittels Elektroden [Vaupel et al., 2001] oder Visualisierung der hypoxischen Bereiche durch antikörpervermittelte Fluoreszenzreaktion [Brown, 2002] konnte gezeigt werden, dass solide Tumoren große Unterschiede hinsichtlich des Sauerstoffangebots aufweisen und bis zu 50-60\% des Gewebes hypoxisch oder anoxisch sind [Vaupel and Mayer, 2007]. In soliden Tumoren kommt es durch eine gesteigerte Proliferation, erhöhten Metabolismus und inadäquate Vaskularisierung zu ei- 
nem Missverhältnis zwischen Sauerstoffangebot und Sauerstoffbedarf. Darüber hinaus führt Tumoranämie, die tumorassoziiert oder infolge einer anti-Tumor-Therapie entsteht, zu einem geringeren Sauerstoffangebot [Vaupel et al., 2001]. Dies führt in hypoxischen Zellen zu einer Stabilisierung des Transkriptionsfaktors HIF- $1 \alpha$, für den erhöhte Proteinlevel in vielen Tumoren nachgewiesen werden konnte [Talks et al., 2000]. In Hinblick auf Tumorbiologie ist anzumerken, dass entscheidende Anpassungsvorgänge im Rahmen des Tumorwachstums, wie Tumorangiogenese, pH-Regulation und metabolische Adaptation, letztlich HIF-1-vermittelt eingeleitet werden [Wenger et al., 2005]. HIF-1-Akkumulation führt zur Tumorprogression und geht einher mit einer schlechteren Prognose sowie erhöhter Resistenz gegenüber Chemotherapie und Radiatio [Semenza, 2002].

Eine Stabilisierung von HIF- $1 \alpha$ in soliden Tumoren kann außerdem unter normoxischen Bedingungen erfolgen, wenn es zu Mutationen auf Stufe der HIF-1 $\alpha$-Regulation kommt. pVHL ist für die Degradierung der $\alpha$-Untereinheit verantwortlich. Mutationen von VHL führen zu einer Akkumulation von HIF-1 $\alpha$ und einer vermehrten Expression seiner Zielgene, unabhängig von dem Sauerstoffangebot [IIliopoulos et al., 1996; Maxwell et al., 1999]. Die Bedeutung der pVHL-abhängigen Degradierung von HIF-1 $\alpha$ für das Tumorwachstum wird bei dem erblichen Von-Hippel-Lindau-Syndrom deutlich, bei der Keimbahnmutationen im VHL-Gen zu dessen Inaktivierung führen. Es kommt zu zahlreichen gut durchbluteten Tumoren, wie Hämangioblastom der Retina und des zentralen Nervensystems, Nierenzellkarzinom, Phäochromozytom und Neoplasien des endokrinen und exokrinen Pankreas [Latif et al. 1993].

\subsubsection{Die Bedeutung von HIF-1 für die Angiogenese}

In soliden Tumoren kommt es häufig zu einem Missverhältnis zwischen Sauerstoffangebot und Sauerstoffbedarf, sodass hypoxische oder gar anoxische Bereiche nachgewiesen werden können. Während des Tumorwachstums kommt es zur Bildung eines chaotischen Gefäßnetzwerks mit großer Variabilität des Gefäßdurchmessers und der Gefäßdichte, welches mit einem normalen Gefäßnetzwerk kaum vergleichbar ist [Konerding et al., 1995]. Die Distanz zwischen Blutgefäß und Tumorzelle ist ein limitierender Faktor für das weitere Tumorwachstum, da die Zellen aufgrund ihres gesteigerten Metabolismus auf eine adäquate Sauerstoffversorgung angewiesen sind. In soliden Tumoren kommt es infolge der hypoxischen Bedingungen zu einer gesteigerten Neovaskularisierung und besseren Sauerstoffversorgung des Gewebes. Der Transkriptionsfaktor HIF-1 spielt hierbei eine Schlüsselrolle, da er die Expression einer Reihe 
von Genen reguliert, die für Angiogenese verantwortlich sind [Hanahan and Weinberg, 2000]. Im Zuge der Stabilisierung von HIF-1 $\alpha$ kommt es zum Beispiel zu einer vermehrten Expression des vascular endothelial growth factor (VEGF), der direkt die Angiogenese stimuliert, indem er über eine Bindung an seinen VEGF-Rezeptor das Wachstum von Endothelzellen beeinflusst [Ferrara and Davis-Smyth, 1997]. Die Gefäßdichte steigt und die Diffusionsstrecke von Sauerstoff nimmt ab. Vergleicht man das Wachstumspotential von Teratokarzinomen, ausgehend von Wildtyp und HIF- $1 \alpha$-defizienten embryonalen Stammzellen, fällt auf, dass HIF1-defiziente Tumore signifikant kleiner sind und geringere Level an VEGF aufweisen Ryan et al., 1998].

\subsubsection{Die Bedeutung von HIF-1 für den Metabolismus}

Bereits vor 70 Jahren hat Otto Warburg bei soliden Tumoren den sogenannten Warburgeffekt beschrieben, der den Wechsel vom oxidativen Abbau der Glukose zur anaeroben Glykolyse beschreibt: Selbst in normoxischen Tumorzellen kommt es zu einer verminderten aeroben Glykolyse und als Folge der anaeroben Glykolyse zu einem vermehrten Anstieg des Laktats [Warburg, 1956]. HIF-1 $\alpha$ ist in der Regulation des Zellmetabolismus über die Expression diverser Enzyme involviert. Entscheidend für den Glukosemetabolismus sind die Expression von Glukosetransportern, Enzyme für anaerobe Glykolyse und Laktat- und Pyruvatproduktion, die allesamt Zielgene des Transkriptionsfaktors HIF-1 sind [Wenger, 2002]. Physiologisch kommt es unter hypoxischen Bedingungen über eine Stabilisierung von HIF- $1 \alpha$ zu einem vermehrten Abbau der Glukose über anaerobe Glukolyse (sogenannter Pasteureffekt) und ein Mangel an Sauerstoff wird ausgeglichen. Die konstitutive Aktivierung von HIF-1 in Tumorgewebe führt über den anaeroben Abbau der Glukose zu einer erhöhten Toleranz gegenüber Sauerstoffmangelbedingungen. Darüber hinaus führen andere HIF-1-abhängige Regulationen, wie pH-Pufferung über die Expression der Transmembranen Carboanhydrase IX, zum weiteren Tumorprogress [Wykoff et al., 2000].

\subsubsection{Die Bedeutung von HIF-1 für die Metastasenbildung}

Kommt es im Zuge eines Krebsleidens zur Metastasenbildung, verschlechtert sich die Prognose für den Patienten drastisch. Bis es zur Metastasenbildung kommt, sind eine Reihe von Schritten erforderlich, wie invasives Wachstum, Intra- und Extravasation und schließlich Proliferation. Für Tumore mit erhöhtem HIF-1 $\alpha$-Proteinlevel konnte eine erhöhte Wahrscheinlichkeit für Metastasenbildung gezeigt werden. HIF-1-abhängig werden eine Reihe von Genen re- 
guliert, die Zell-Zell-Adhäsion vermitteln, so zum Beispiel E-Cadherin. E-Cadherin, ein transmembranäres Glykoprotein, vermittelt Zell-Zell-Kontakte und hat über zytoplasmatische Interaktionen negativen Einfluss auf das Zellwachstum. Untersuchungen haben gezeigt, dass eine Inaktivierung von E-Cadherin oder eine vermindert Expression zu einer Erhöhung der Metastasenwahrscheinlichkeit eines Tumors führt [Hanahan and Weinberg, 2000]. HIF-1 reguliert die E-Cadherinexpression über seine Zielgene Snail und SIP1, deren Proteinprodukte als Repressoren fungieren [Evans et al., 2007]. Im Zuge einer Stabilisierung von HIF-1 $\alpha$ kommt es durch vermehrte Expression von Snail und SIP1 zu einer verminderten E-Cadherinexpression und einer Erhöhung der Zellmobilität.

Darüber hinaus fördert die Stabilisierung von HIF-1 $\alpha$ die Metastasenbildung über die Expression des Zielgens Lysyloxidase (LOX). Für Brustkrebs konnte gezeigt werden, dass eine vermehrte LOX-Expression das invasive Wachstum und damit die Wahrscheinlichkeit einer Metastasierung erhöht. LOX, eine Aminooxidase, ist für die Katalyse kovalenter crosslinks zwischen Kollagen und Elastin der extrazellulären Matrix verantwortlich. Die HIF-1vermittelte Dysregulation der Expression der LOX im Rahmen des Tumorwachstums kann zur Förderung der Tumorinvasivität führen [Erler et al., 2006].

\subsubsection{Die Bedeutung von HIF-1 für die anti-Tumor-Resistenzbildung}

Resistenzbildungen des Tumors gegenüber möglichen Therapiestrategien haben einen bedeutenden Einfluss auf die Prognose der Patienten. Bereits 1953 konnte ein Zusammenhang zwischen Oxygenierung und Effektivität einer Radiatio aufgezeigt werden. Hypoxische Bedingungen schützen die Zellen vor dem zytotoxischen Effekt der ionisierenden Strahlung [Gray et al., 1953]. Daraus wurde geschlussfolgert, dass hypoxische Bedingungen der limitierende Faktor einer Radiatio sei. Um der Entstehung von Hypoxie-assoziierter Resistenzbildung entgegenzuwirken, wurde der Sauerstoffpartialdruck im Blut mit Hilfe hyperbarer Beatmung, Bluttransfusionen und Blutsubstitutionen von Sauerstoffträgern angehoben [Overgaard, 1994; Overgaard and Horsman, 1996]. Diese Untersuchungen brachten jedoch nicht den gewünschten Erfolg. Neuere Untersuchungen zeigten, dass HIF-defiziente Tumorzellen sensitiver auf Bestrahlung reagieren als Wildtypzellen, der Transkriptionsfaktor HIF-1 demnach einen negativen Prognosefaktor darstellt [Unruh et al., 2003]. Die Stabilisierung von HIF-1 $\alpha$ führt zu einer Expression zahlreicher Zielgene, die das Überleben der einzelnen Tumorzellen fördern und somit einen Schutz gegenüber Radiatio vermitteln. Neben der Zerstörung des Tumorgewebes ist die Schädigung der Tumorvaskularisierung aufgrund einer Bestrahlungsthe- 
rapie ein wichtiges therapeutisches Ziel. HIF-1-vermittelte Expression des Wachstumsfaktors VEGF führt zum Beispiel zu einer besseren Vaskularisierung [Moeller et al., 2004].

Neben der Bestrahlung ist die Chemotherapie eine weitere bedeutende Behandlungsmethode von soliden Tumoren. Hypoxische Zellen sind oft allein aufgrund ihrer Distanz zu den Blutgefäßen schlecht für eine chemotherapeutische Therapie zugänglich [Durand, 1994]. Zudem kommt es unter Hypoxie zu einem Selektionsdruck von Zellen, bei denen es zu einem Verlust ihres apoptotischen Potentials kommt. So konnte gezeigt werden, dass unter Sauerstoffmangelbedingungen eine Selektion von Zellen stattfindet, die ihre Sensitivität der p53-vermittelen Apoptose verloren haben. p53-vermittelte Apoptose ist entscheidend für den Zelluntergang nach einem Chemotherapie-induzierten DNA-Schaden [Graeber et al., 1996]. Die Aktivierung des Transkriptionsfaktors HIF-1 führt darüber hinaus zu einer gesteigerten Expression von Zielgenen, die direkt in die Resistenzbildung gegenüber Chemothereapie involviert sind, wie das multi drug resistance protein 1 (MDR-1). In der Literatur werden neben MDR-1 auch die älteren Namen P-Glykoprotein bzw. ABCB 1 (ATP-binding cassette subfamily B) verwendet. MDR-1 gehört zur Familie der ABC-Transporterfamilie, die ATP-abhängig diverse Xenobiotika mit unterschiedlichen Konformitäten über die Zellmembran an die Umgebung aus der Zelle abgeben und so die Konzentration innerhalb der Zelle auf subtoxische Werte absenken [Fardel et al., 1996]. Viele klinisch relevante Chemotherapeutika sind Substrate von MDR-1, so zum Beispiel Doxorubicin, Etoposid und Vinblastin [Froelich-Ammon and Osheroff, 1995; Rabik and Dolan, 2007].

\subsubsection{Die Bedeutung der PHDs für das Tumorwachstum und die anti-Tumor-Therapie}

Die Einflussnahme von HIF-1 auf die Tumorentstehung, die Tumorprogression und antiTumor-Resistenz konnte in vielen Bereichen aufgezeigt werden. Für die sauerstoffabhängige Regulation von HIF-1 sind PHDs verantwortlich, indem sie die Untereinheit HIF-1 $\alpha$ hydroxylieren und so für den weiteren Abbau markieren. Neuere Studien zeigen ebenfalls einen Einfluss auf die Tumorbiologie durch die PHDs über die Beeinflussung der Aktivität von HIF-1.

Succinatdehydrogenase (SDH), das einzige membranständige Enzym des Zitronensäurezyklus, katalysiert die Oxidation von Succinat zu Fumarat. Untersuchungen haben gezeigt, dass somatische Mutationen im Gen der SDH zur Ausbildung eines Phäochromozytomen führen und somit als ein Beispiel für ein mitochondriales Tumorsuppressorgen angesehen werden kann [Pollard et al., 2003]. Die genauen Hintergründe, die zu einer Tumorentstehung führen, waren lange unklar, bis gezeigt werden konnte, dass es infolge einer Inhibition der SDH zur 
Stabilisierung von HIF-1 $\alpha$ und Steigerung der transkriptionellen Aktivität kommt. Über die mitochondriale Dysfunktion kommt es zur Akkumulation von Succinat im Mitochondrium und Zytosol und über eine Produkthemmung zur Erniedrigung der Aktivität der PHDs [Selak et al. 2005]. Ähnlich führt eine relevante Mutation im Gen für die Fumaratdehydrogenase über eine Erhöhung der zellulären Fumaratkonzentration und einer kompetitiven Inhibition der 2-Oxoglutaratbindungsstelle der PHDs zu einer Erniedrigung der Aktivität. Es kommt zur Stabilisierung und Akkumulation von HIF-1 $\alpha$ [Isaacs et al., 2005].

Für die sauerstoffabhängige Markierung der HIF-1 $\alpha$-Untereinheit sind drei Isoformen der PHDs verantwortlich, die sich in ihrer Reaktion ähneln, aber sich im Hinblick auf ihr Expressionsprofil, zellulärer Lokalisation, weiteren Proteininteraktionen und ihrer Induktion unter hypoxischen Bedingungen unterscheiden. PHD2 kommt unter normoxischen Bedingungen die größte Bedeutung für die Markierung von HIF-1 $\alpha$ zu. Im Rahmen von immunhistochemischen Untersuchungen von Plattenepithelkarzinomen des HNO-Bereichs von PHD2 hinsichtlich Expression und Lokalisation konnte gezeigt werden, dass eine erhöhte Expression von PHD2 mit geringer Differenzierung und schlechter Prognose einhergeht. In normalem Epithel nimmt die Expression von PHD2 im Zuge der Differenzierung ab. In Plattenepithelkarzinomzellen hingegen kommt es zu einer erhöhten Expression, die zunimmt, je undifferenzierter die Zellen sind und deren Lokalisation vom Zytoplasma in den Zellkern wechselt. Erhöhte Level von PHD2 auf RNA- und Proteinebene sowie Lokalisation im Zellkern korrelieren mit undifferenzierten und proliferierenden Tumoren [Jokilehto et al., 2006]. Darüber hinaus konnte gezeigt werden, dass die Expression von PHD2 die Zellkoloniebildung beeinflusst. Zelllinien, die mit verschiedenen lentiviralen Vektoren, die für eine shRNA gegen PHD2 kodieren, transduziert wurden, weisen im Vergleich zum Wildtyp eine geringere Expression von PHD2 auf. Der knock-down ist je nach shRNA verschieden stark ausgeprägt. Das Potential zur Zellkoloniebildung wurde anschließend für die unterschiedlichen shRNAs mit Hilfe eines soft-agar assays untersucht. Die Ergebnisse zeigen, dass es unter moderater Erniedrigung von PHD2 zu einer starken Koloniebildung kommt, hingegen bei deutlicher Erniedrigung eine Koloniebildung ausbleibt. Diese Beobachtungen konnten in vivo am Mausmodell bestätigt werden. Fünf Monate nach Injektion der Zellen zeigte sich eine Korrelation zwischen einem PHD2-knockdown und Tumorwachstum. Moderate Erniedrigung von PHD2 führten zum Tumorwachstum, bei einer deutlichen Erniedrigung unterblieb die Tumorentstehung. Diese Ergebnisse deuten auf eine biphasische Bedeutung von PHD2 in der Tumorbiologie hin. Je nach Ausprägung der Erniedrigung kommt es zur Tumorbildung oder sie bleibt aus [Lee K et al., 2008]. 
Neben dem direkten Einfluss auf das Tumorgewebe, konnte ein Zusammenhang zwischen PHD2 und der Gefäßarchitektur aufgezeigt werden. Heterozygoten PHD2 ${ }^{+/-}$-defizienten Mäusen wurden Tumorzellen verschiedenen Ursprungs implantiert. Diese Haplodefizienz führt innerhalb der Endothelzellen zu messbar erhöhten Proteinleveln von HIF-1 $\alpha$ gegenüber dem Wildtyp. Des weiteren wurde der Einfluss auf die Gefäßarchitektur und Metastasenbildung untersucht. Zunächst konnte gezeigt werden, dass die Haplodefizienz von PHD2 keinen Einfluss auf die Tumorgröße hat, aber signifikant die Intravasation und Metastasenbildung verringert. Darüber hinaus konnte ein positiver Einfluss auf die Tumorperfusion und Tumoroxygenierung gezeigt werden. Die Tumore in heterozygoten PHD2-defizienten Mäusen wiesen im Vergleich jeweils eine besser Perfusion sowie Oxygenierung auf. Die dreidimensionale Gefäßarchitektur und Struktur zeigte sich unter Haplodefizienz im Vergleich organisiert und kontinuierlich. Eventuell hat diese Normalisierung der Gefäßarchitektur positiven Einfluss auf die Zugänglichkeit der Chemotherapeutika [Mazzone et al., 2009].

\subsection{Regulation der PHDs}

\subsubsection{Regulation der PHDs durch Protein-Protein-Interaktion}

Für die sauerstoffabhängige Regulation der Stabilität von HIF- $1 \alpha$ sind die PHDs verantwortlich, die selbst in ihrer Expression sowie Aktivität reguliert werden. Folgende Beispiele zeigen, dass die drei PHDs auf heterogene Art und Weise reguliert werden. Dies lässt vermuten, dass sich die PHDs in ihrer physiologischen Funktion unterscheiden.

Es konnte gezeigt werden, dass PHD2 und 3 unter hypoxischen Bedingungen vermehrt exprimiert werden [Epstein et al., 2001]. Im Rahmen eines positiven Feedback-Mechanismus werden PHD2 und 3 unter Hypoxie HIF-1-abhängig verstärkt expremiert, sodass bei Reoxygenierung der Zelle eine verstärkte HIF-Degradierung möglich ist. PHD3 ist sowohl Zielgen von HIF- $1 \alpha$ und HIF- $2 \alpha$, wohingegen PHD2 lediglich von HIF-1 $\alpha$ induziert wird [del Peso et al., 2003; Aprelikova et al., 2004].

Für den Abbau von PHD1 und 3 ist das Proteasom verantwortlich. Die E3-Ubiquitin-Ligasen Siah1 und Siah2, selbst hypoxisch induziert, markieren PHD1 und 3 unter Hypoxie für den Abbau. Auf die Stabilität von PHD2 haben Siah1 und Siah 2 jedoch keinen Einfluss [Nakayama et al., 2004].

Darüber hinaus sind einige weitere Proteine bekannt, die mit den PHDs interagieren, aber dessen Rolle teilwese noch unklar ist. So interagiert zum Beispiel die Peptidyl-Prolyl-cis/trans- 
Isomerase (PPIase) FKBP38 mit PHD2 und übt so Einfluss auf die PHD2-Proteinstabilität [Barth et al., 2007]. Eine Interaktion zwischen dem TRiC-Chaperonin und PHD3 konnte gezeigt werden. PHD1 und 2 interagieren nicht mit TRiC-Chaperonin. Da Chaperone Einfluss auf die Proteinfaltung nehmen, könnte TRiC ein möglicher Faltungshelfer von PHD3 sein [Masson et al., 2004].

\subsubsection{Regulation der PHDs durch kleine Moleküle}

Eisen wird für die Hydroxylierung der $\alpha$-Untereinheit als Kofaktor benötigt. Da Eisen für die Reaktion essentiell ist, inhibieren Eisenchelatoren, wie zum Beispiel Desferrioxamin, die Reaktion der PHDs [Nytko et al., 2007]. Andere Metalle, wie Cobalt und Nickel, führen ebenfalls zu einer geringeren Aktivität der PHDs. Der genaue Wirkmechanismus hinter dieser Hemmung ist allerdings noch ungeklärt. Vorstellbar wäre eine direkte Konkurrenz mit Eisen, eine Verminderung des Ascorbats oder ein anderer komplexer Mechanismus [Hirsilä et al., 2003; Salnikow et al., 2004].

Für die Hydroxylierung ist es notwendig, dass Eisen in seiner zweiwertigen Form vorliegt. Ascorbat wird benötigt, um das Eisen in seiner zweiwertigen Form zu halten. In Abwesenheit von Ascorbat zeigen die PHDs keine Aktivität [Knowles et al., 2003]. Reaktive Sauerstoffspezies (ROS) führen über eine Oxydierung von Eisen und damit Überführung in seine dreiwertige Form zu einer Inhibition der PHDs. Ascorbat kann diesem Effekt entgegen wirken [Gerald et al. 2004]. Darüber hinaus konnte gezeigt werden, dass unter normoxischen Bedingungen Stickstoffmonoxid die PHDs hemmt. Vermutet wird dabei eine Konkurrenz mit Sauerstoff um das aktive Zentrum [Metzen et al., 2003b].

Bei der Hydroxylierung entsteht mit der oxidativen Decarboxylierung von 2-Oxoglutarat $\mathrm{CO}_{2}$ sowie Fumarat. Diverse Zwischenprodukte des Zitratzyklus, wie Succinat, Fumarat, Oxalacetat und Pyruvat, sind kompetitive Inhibitoren der PHDs, da sie mit 2-Oxoglutarat um das aktive Zentrum konkurrieren, es aber zu keiner Reaktion kommt. Bei einem angeborenen Defekt der Succinat-Dehydrogenase und der Fumarat-Hydratase konnte die Entstehung von Tumoren als Folge einer Hemmung der PHDs beobachtet werden [Isaacs et al., 2005; Dalgard et al., 2004].

\subsubsection{PHD-Inhibitoren}

Über eine Inhibition der PHDs kann sowohl in vitro als auch in vivo Einfluss auf die Aktivierung des HIF-1-pathways genommen werden [Warnecke et al., 2003]. So kann un- 
ter normoxischen Bedingungen direkt Einfluss auf die HIF-1-abhängige Expression zahlreicher Zielgene genommen werden. Von besonderem Interesse ist hierbei die Behandlung der chronischen Anämie. Derzeit wird bei chronischer Anämie rekombinantes EPO eingesetzt. Gegen rekombinantes EPO können sich jedoch nach längerer Verwendung neutralisierende Antikörper bilden, die mit endogenem EPO kreuzreagieren und das Krankheitsbild der Erythrozytenanämie hervorrufen [Casadevall et al., 2002]. Der Einsatz von PHD-Inhibitoren könnte eine neue Möglichkeit der Behandlung darstellen. Infolge der Stabilisierung der $\alpha$ Untereinheit kommt es zur vermehrten Expression von EPO und somit zur Anregung der Erythropoese. Durch die Verwendung von PHD-Inhibitoren und die Anhebung der endogenen EPO-Produktion wird dies umgangen. Außerdem wird die orale Anwendung der PHDInhibitoren durch den Patienten besser toleriert als EPO-Spritzen. Diverse Sustanzen, darunter vor allem 2-Oxoglutaratantagonisten, werden derzeit in vitro und in vivo genutzt und getestet. Für die Anwendung am Menschen werden derzeit PHD-Inhibitoren der Firma FibroGen (Helsinki, Finnland) in Phase-II-Studien getestet.

In vitro sind das lipophile Derivat Dimethyloxalylglycin (DMOG) und sein Derivat $\mathrm{N}$ Oxalylglycin (N-OG) potente PHD-Inhibitoren [Jaakkola et al., 2001]. DMOG penetriert in die Zelle und es kommt neben der Inhibition der PHDs zu einer Inhibition aller Enzyme der Oxoglutarat-abhängigen Dioxygenasen-Familie. Eine Behandlung nimmt demnach Einfluss auf alle Reaktionswege, in denen Enzyme der Dioxygenasen-Familie involviert sind, zum Beispiel die Kollagen-modifizierenden Prolyl-4-Hydroxylasen. Eine längere Therapie in vivo könnte den Auf- und Umbau des Bindegewebes negativ beeinflussen.

Eine HIF- $1 \alpha$-Stabilisierung und infolge dessen eine Induktion der HIF-Zielgene in vitro und in vivo konnte darüber hinaus für L-mimosin (L-Mim), 6-chlor-3-hydroxychinolin-2-carbonic acid-N-carboxymethylamid (S956711) sowie Ethyl-3,4-Dihydroxybenzoat (3,4-DHB) gezeigt werden. Durch die Behandlung kam es in der Zellkultur zu einer geringeren Proliferationsrate der Zellen in Abhängigkeit von der Konzentration der Inhibitoren. Als Zeichen der zellulären Schädigung konnte eine gesteigerte LDH-Aktivität festgestellt werden. Am Rattenmodell konnte durch die Behandlung mit L-Mim sowie S956711 für die Niere nach sechs Stunden eine erhöhte Konzentration des Transkriptionsfaktors HIF-1 $\alpha$ im Zellkern und Induktion der Angiogenese gezeigt werden. Dieser Effekt könnte in Zukunft vor Herzoperationen oder Transplantationen ausgenutzt werden, um möglichen Ischämien vorzubeugen [Warnecke et al., 2003.

HIF-1-abhängig werden über 100 Genen reguliert, darunter Gene für Sauerstoffversorgung, Angiogenese, Zellwachstum, Zellmobilität, pH-Regulation und Nährstoffversorgung [Wen- 
ger, 2002]. Eine Beeinflussung der HIF-1 $\alpha$-Stabilität über die Inhibition der PHDs wird sich demnach sehr unspezifisch auf die Expression diverser Gene auswirken. Dies muss bei der Berücksichtigung der Nebenwirkungen beachtet werden. Dass bereits die leichte Erhöhung des Transkriptionsfaktors HIF- $1 \propto$ unter Normoxie eindrücklich Einfluss nimmt, zeigt das Krankheitsbild der Chuvash Polycythaemia. Eine homozygote Mutation des VHL-Gens wirkt sich auf die Stabilität der $\alpha$-Untereinheit aus. Zu beobachten sind Hämangiome, niedriger Blutdruck, periphere Thrombosen, Varizenbildung sowie eine geringere Lebenserwartung aufgrund cerebrovaskulären Ereignissen [Gordeuk et al., 2004].

Darüber hinaus gibt es neben HIF-1 $\alpha$ weitere Interaktionspartner der PHDs, auf die infolge einer Inhibition ebenfalls Einfluss genommen wird. Es wurden Gene identifiziert, die sowohl unter hypoxischen Bedigungen als auch nach Behandlung mit PHD-Inhibitoren induziert wurden, allerdings unabhängig von HIF-1 $\alpha$ und HIF-2 $\alpha$ [Elvidge et al., 2006].

\subsection{Fragestellung und Zielsetzung der Arbeit}

HIF-1 ist ein essentieller Transkriptionsfaktor, der die Expression von mehr als 100 Zielgenen reguliert, die für Proteine der Erythropoese, Angiogenese, $\mathrm{pH}$-Regulation und metabolische Adaptation, kodieren. In Hinblick auf Tumorbiologie konnte gezeigt werden, dass es im Rahmen der HIF-1-Akkumulation in Tumorzellen häufig zur Tumorprogression und Resistenzbildung gegenüber einer anti-Tumor-Therapie kommt [Pouysségur et al., 2006]. Für die sauerstoffabhängige Regulation von HIF-1 sind die PHDs verantwortlich, indem sie die Untereinheit HIF- $1 \alpha$ hydroxylieren und für den weiteren Abbau markieren. Während die Bedeutung von HIF-1 für die Tumorbiologie in vielen Bereichen geklärt ist, ist der Einfluss der PHDs auf Tumorentstehung, Tumorprogression und Tumorresistenz unter Therapie weitestgehend unklar.

Die PHDs werden zunehmend als Ziel einer spezifischen Therapie gesehen. Die Inhibition der PHDs ist bereits in Phase-II-Studien in Erprobung, wobei die zellulären Auswirkungen einer Inhibition derweil noch nicht abschließend geklärt sind und bei der Entwicklung dieser Medikamente betrachtet werden müssen.

Ziel dieser Arbeit ist es, den möglichen Effekt der PHDs auf die Entwicklung einer Resistenz im Rahmen einer Chemotherapie zu untersuchen. Dazu soll zunächst der Effekt einer unspezifischen Inhibition aller PHDs mit Dimethyloxalylglycin (DMOG) auf eine mögliche Resistenzbildung gegenüber den klinisch-relevanten Chemotherapeutika Etoposid und Carboplatin untersucht werden. Um festzustellen, ob der Effekt auf die Resistenzbildung im Rahmen 
einer anti-Tumor-Therapie HIF-1 $\alpha$-abhängig ist, soll der Einfluss einer DMOG-induzierten PHD-Inhibition in HIF-1 $\alpha$-knock-out-Zellen untersucht werden. Weiterhin soll mithilfe einer Tetrazyklin-induzierbaren PHD2- bzw. PHD3-knock-down-Zelllinie der Einfluss eines spezifischen PHD2- bzw. PHD3-knock-downs auf die Resistenzbildung gegenüber Etoposid und Carboplatin betrachtet werden. Um die erhobenen Ergebnisse richtig interpretieren zu können, sollen die Zelllinien hinsichtlich Zellzyklus, Zellvitalität und Zellproliferation charakterisiert werden.

Für eine gesteigerte Resistenzbildung können Veränderungen auf verschiedenen Ebenen verantwortlich sein. Unter anderem kann ein verminderter Influx bzw. gesteigerter Efflux zu einer geringeren intrazellulären Akkumulation des Zytostatikums führen. Um schließlich den Einfluss der PHDs auf die Transporterkapazität und somit der Resistenzbildung zu untersuchen, sollen die Transportkapazität und die Expression relevanter Transporter in Abhängigkeit einer DMOG-Behandlung sowie eines PHD2-knock-downs betrachtet werden. 


\section{Material und Methoden}

\subsection{Zelllinien}

\subsubsection{HeLa-Zellen}

HeLa-Zellen, humane Zervix-Adenokarzinomzellen, wurden von der American Type Culture Collection (ATCC, Rockville, MD, USA) bezogen.

\subsubsection{T-REx-HeLa-Zellen}

T-REx-HeLa-Zellen (Invitrogen, Karlsruhe, Deutschland) sind stabil transfiziert mit dem Plasmid pcDNA ${ }^{\mathrm{TM}} 6 / \mathrm{TR}$. Dieses Plasmid kodiert für einen Tetrazyklin (Tet) Repressor (TetR), welcher unter der Kontrolle eines CMV-Promotors (CMVP) konstitutiv exprimiert wird. Ein zusätzliches Blasticidinresistenzgen ermöglicht durch Zugabe von Blasticidin $(5 \mu \mathrm{g} / \mathrm{ml}$; Invitrogen) zum Zellkulturmedium der T-REx-HeLa-Zellen eine Selektion der transfizierten Zellen, die das Plasmid stabil integriert haben.

\subsubsection{PHD2- und PHD3-knock-down-Zellen}

In der Abteilung Herz- und Kreislaufphysiologie am Zentrum für Physiologie der Universitätsmedizin Göttingen wurde mit Hilfe der T-REx-HeLa-Zellen eine PHD2 (2.1.1-16)und PHD3 (3.3.3)-induzierbare knock-down-Zelllinie durch Frau cand. med. Sinja Le Huu etabliert. Bei diesen Zelllinien wird Tet-abhängig eine shRNA gebildet, die komplementär zu der PHD2-mRNA bzw. PHD3-mRNA ist und so deren vorzeitigen Abbau durch RNAsen induziert. Dazu wurden die T-REx-HeLa-Zellen mit pENTR $^{\mathrm{TM}} / \mathrm{H} 1 / \mathrm{TO}$ shPHD2- bzw. $\mathrm{pENTR}^{\mathrm{TM}} / \mathrm{H} 1 / \mathrm{TO}$ shPHD3-kodierenden Plasmiden stabil transfiziert. Diese exprimieren die shRNAs unter Kontrolle der TATA-Box eines CMV-Promoters. Expression der shRNAs kann durch Bindung des TetR an die Sequenz eines Tet Operators (TetO), der vor und hinter der TATA-Box der kodierenden Region liegt, beeinflusst werden. In Abwesenheit von Tet im Zellkulturmedium kann der TetR als Homodimer mit hoher Affinität an die Sequenz des TetO bin- 
den. So wird die Bindungsstelle der Polymerase-III-Promotorregion blockiert und es kommt zu einer verminderten Expression der shRNAs.

1

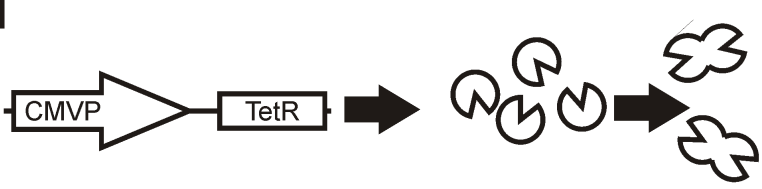

3

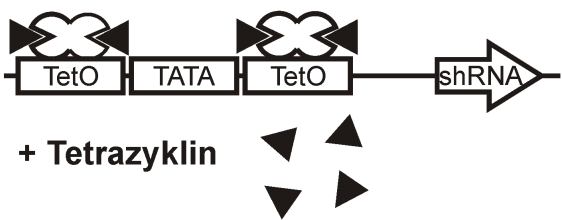

2

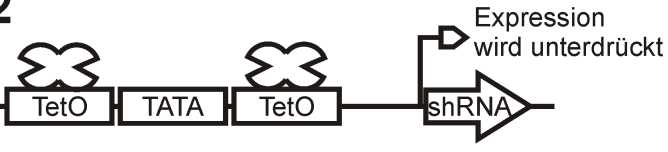

4

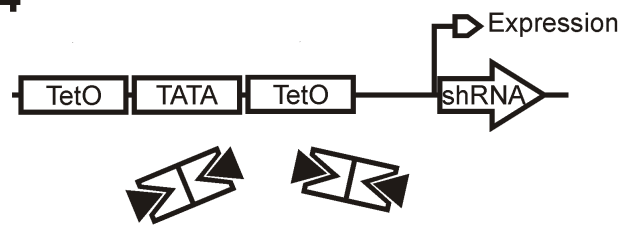

Abbildung 2.1: Tetrazyklin-induzierbare Expression der shRNA. (1) Der Tet Repressor (TetR) auf dem Plasmid pcDNA ${ }^{\mathrm{TM}} 6 / \mathrm{TR}$ wird CMV-Promotor-abhängig (CMVP) konstitutiv exprimiert und bildet Homodimere. (2) Die TetR Homodimere binden mit hoher Affinität an den Tetrazyklin Operator (TetO) auf dem Plasmid pENTR ${ }^{\mathrm{TM}} / \mathrm{H} 1 / \mathrm{TO}$. So wird die Bindungsstelle für die Polymerase III (Pol III) blockiert und es kommt zu einer verminderten Expression der nachfolgender shRNA. (3) Nach Zugabe von Tet bilden Tet und TetR Tet-TetR Komplexe. (4) Aufgrund der Bindung von Tet kommt es zu einer Konformationsänderung des TetR und zur Dislokation zwischen TetR und TetO. Die Bindungsstelle für die Pol III wird frei und es kommt zur vermehrten Expression der shRNA.

Tet bindet mit hoher Affinität den TetR. In Anwesenheit von Tet im Zellkulturmedium kommt es daher zur Bildung des Tet-TetR-Komplexes und Konformationsänderung des TetR und somit zur Freilegung der Bindungsstelle der Pol-III-Promotorregion und vermehrten Expression der shRNAs (siehe Abbildung 2.1). Ein zusätzliches Zeocinresistenzgen auf dem transfizierten Plasmid ermöglicht durch Zugabe von Zeocin ${ }^{\mathrm{TM}}(375 \mu \mathrm{g} / \mathrm{ml}$; Invitrogen) in das Zellkulturmedium eine Selektion der transfizierten Zellen, die das Plasmid stabil integriert haben. Die Zugabe von Tet (10 $\mu \mathrm{g} / \mathrm{ml}$; Sigma-Aldrich, St. Spruce, USA) zum Zellkulturmedium für $24 \mathrm{~h}$ führt zu einer verminderten Expression von PHD2 in der 2.1.1-16-Zelllinie unter Normoxie und Hypoxie, bzw. vermindert die Expression von PHD3 in der 3.3.3-Zelllinie unter Hypoxie. Ein ähnlicher Effekt ist nicht zu beobachten bei den ursprünglichen T-RExHeLa-Zellen. Dies schließt einen Tet-unspezifischen Effekt als Ursache für die verminderte Expression von PHD2 bzw. PHD3 aus (siehe Abbildung 2.2, Seite 22). 

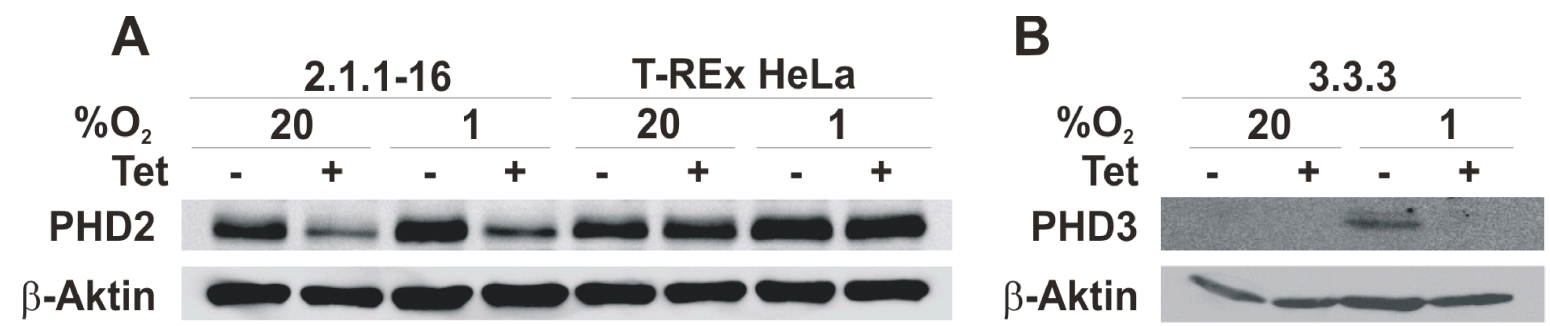

Abbildung 2.2: Die Expression von PHD2 bzw. PHD3 der etablierten PHD2 (2.1.1-16)- bzw. PHD3 (3.3.3)knock-down-Zelllinien ist abhängig von einer Inkubation mit Tetrazyklin. T-REx-HeLa- und 2.1.1-16-Zellen (A) bzw. 3.3.3-Zellen (B) wurden für $24 \mathrm{~h}$ in An- (+ Tet) bzw. Abwesenheit (Tet) von Tet $(10 \mu \mathrm{g} / \mathrm{ml})$ bei $37^{\circ} \mathrm{C}$ unter Normoxie $\left(20 \% \mathrm{O}_{2}\right)$ und Hypoxie $\left(1 \% \mathrm{O}_{2}\right)$ inkubiert. Anschließend wurden die Zellen lysiert und die Proteinexpression von PHD2 bzw. PHD3 und $\beta$-Aktin über Western Blots nachgewiesen [Le-Huu, 2009].

\subsubsection{HIF-1 $\alpha$-knock-out-Zellmodelle}

In der Arbeitsgruppe von Prof. R. S. Johnson (University of California San Diego, La Jolla, USA) wurden HIF-1 $\alpha$-knock-out-Mäuse hergestellt, die einen embryonalen letalen Phänotyp aufwiesen [Ryan et al., 2000]. Die HIF-1 $\alpha$-knock-out-Modelle wurden von der Arbeitsgruppe genutzt, um Maus-embryonale Fibroblasten (MEF) zu gewinnen. Dazu wurden aus HIF-1 $\alpha$ knock-out-Mausembryonen sowie parallel dazu aus HIF-1 $\alpha$-Wildtyp-Geschwisterembryonen am Tag E9.5 MEFs isoliert und anschließend immortalisiert/transformiert. Die Zellen wurden mit einem SV40 large T Antigen und dem Onkogen H-ras exprimierenden Plasmid stabil transfiziert. Diese Zellinien (MEF Hif- $1 \alpha^{-/-}$und MEF Hif- $1 \alpha^{+/+}$) wurden freundlicherweise von Prof. R. S. Johnson für die vorliegenden Untersuchungen zur Verfügung gestellt.

\subsection{Zellkultur}

Die Kultivierung der T-REx-HeLa-, 2.1.1-16- und 3.3.3-Zellen erfolgte in Dulbecco's modified Eagle's medium (DMEM; PAN, Aidenbach, Deutschland) mit 4,5 g/l Glucose, 584 mg/l Glutamin, $110 \mathrm{mg} / \mathrm{l}$ Pyruvat und 3,7 g/l $\mathrm{NaHCO}_{3}$. Zusätzlich wurden $10 \%$ Tet-freies fetales Kälberserum (FKS; Biochrom, Berlin, Deutschland), Penicillin (100 U/ml; Invitrogen), Streptomycin (100 $\mu \mathrm{g} / \mathrm{ml}$; Invitrogen) und Blasticidin ( $5 \mu \mathrm{g} / \mathrm{ml}$; Invitrogen) in das Zellkulturmedium zugegeben. 
Die Kultivierung der HeLa-Zellen erfolgte in DMEM mit 4,5 g/l Glucose, 584 mg/l Glutamin, $110 \mathrm{mg} / \mathrm{l}$ Pyruvat und 3,7 g/l NaHCO 3 . Zusätzlich wurden $10 \%$ FKS, Penicillin (100 U/ml) und Streptomycin $(100 \mu \mathrm{g} / \mathrm{ml})$ in das Zellkulturmedium zugegeben.

Die Kultivierung der MEF-Hif- $1 \alpha^{+/+}$- und MEF-Hif-1 $\alpha^{-/-}$-Zellen erfolgte in DMEM mit 4,5 g/l Glucose, 584 mg/l Glutamin, 110 mg/l Pyruvat und 3,7 g/l NaHCO 3 . Zusätzlich wurden $10 \%$ FKS, Penicillin $(100 \mathrm{U} / \mathrm{ml})$ und Streptomycin $(100 \mu \mathrm{g} / \mathrm{ml})$ in das Zellkulturmedium zugegeben.

Die Zellen wurden bei $20 \% \mathrm{O}_{2}, 5 \% \mathrm{CO}_{2}$ und $37^{\circ} \mathrm{C}$ in einem Zellkultur-Brutschrank (Binder, Tuttlingen, Deutschland) kultiviert. Experimente unter hypoxischen Bedingungen (1\% $\mathrm{O}_{2}, 5 \% \mathrm{CO}_{2}, 37^{\circ} \mathrm{C}$ ) erfolgten in einer Hypoxie-Werkbank (InVIVO2, Ruskinn, Bridgend, $\mathrm{UK})$.

\subsection{Bestimmung der Zellzahl und Zell-Vitalität}

T-REx-HeLa-, 2.1.1-16- und 3.3.3-Zellen wurden in An- und Abwesenheit von Tet (10 $\mu \mathrm{g} / \mathrm{ml}$ ) in $3 \mathrm{~cm}$ Schalen mit der Zielkonzentration $2 \times 10^{5} / \mathrm{ml}$ ausgesät. Anschließend folgte eine Inkubation bei $37^{\circ} \mathrm{C}$. Alle $48 \mathrm{~h}$ wurde das Medium einschließlich Tet gewechselt. Um die Zellkonzentration zu bestimmen, wurde das Zellkulturmedium zu unterschiedlichen Zeitpunkten entfernt und die Zellen mit PBS (137 mM NaCl, 2,7 mM KCl, 4,3 mM Na $2 \mathrm{HPO}_{4} \cdot 7 \mathrm{H}_{2} \mathrm{O}$, $\left.1,4 \mathrm{mM} \mathrm{KH}_{2} \mathrm{PO}_{4}\right)$ gewaschen. Die Zellen wurden mit $200 \mu \mathrm{l}$ Trypsin/EDTA $(0,05 \%$ Trypsin, $0,02 \%$ EDTA in PBS) vom Plastikboden gelöst und anschließend in 2,8 ml Zellkulturmedium aufgenommen. $20 \mu \mathrm{l}$ der Zellsuspension wurden in eine Cellometer-Zähl-Kammer pipettiert und die Zellkonzentration durch eine automatische, mikroskopisch-gesteuerte Auswertung bestimmt (Nexcelom Bioscience, Massachusetts, USA). Die Wachstumsrate $\mu$ ist ein Maß für die Geschwindigkeit des Zellwachstums. In der exponentiellen Phase einer Wachstumskurve entspricht die Steigung der Kurve der Wachstumsrate. Um die Zell-spezifische Wachstumsrate $\mathrm{zu}$ bestimmen, wurde in der exponentiellen Wachstumsphase die Steigung der jeweiligen Kurve nach folgender Formel bestimmt.

$$
\mu=\left(\log _{10} N_{1}-\log _{10} N_{0}\right) /\left(t_{1}-t_{0}\right)
$$

Die Verdopplungszeit $\mathrm{G}$ steht mit der Wachstumsrate $\mu$ im Verhältnis und kann berechnet werden. 


$$
G=\left(\log _{10} 2 / \mu\right) \cdot 24
$$

Parallel dazu wurden $20 \mu \mathrm{l}$ der Zellsuspension im Verhältnis 1:1 mit Trypanblau $(0,1 \%$ in $\mathrm{H}_{2} \mathrm{O}$, filtriert) für 2 min gefärbt. $20 \mu \mathrm{l}$ der Zellsuspension wurden in eine Cellometer-ZählKammer pipettiert und das Verhältnis der Anzahl blau gefärbter zur Anzahl nicht-gefärbter Zellen als Maß für die Zellvitalität per automatischer, mikroskopisch-gesteuerter Auswertung bestimmt.

\subsection{Zytotoxizitätsnachweis durch MTT-Assay}

Der MTT-Test ist ein Zytotoxizitätstest, bei dem das gelbe Tetrazoliumsalz MTT (3-[4,5Dimethylthiazol-2-yl]-2,5-Diphenyltetrazoliumbromid) in lebenden Zellen durch membrangebundene, mitochondriale Succinat-Dehydrogenasen enzymatisch reduziert und so am Tetrazolring gespalten wird. Es entstehen wasserunlösliche blau-violette Formazankristalle. Durch Lyse der Zellen und Lösen der Formazankristalle kann die Menge des umgesetzten MTTs fotometrisch bestimmt werden (siehe Abbildung 2.3. Seite 25). Die Absorption des blau-violetten Farbstoffes ist dabei direkt proportional zur Anzahl der lebenden Zellen bzw. deren Stoffwechselaktivität [Hansen et al., 1989].

T-REx-HeLa-, 2.1.1-16- und 3.3.3-Zellen wurden in An- und Abwesenheit von Tet (10 $\mu \mathrm{g} / \mathrm{ml}$ ) in Zellkulturflaschen für insgesamt $48 \mathrm{~h}$ bei $37^{\circ} \mathrm{C}$ inkubiert. Nach $24 \mathrm{~h}$ wurde das Medium einschließlich Tet gewechselt. Anschließend wurden die Zellen mit der Zielkonzentration $2 \times 10^{5} / \mathrm{ml}$ in 96-Lochplatten ausplattiert und mit bzw. ohne Etoposid (Sigma-Aldrich), Doxorubicin (Sigma-Aldirch), Vinblastin (Sigma-Aldrich) bzw. Carboplatin (Sigma-Aldrich) in den jeweils angegebenen Konzentrationen in An- und Abwesenheit von Tet bei $37^{\circ} \mathrm{C}$ unter Normoxie oder Hypoxie für $48 \mathrm{~h}$ inkubiert. In manchen Experimenten wurde zudem Verapamil (5 $\mu \mathrm{g} / \mathrm{ml}$, Sigma-Aldrich) hinzugegeben.

HeLa-Zellen wurden mit der Zielkonzentration von 2 x $10^{5} / \mathrm{ml}$ in 96-Lochplatten in Anund Abwesenheit von DMOG (1 mM, Sigma-Aldrich) ausplattiert. Nach 24 h Inkubation bei $37^{\circ} \mathrm{C}$ unter Normoxie wurden die Zellen mit bzw. ohne Etoposid in den jeweils angegebenen Konzentrationen bei $37^{\circ} \mathrm{C}$ für $48 \mathrm{~h}$ inkubiert.

MEF-Hif- $1 \alpha^{+/+}$- und MEF-Hif-1 $\alpha^{-/-}$-Zellen wurden mit der Zielkonzentration von $0,3 \mathrm{x}$ $10^{5} / \mathrm{ml}$ in 96-Lochplatten in An- und Abwesenheit von DMOG (1 mM) in 96-Lochplatten 
ausplattiert. Nach $24 \mathrm{~h}$ Inkubation bei $37^{\circ} \mathrm{C}$ unter Normoxie wurden die Zellen mit bzw. ohne Etoposid in den jeweils angegebenen Konzentrationen bei $37^{\circ} \mathrm{C}$ für weitere $24 \mathrm{~h}$ inkubiert.

In allen Experimenten wurde anschließend der Überstand abgesaugt und pro Loch $100 \mu \mathrm{l}$ der MTT/Zellkulturmedium-Lösung (Stocklösung: $5 \mathrm{mg} / \mathrm{ml}$ MTT in PBS gelöst, steril filtriert; 1:10 in Zellkulturmedium gelöst, Sigma-Aldrich) gegeben. Es folgte eine Licht-geschützte Inkubation für $2 \mathrm{~h}$ bei $37^{\circ} \mathrm{C}$. Der Überstand wurde abgenommen und pro Vertiefung $100 \mu \mathrm{l}$ des Lysepuffers (Isopropanol, 0,1 \% HCl) zugegeben. Nach Lyse der Zellen und Lösen der Formazankristalle wurde die Absorption bei $570 \mathrm{~nm}$ (Microplate Reader Model 680, Biorad, München, Deutschland) gemessen. Als Leerwert diente die Absorption der entsprechenden Lösung ohne Zellen. Die Etoposid-induzierte Zytotoxizität wurde berechnet auf Basis der Absorption in den Vertiefungen von Etoposid-behandelten Zellen in Relation zu der Absorption in den Vertiefungen von nicht-behandelten Zellen (entspricht $100 \%$ Zellüberleben) bzw. der Absorption des Leerwerts (entspricht $100 \%$ Zytotoxizität).
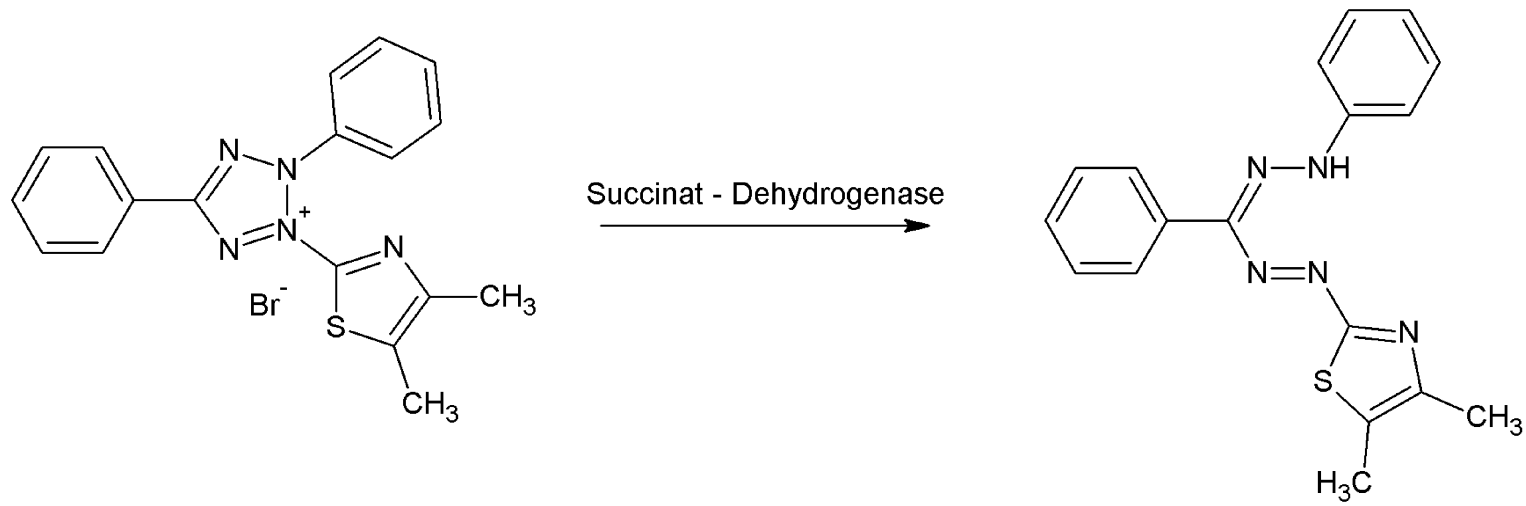

Abbildung 2.3: Das Tetrazoliumsalz MTT wird in lebenden Zellen enzymatisch gespalten. In lebenden Zellen wird das blaue Tetrazoliumsalz MTT durch mitochondriale Succinat-Dehydrogenasen enzymatisch reduziert und am Tetrazolring gespalten. Es entstehen wasserunlösliche, blau-violette Formazankristalle, die nach Zelllyse und Lösen der Kristalle fotometrisch bestimmt werden können. Die Absorption bei $570 \mathrm{~nm}$ ist direkt proportional zur Anzahl der lebenden Zellen.

\subsection{MTT-unabhängige Bestimmung der Zytotoxizität}

Für eine MTT-unabhängige Bestimmung der Zytotoxizität wurde der MultiTox-Fluor-Multiplex-Zytotoxizitäts-Assay der Firma Promega (Promega Corporation, Madison, USA) verwendet. Dabei nehmen nur intakte Zellen das GF-AFC-Substrat auf, welches durch eine nur in 
lebenden Zellen aktive Protease gespalten wird. Es entsteht eine Substanz, die durch Fluoreszenz nachweisbar ist. Die Fluoreszenz ist proportional zur Anzahl der lebenden Zellen.

T-REx-HeLa- und 2.1.1-16-Zellen wurden in An- und Abwesenheit von Tet (10 $\mu \mathrm{g} / \mathrm{ml})$ in Zellkulturflaschen für insgesamt $48 \mathrm{~h}$ inkubiert. Nach $24 \mathrm{~h}$ wurde das Medium einschließlich Tet gewechselt. Anschließend wurden die Zellen mit der Zielkonzentration 2 × 10 $/ \mathrm{ml}$ in 96Lochplatten ausplattiert und mit bzw. ohne Etoposid in den jeweils angegebenen Konzentrationen bei $37^{\circ} \mathrm{C}$ behandelt. Nach $48 \mathrm{~h}$ wurden je Vertiefung $100 \mu \mathrm{l}$ MultiTox-Fluor-MultiplexZytotoxizitäts-Reagenz zugegeben. Nach einer 30 minütigen Inkubation bei $37^{\circ} \mathrm{C}$ wurde die Fluoreszenz (Extinktion 400 nm; Emission 505 nm) mit einem Fluorometer (Berthold, Bad Wildbad, Deutschland) gemessen. Als Leerwert wurde die Fluoreszenz der entsprechenden Lösung ohne Zellen bestimmt. Die Etoposid-induzierte Zytotoxizität wurde berechnet auf Basis der Fluoreszenz in den Vertiefungen von Etoposid-behandelten Zellen in Relation zu der Fluoreszenz in den Vertiefungen von nicht-behandelten Zellen (entspricht $100 \%$ Zellüberleben) bzw. der Fluoreszenz des Leerwerts (entspricht $100 \%$ Zytotoxizität).

\subsection{Bestimmung der Caspase-3/7-Aktivität}

Die Caspase-3/7-Aktivität wurde mit Hilfe des Caspase-Glo Assays (Promega) bestimmt. Zugabe des Caspase-Glo-3/7-Reagenz führt zur Lyse der Zellen und somit zur Freigabe der aktiven Caspase 3/7, welche den prolumineszenten Farbstoff DEVD-Aminoluciferin fragmentieren. Das Enzym Luciferase, ein Bestandteil des Caspase-Glo-3/7-Reagenz, ist für die Lumineszenzreaktion verantwortlich. Die Lumineszenz ist dabei proportional zur aktiven Caspase $3 / 7$.

T-REx-HeLa- und 2.1.1-16-Zellen wurden in An- und Abwesenheit von Tet $(10 \mu \mathrm{g} / \mathrm{ml})$ in Zellkulturflaschen für insgesamt $48 \mathrm{~h}$ inkubiert. Nach $24 \mathrm{~h}$ wurde das Zellkulturmedium einschließlich Tet gewechselt. Anschließend wurden die Zellen mit der Zielkonzentration 2 $\mathrm{x} 10^{5} / \mathrm{ml}$ in 96-Lochplatten ausplattiert und mit bzw. ohne Etoposid $(60 \mu \mathrm{M})$ bei $37^{\circ} \mathrm{C}$ behandelt. Nach einer 48 stündigen Inkubation wurde bei Raumtemperatur je Vertiefung $100 \mu \mathrm{l}$ Caspase-Glo-3/7-Reagenz hinzugegeben. Nach einer 30 minütigen Inkubationszeit bei Raumtemperatur wurde die Lumineszenz gemessen (Centro LB 960, Berthold Technologies, Bad Wildbad, Deutschland). 


\subsection{Zellzyklusanalyse}

Der prozentuale Anteil der Zellen in den verschiedenen Phasen des Zellzyklus wurde anhand durchflußzytometrischer Untersuchungen von Propidiumjodid (PJ)-gefärbten Zellen untersucht. Je nach DNA-Gehalt der Zelle und damit abhängig vom Zellzyklus interkaliert PJ unterschiedlich stark mit der vorhandenen DNA. Die Menge des interkalierten PJ kann mit einem Durchflußzytometer bestimmt werden. Die in Lösung befindlichen Zellen durchwandern während der Messung einzeln eine Kapillare und die Fluroeszenz-Emission des PJ wird bestimmt, die Auskunft über den DNA-Gehalt und somit das Stadium des Zellzyklus gibt.

T-REx-HeLa- und 2.1.1-16-Zellen wurden mit der Zielkonzentration 2 x $10^{5} / \mathrm{ml}$ in $10 \mathrm{~cm}$ Schalen ausgesät und in An- bzw. Abwesenheit von Tet bei $37^{\circ} \mathrm{C}$ für insgesamt $48 \mathrm{~h}$ inkubiert. Das Medium einschließlich Tet wurde nach 24 h erneuert. Das Medium wurde abgesaugt und die Zellen mit eiskaltem PBS gewaschen. Mit $400 \mu 1$ Trypsin wurden die Zellen vom Plastikboden gelöst und mit PBS gewaschen. 1 x $10^{6}$ Zellen wurden in $3 \mathrm{ml} 75 \%$ igen eiskaltem Ethanol in ein Messröhrchen überführt und bei $-20^{\circ} \mathrm{C}$ für $24 \mathrm{~h}$ gelagert. Bei $500 \mathrm{x} \mathrm{g}$ wurden die Proben für fünf min zentrifugiert. Anschließend wurde der Überstand dekantiert. Überschüssige Ethanolreste wurden am Glasrand mit einem Tupfer vorsichtig aufgenommen und die Zellpellets für 5 min getrocknet. Die Zellen wurden in $450 \mu$ PBS (steril filtriert) gelöst und $50 \mu \mathrm{l}$ RNase (Stocklösung: $1 \mathrm{mg} / \mathrm{ml}$; Hoffmann-La Roche, Basel, Schweiz) und $25 \mu \mathrm{l}$ PJ (Stocklösung: $1 \mathrm{mg} / \mathrm{ml}$, Sigma-Adrich) zugegeben. Die Proben wurden für $30 \mathrm{~min}$ im Dunkeln inkubiert und anschließend das Stadium des Zellzyklus bei ca. 20000 Zellen pro Probe mit Hilfe des FacsCALIBUR (Becton Dickinson, San Jose, USA) bestimmt.

\subsection{Bestimmung der Transporteraktivität}

\subsubsection{Bestimmung des Etoposid-Influx}

Die Messungen wurden in Kooperation mit der Arbeitsgruppe von PD Dr. Y. Hagos, Abteilung Vegetative Physiologie und Pathophysiologie der Universität Göttingen, durchgeführt.

T-REx-HeLa- und 2.1.1-16-Zellen wurden für insgesamt $48 \mathrm{~h}$ in An- und Abwesenheit von Tet $(10 \mu \mathrm{g} / \mathrm{ml})$ in 24-Lochplatten mit der Zielkonzentration von $2 \times 10^{5} / \mathrm{ml}$ bei $37^{\circ} \mathrm{C}$ unter normoxischen Bedingungen inkubiert. Nach $24 \mathrm{~h}$ wurde das Medium einschließlich Tet gewechselt. 
MEF-Hif- $1 \alpha^{+/+}$- und MEF-Hif- $1 \alpha^{-/}$-Zellen wurden für $24 \mathrm{~h}$ in An- und Abwesenheit von DMOG $(1 \mu \mathrm{M})$ mit der Zielkonzentration von $0,3 \times 10^{5} / \mathrm{ml}$ bei $37^{\circ} \mathrm{C}$ unter normoxischen Bedingungen inkubiert.

Die Zellen wurden drei Mal mit 0,5 ml PBS gewaschen. Für die Influxmessungen wurde Ringerlösung (130 mM NaCl, $4 \mathrm{mM} \mathrm{KCl}, 1 \mathrm{mM} \mathrm{CaCl} 2,1 \mathrm{mM} \mathrm{MgSO}_{4}, 1 \mathrm{mM} \mathrm{NaH} \mathrm{PO}_{4}, 20$ $\mathrm{mM}$ HEPES, $18 \mathrm{mM}$ Glucose bei $\mathrm{pH}$ 7.4) benutzt. Es folgte die Inkubation von $200 \mu \mathrm{l}$ des entsprechenden Transportermediums (Ringerlösung, $10 \mathrm{nM}\left[{ }^{3} \mathrm{H}\right]$-Etoposid (spezifische Aktivität von 338,7 mCi/mmol, Hartmann Analytics, Braunschweig, Deutschland) und $1 \mu \mathrm{M}$ Etoposid „kalt“) für fünf min. Der uptake wurde gemessen, indem der Überstand samt radioaktivem tracer entfernt und die Zellen drei Mal mit je 0,5 ml eiskaltem PBS gewaschen wurden. Es wurden jeweils 0,5 ml einer $1 \mathrm{M} \mathrm{NaOH}$ Lösung hinzugegeben und die Zellen vorsichtig für 120 min geschüttelt. Anschließend wurde mit 0,5 ml einer $1 \mathrm{M} \mathrm{HCl}$ Lösung neutralisiert und der Überstand in ein Szintillationsröhrchen überführt. Nach Zugabe von 2,5 ml der Szintilliationslösung (Lumasafe Plus; PerkinElmer, Massachusetts, USA) erfolgte die Bestimmung der $\left[{ }^{3} \mathrm{H}\right]$ Konzentration über Flüssigkeitsszintillationsmessung (Tricarb 2900TR, Perkin Elmer). Die Ergebnisse ohne Tet- bzw. DMOG-Behandlung wurden jeweils als $100 \%$ Influx definiert und die Werte mit Behandlung dazu in Relation gesetzt.

\subsubsection{Bestimmung des MDR-1-Efflux}

Der MDR-1-Efflux wurde mit Hilfe des Multidrug Resistance Direct Dye Efflux Assays (Millipore, Billerica, USA) bestimmt. T-REx-HeLa-, MEF-Hif- $1 \alpha^{+/+}$- und MEF-Hif-1 $\alpha^{-/-}$ Zellen wurden für $24 \mathrm{~h}$ in An- und Abwesenheit von DMOG $(1 \mathrm{mM})$ bei $37^{\circ} \mathrm{C}$ unter normoxischen Bedingungen in Zellkulturflaschen kultiviert. Die Zellen wurden mit $200 \mu \mathrm{l}$ Trypsin vom Plastikboden gelöst und in 4,8 ml Medium aufgenommen. Anschließend wurde die Zellkonzentration bestimmt und 7,5 x $10^{5}$ Zellen in ein Falconröhrchen überführt. Die Zellen wurden, wie auch in den folgenden Zentrifugationsschritten, für $5 \mathrm{~min}$ bei $200 \mathrm{x} \mathrm{g}$ zentrifugiert und das Zellpellet in 0,75 ml einer eiskalter DiOC $_{2}$-Lösung $(1 \mu \mathrm{g} / \mathrm{ml})$ für $15 \mathrm{~min}$ lichtgeschützt inkubiert. Zwei Mal wurden die Zellen zentrifugiert und das Pellet jeweils in 1,875 ml kaltem Puffer (1000 ml RPMI-1640, 34,5 ml $30 \%$ BSA in PBS, $50 \mu \mathrm{g} / \mathrm{ml}$ Gentamicin) resuspendiert. Je $625 \mu \mathrm{l}\left(2,5 \times 10^{5}\right.$ Zellen) wurden auf drei Falkonröhrchen aufgeteilt und der Überstand nach der Zentrifugation verworfen. Die Zellen wurden in folgenden Medien resuspendiert:

- A: Puffer, $37^{\circ} \mathrm{C}$, zusätzlich DMSO (1:1000 in Puffer)

- B: Puffer, $37^{\circ} \mathrm{C}$, zusätzlich Vinblastin ( $22 \mu \mathrm{M}$ in Puffer) 
- C: Puffer, $4^{\circ} \mathrm{C}$

Die Falconröhrchen A und B wurden in ein Wasserbad $\left(37^{\circ} \mathrm{C}\right)$, Falconröhrchen $\mathrm{C}$ wurde auf Eis gestellt. Die Inkubation erfolgte lichtgeschützt für $30 \mathrm{~min}$. Durch Zugabe von $5 \mathrm{ml}$ je Falconröhrchen einer eiskalten Pufferlösung wurde die Reaktion gestoppt. Die Falconröhrchen wurden zentrifugiert und der Überstand verworfen. Die folgenden Schritte erfolgten auf Eis. Das Pellet wurde je in $1 \mathrm{ml}$ eiskaltem Puffer gelöst und abermals zentrifugiert. Der Überstand wurde verworfen und $300 \mu \mathrm{l}$ des Puffers wurden hinzugegeben und das Pellet resuspendiert. Je $100 \mu \mathrm{l}$ wurden in einer 96-Lochplatte überführt und anschließend die Fluoreszenz (Extinktion $485 \mathrm{~nm}$; Emission $535 \mathrm{~nm}$ ) gemessen. Die Fluoreszenz der Probe bei $4^{\circ} \mathrm{C}$ (Probe C; kein Export des Farbstoffes) wurde als Ruhewert definiert. Der Efflux wurde berechnet auf Basis der Fluoreszenz bei $37^{\circ} \mathrm{C}$ in Anwesenheit von DMSO im Verhältnis zum Ruhewert. Der Anteil an $\mathrm{DiOC}_{2}$, der nicht MDR-1-vermittelt über die Zellmembran transportiert wurde, wurde berechnet auf Basis der Fluoreszenz bei $37^{\circ} \mathrm{C}$ bei Anwesenheit von $22 \mu \mathrm{l}$ Vinblastin.

\subsection{Spezifischer Proteinnachweis}

\subsubsection{Proteinextraktion}

Nach zweimaligem Waschen der Zellen mit eiskaltem PBS erfolgte die Proteinextraktion aus Zellen in einer $10 \mathrm{~cm}$ Schale durch Zugabe von $400 \mu$ Lysepuffer (10 mM Tris pH 8,0, $1 \mathrm{mM}$ EDTA, $400 \mathrm{mM} \mathrm{NaCl}, 0,1 \%$ Triton, EDTA-freier Protease-Inhibitor von Roche). Anschließend wurden die Proben für 20 min bei 16100 x g und $4^{\circ} \mathrm{C}$ zentrifugiert. Das Pellet wurde verworfen und der Überstand bei $-20^{\circ} \mathrm{C}$ eingefroren. Zur Extraktion der Membranproteine wurden $400 \mu \mathrm{l}$ Lysepuffer (2\% SDS, 50 mM Tris-HCl, pH 6,8, EDTA-freier ProteaseInhibitor von Roche) eingesetzt. Anschließend wurden die Proben zwei Mal für jeweils 15 sec mit Ultraschall aufgeschlossen. Die Proben wurden für $10 \mathrm{~min}$ bei $3000 \mathrm{rpm}$ bei $8^{\circ} \mathrm{C}$ zentrifugiert. Zur quantitativen Bestimmung der Proteinkonzentration wurde die Messung nach Bradford (1976) mit dem Protein-Assay-Reagenz (Bio-Rad Laboratories, München, Deutschland) durchgeführt. Der Farbstoff Coomassie Brillant-Blue G-250 bildet mit kationischen und hydrophoben Seitenketten der Proteine Farbkomplexe, für die das Absorptionsmaximum bei $595 \mathrm{~nm}$ liegt. Durch eine fotometrische Bestimmung der Absorption kann in Bezug auf eine parallel angefertigte und gemessene Standardreihe (0-8 $\mu \mathrm{g} / \mu \mathrm{l} \mathrm{BSA})$ mit bekannter Proteinkonzentation auf die Proteinkonzentration der Proben geschlossen werden. Die Messung erfolgte mit dem Microplate Reader Model 680 (Bio-Rad). 


\subsubsection{Protein-Gelektrophorese}

Bei der Gelelektrophorese werden Proteine nach ihrem Molekulargewicht in einem denaturierendem Polyacrylamidgel aufgetrennt. Die Eigenladung der Proteine wird durch SDS überdeckt, sodass die Proteine nur nach ihrem Molekulargewicht und nicht nach ihrer Ladung im elektrischen Feld aufgetrennt werden. Zur Probenvorbereitung wurden $30 \mu \mathrm{g}$ Protein mit $5 \mathrm{x}$ Laemmlipuffer (190 mM SDS, 55 mM EDTA, $55 \mathrm{mM} \mathrm{NaH}_{2} \mathrm{PO}_{4}, 20 \% \beta$-Mercaptoethanol, 25 $\%$ Glycerin, 0,1 \% Brompheolblau) versetzt und anschließend für zehn min auf $90^{\circ} \mathrm{C}$ erhitzt. Die Proben wurden auf ein 5-12 \%iges Polyacrylamidgel in SDS-Laufpuffer (25 mM Tris, $250 \mathrm{mM}$ Glycin, 0,1 \% SDS) geladen und elektrophoretisch aufgetrennt. Als Größenmarker wurde ein 170 - 10 kDa Protein-Marker (PageRuler Prestained Protein Ladder; Fermentas, St. Leon-Rot, Deutschland) eingesetzt.

\subsubsection{Western Blot}

Der Nachweis der Proteinexpression erfolgte durch Immundetektion mit Hilfe von spezifischen Antikörpern. Mit einem senkrecht zum Polyacrylamid-Gel gerichteten elektrischen Feld (2 mA/ $\mathrm{cm}^{2}$, PerfectBlue Semi-Dry Elektroblotter; PEQLAB, Erlangen, Deutschland) wurden zunächst die in der Gelelektrophorese aufgetrennten Proteine auf eine Nitrocellulosemembran transferiert (GE Healthcare, München, Deutschland). Dadurch sind sie für die Antigen-Antikörper-Reaktion zum Nachweis der Proteine zugänglich. Anschließend wurden unspezifische Proteinbindungsstellen für eine h mit $5 \%$ Milch in PBS geblockt. Es folgte die Inkubation mit dem Primärantikörper (siehe Tabelle 2.1) in PBS mit $5 \%$ Milch für über Nacht bei $4^{\circ} \mathrm{C}$.

Tabelle 2.1: Auflistung der verwendeten Primärantikörper

\begin{tabular}{lll}
\hline Primärantikörper & Verdünnung & Firma \\
\hline \hline anti PHD2 (NB 100-137) & $1: 1000$ & Novus, Littleton, USA \\
Maus anti $\beta$ Aktin (A 5441) & $1: 1000$ & Sigma, Saint Louis, USA \\
anti Human HIF-1 $\alpha(610959)$ & $1: 1000$ & BD Transduction, Laboratories, \\
& & Heidelberg, Deutschland \\
anti Maus HIF-1 $\alpha($ NB100-479) & $1: 1000$ & Novus \\
anti MDR-1 (517310) & $1: 20$ & Calbiochem, San Diego, USA \\
\hline
\end{tabular}


Die Membran wurde 15 min mit PBS gewaschen und für eine h mit dem Sekundärantikörper (siehe Tabelle 2.2), gelöst in PBS mit $5 \%$ Milch, inkubiert. Es folgten drei weitere Waschschritte für jeweils 15 min mit PBS. Der Sekundärantikörper bindet spezifisch an den Fc-Bereich des Primärantikörpers und kann anschließend als Enzym-Antikörper-Konjugat über Chemilumineszenz detektiert werden. Als Enzym diente die konjugierte MeerrettichPeroxidase, die in einer Oxidation von Luminol eine Chemilumineszenz auslöst. Dazu wurde die Nitrocellulosemembran mit 1,25 mM Luminol, 0,1 M Tris/HCL pH 8,5, $1 \%$ o $\mathrm{H}_{2} \mathrm{O}_{2}$ und 0,225 mM Cumarsäure für eine min inkubiert. Die Chemilumineszenzsignale wurden mit einer Lumineszenz-Kamera (LAS-3000, Fujifilm, Düsseldorf, Deutschland) detektiert.

Tabelle 2.2: Auflistung der verwendeten Sekundärantikörper

\begin{tabular}{lll}
\hline Sekundärantikörper & Verdünnung & Firma \\
\hline \hline Ziege anti-Kaninchen IgG & $1: 30000$ & $\begin{array}{l}\text { Santa Cruz Biotechnology, Santa } \\
\text { Cruz, USA }\end{array}$ \\
& & Santa Cruz \\
\hline
\end{tabular}

\subsection{Nachweis spezifischer mRNA-Transkripte mittels RT-PCR}

\subsubsection{RNA-Extraktion}

Zellen in einer $10 \mathrm{~cm}$ Schale wurden nach zweimaligem Waschen mit eiskaltem PBS durch Zugabe von $2250 \mu \mathrm{l}$ Solution D (4 M Guanidinthiocyanit, $25 \mathrm{mM}$ Natriumacetat, 0,5 \% Sarcosyl) lysiert. Je $750 \mu$ pro Probe wurden anschließend in ein Zentrifugenröhrchen (2 ml) pipettiert. Anschließend wurden $75 \mu \mathrm{l} 2 \mathrm{M}$ Natriumacetat pH 4,0, $750 \mu \mathrm{l}$ Phenol und 150 $\mu$ l Chloroform-Isoamylalkohol (49:1) zugegeben. Nach Zugabe jeder einzelnen Lösung wurden die Proben gevortext. Anschließend wurden die Proben für $20 \mathrm{~min}$ bei $16100 \mathrm{x}$ g und $4^{\circ} \mathrm{C}$ zentrifugiert und die wässrige obere Phase in ein neues Zentrifugenröhrchen unter Zugabe von $750 \mu \mathrm{l}$ Isopropanol überführt. Die Proben wurden bei $-20^{\circ} \mathrm{C}$ für 20 min inkubiert und anschlieBend für $20 \mathrm{~min}$ bei $16100 \mathrm{x}$ g und $4^{\circ} \mathrm{C}$ zentrifugiert. Der Überstand wurde verworfen. Das Pellet wurde in $300 \mu$ l Solution D aufgenommen und in ein neues Zentrifugenröhrchen unter Zugabe von $300 \mu l$ Isopropanol überführt. Anschließend erfolgte ein weiterer Fällungsschritt bei $-20{ }^{\circ} \mathrm{C}$ für $20 \mathrm{~min}$ mit nachfolgender Zentrifugation bei $4^{\circ} \mathrm{C}$ und $16100 \mathrm{x} \mathrm{g}$ für $20 \mathrm{~min}$. Das Pellet wurde mit 70 \%igem Ethanol gewaschen und in DEPC- $\mathrm{H}_{2} \mathrm{O}(0,2 \%$ Diethylpyro- 
carbonat) aufgenommen. Die RNA-Konzentration und -Reinheit wurde anhand der optischen Dichte bei $260 \mathrm{~nm}$ und $280 \mathrm{~nm}$ fotometrisch bestimmt (SmartSpec Plus Spectrophotometer, BioRad, München, Deutschland).

\subsubsection{Reverse Transkription}

Aus der isolierten RNA wurde über eine reverse Transkription die komplementäre cDNA synthetisiert (First Strand cDNA Synthesis Kit; Fermentas). Hierbei wurden $2 \mu \mathrm{g}$ RNA pro Probe eingesetzt und mit DEPC- $\mathrm{H}_{2} \mathrm{O}$ auf ein Totalvolumen von $10 \mu \mathrm{l}$ aufgefüllt. Anschließend erfolgte die Zugabe von $1 \mu \mathrm{l}$ Oligo(dT) ${ }_{18}$-Primer mit nachfolgender Inkubation für zehn min bei $65^{\circ} \mathrm{C}$. Es folgte die Zugabe von $4 \mu \mathrm{l} 5$ x Reaktionspuffer $(250 \mathrm{mM}$ Tris- $\mathrm{HCl}, 250 \mathrm{mM}$ $\mathrm{KCl}, 20 \mathrm{mM} \mathrm{MgCl} 2,50 \mathrm{mM}$ DTT), $1 \mu \mathrm{l}$ Ribonuclease-Inhibitor (20 U/ $\mu \mathrm{l})$ und $2 \mu \mathrm{l}$ des $10 \mathrm{mM}$ Nukleotid Mix. Nach Zugabe von $2 \mu$ reverser Transkriptase (20 U/ $\mu$ l) folgte eine Inkubation der Proben für eine h bei $37^{\circ} \mathrm{C}$. Zum Abstoppen der reversen Transkription wurden die Proben anschließend für zehn min auf $65^{\circ} \mathrm{C}$ erhitzt. Die aus der Reaktion enstandenen cDNAs wurden bei $-20^{\circ} \mathrm{C}$ gelagert.

\subsubsection{Polymerase-Ketten-Reaktion (PCR)}

Für die RT-PCR wurden $10 \mu \mathrm{l} 2$ x Master Mix (Fermentas), $7 \mu \mathrm{l}$ Nuklease-freies $\mathrm{H}_{2} \mathrm{O}, 1$ $\mu \mathrm{l}$ cDNA und jeweils $1 \mu \mathrm{l}$ der forward- und reverse-Primer (Stocklösung: $20 \mu \mathrm{M}$ ) eingesetzt. Die RT-PCR-Reaktion erfolgte im Thermocycler Primus 96 (Peqlab, Erlangen, Deutschland). Zunächst wurde die dsDNA durch zweiminütige Hitzebehandlung $\left(95^{\circ} \mathrm{C}\right)$ denaturiert. Im ersten Schritt (annealing) folgte dann für 30 Sekunden eine Hybridisierung der Primer an die spezifischen DNA-Abschnitte bei der für die jeweiligen Primer geeigneten Temperatur (siehe Tabelle 2.3, Seite 33). Im nächsten Schritt (elongation) synthetisiert die DNA-Polymerase den komplementären Strang $\left(72^{\circ} \mathrm{C}\right.$ für 30 Sekunden). Im Anschluss folgte ein Denaturierungsschritt $\left(95^{\circ} \mathrm{C}\right.$ für $\left.1 \mathrm{~min}\right)$. Das Wiederholen der beschriebenen Schritte (denaturing, annealing und elongation) führt zu einer exponentiellen Zunahme der Kopienanzahl der gewünschten DNA-Sequenz. Die Zykluszahl wurde so gewählt, dass der gesättigte Bereich der RT-PCRReaktion noch nicht erreicht wurde und eine quantitative Aussage möglich ist. Die in dieser Arbeit verwendeten Primer wurden so ausgewählt, dass sie nur an Sequenzen der nachzuweisenden cDNAs binden sollten (http://blast.ncbi.nlm.nih.gov/Blast.cgi). Die forward- und reverse-Primer sollten weiterhin in zwei unterschiedlichen Exons eines Gens spezifisch bin- 
den, so dass nur die cDNA aber nicht kontaminierende genomische DNA amplifiziert werden kann.

Tabelle 2.3: Auflistung der verwendeten Primer

\begin{tabular}{lll}
\hline Bezeichnung & Oligonukleotidsequenz $\left(5^{\circ}-3^{\circ}\right)$ & Hybridisierungstemp. \\
\hline \hline hMDR1_for & ATC CAC GGA CAC TCC TAC GA & $58^{\circ} \mathrm{C}$ \\
hMDR1_rev & CCT GTA TTG TTT GCC ACC ACG & $58^{\circ} \mathrm{C}$ \\
mMDR1-1b_for & CCT GTT CTT TCT GGT TAT GG & $55^{\circ} \mathrm{C}$ \\
mMDR1-1b_rev & GCT ACA TTC TGG GTA ACT ACA G & $55^{\circ} \mathrm{C}$ \\
mS12_for & GAA GCT GCC AAG GCC TTA GA & $58^{\circ} \mathrm{C}$ \\
mS12_rev & AAC TGC AAC CAA CCA CCT TC & $58^{\circ} \mathrm{C}$ \\
L28_for & GCA TCT GCA ATG GAT GGT & $58^{\circ} \mathrm{C}$ \\
L28_rev & TGT TCT TGC GGA TCA TGT GT & $58^{\circ} \mathrm{C}$ \\
\hline
\end{tabular}

\subsubsection{Agarose-Gelelektrophorese}

Die Auftrennung und bildliche Darstellung der in der RT-PCR-Reaktion amplifizierten DNAAbschnitte erfolgte durch Agarose-Gelelektrophorese (1\% Agarose in 1 x TAE: $10 \mathrm{mM}$ TrisAcetat, $1 \mathrm{mM}$ EDTA, pH $100 \%$ ) bei ca. $0,9 \mathrm{~V} / \mathrm{cm}^{2}$. Als Größenmarker wurden $6 \mu 100$ bp DNA Ladder oder $10 \mu \mathrm{l} 1 \mathrm{~kb}$ DNA Ladder eingesetzt (Promega). Das Gel wurde anschließend für ca. $20 \mathrm{~min}$ in eine Ethidiumbromid-Färbelösung $\left(0,5 \mu \mathrm{g} / \mathrm{ml}\right.$ Ethidiumbromid in $\left.\mathrm{H}_{2} 0\right)$ gelegt und unter UV-Licht (312 nm, Gene Flash, TopoGEN, Port Orange, USA) dokumentiert.

\subsection{Statistische Auswertung}

Die statistische Auswertung der Daten erfolgte mit Microsoft Office Excel 2003 (Microsoft Corporation, Redmond, USA). Der einseitige Student T-Test für unabhängige Proben wurde zur Überprüfung der Mittelwertsunterschiede herangezogen. Als Signifikanzniveau wurden $p$ $\leq 0,05$ (Symbol: *) und $\mathrm{p} \leq 0,01$ (Symbol: **) gewählt. Die Ergebnisse wurden als Mittelwert \pm Standardabweichung dargestellt. Die grafische Darstellung der Daten wurde mit GraphPad 3.0 (GraphPad Software, Inc., La Jolla, USA) sowie Corel Draw X3 (Corel Corporation, Ottawa, Kanada) durchgeführt. Der schriftliche Satz wurde erstellt mit $\mathrm{LT}_{\mathrm{E}} \mathrm{X}$ (MiKTeX) unter Zuhilfenahme von TeXShop sowie Microsoft Office Word 2003. Für die Literaturverwaltung 
wurde das Programm BibDesk zur Hilfe genommen. Die Erstellung der Reaktionsgleichungen erfolgte mit ChemSketch (ACS/Labs, Toronto, Kanada). 


\section{Ergebnisse}

\subsection{Behandlung von HeLa-Zellen mit dem PHD-Inhibitor DMOG führt zu erhöhter Chemoresistenz gegenüber Etoposid, nicht aber Carboplatin}

Für die Proteinstabilität von HIF-1 $\alpha$ sind die Sauerstoffsensoren PHD1-3 verantwortlich. Das Oxoglutaratanalogon DMOG penetriert in die Zelle und es kommt zu einer Inhibition aller Enzyme der Oxoglutarat-abhängigen Dioxygenasen Familie, so auch PHD1-3. Aus vorangegangenen Studien ist bekannt, dass es in Zellen nach Behandlung mit DMOG zu einer Stabilisation von HIF-1 $\alpha$ kommt [Jaakkola et al., 2001]. Werden HeLa-Zellen für $4 \mathrm{~h}$ bzw. 24 $\mathrm{h}$ mit DMOG $(1 \mathrm{mM})$ behandelt, kommt es zu einer starken Stabilisierung von HIF-1 $\alpha$ unter Normoxie (siehe Abbildung 3.1.

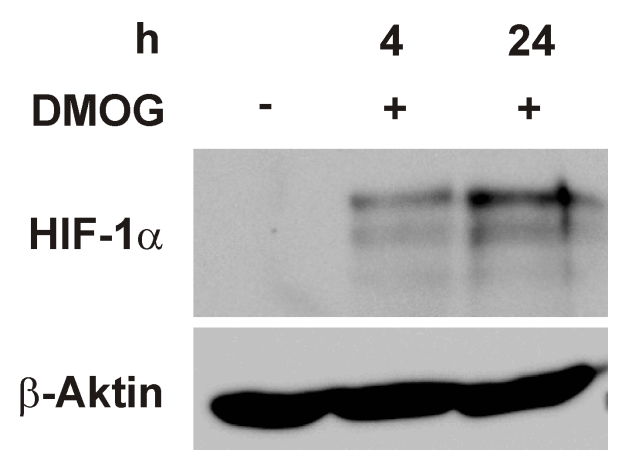

\footnotetext{
Abbildung 3.1: Behandlung von HeLa-Zellen mit dem 2-Oxoglutaratanalogon DMOG führt zu einer Stabilisierung von HIF-1 $\alpha$. HeLa-Zellen wurden mit DMOG (1 mM) für 4 bzw. 24 h unter normoxischen Bedingungen inkubiert und anschließend lysiert. Die Proteinexpression von HIF-1 $\alpha$ und $\beta$-Aktin wurde über Western Blot nachgewiesen.
}

In Tumorzellen geht eine vermehrte Stabilisierung des Transkriptionsfaktors HIF- $1 \alpha$ einher mit therapeutischen Konsequenzen und schlechter Prognose für den Patienten [Maynard and Ohh, 2007]. Es ist bekannt, dass der Transkriptionsfaktor HIF-1 $\alpha$ in der Ausbildung einer Chemoresistenz involviert ist [Unruh et al., 2003]. Um den Effekt auf die Chemoresistenz auf der Stufe der Regulation des Transkriptionsfaktors HIF- $1 \alpha$ zu untersuchen, wurden HeLa-Zellen 
in An- und Abwesenheit des PHD-Inhibitors DMOG mit klinisch-relevanten Chemotherapeutika behandelt.

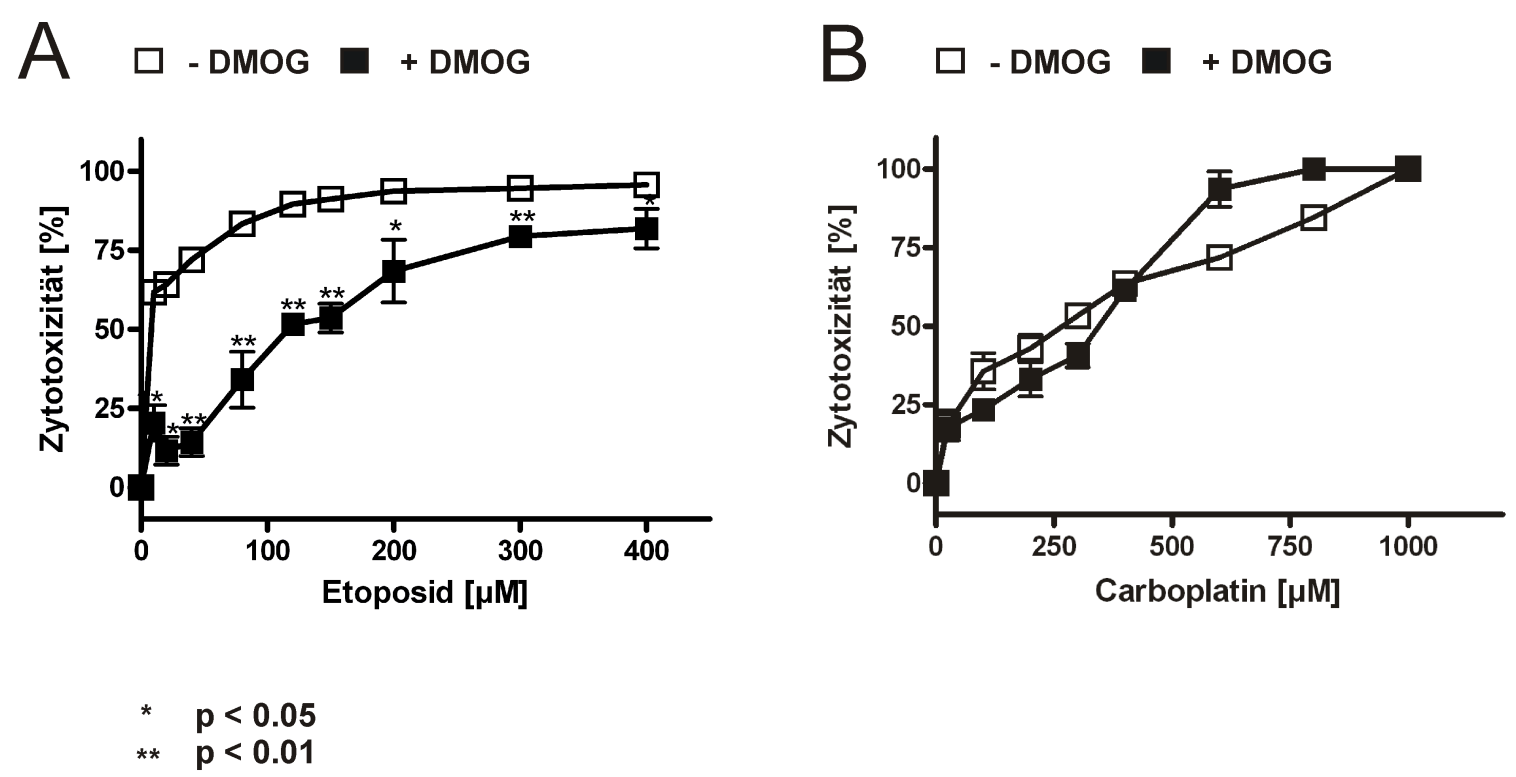

Abbildung 3.2: Inhibition der PHD-Aktivität mit DMOG verringert die Etoposid-induzierte Zytotoxizität, nicht aber die Carboplatin-induzierte Zytotoxizität. HeLa-Zellen wurden in An- und Abwesenheit von DMOG $(1 \mathrm{mM})$ in 96-Lochplatten mit der Konzentration von $2 \times 10^{5} / \mathrm{ml}$ ausgesät und für $24 \mathrm{~h}$ unter normoxischen Bedingungen inkubiert. Anschließend wurden die Zellen mit Etoposid (A) bzw. Carboplatin (B) in angegebener Konzentration behandelt. Nach $48 \mathrm{~h}$ wurde die Zytotoxizität über MTT-Assay bestimmt. $(\mathrm{n}=3 \pm \mathrm{SD}) ; * \mathrm{p} \leq 0,05 ; * * \mathrm{p} \leq 0,01$.

Nach einer Inkubation für $24 \mathrm{~h}$ in An- und Abwesenheit von DMOG (1 mM), wurden die Zellen für $48 \mathrm{~h}$ mit unterschiedlichen Konzentrationen des Topoisomerase-II-Inhibitors Etoposid behandelt. Topoisomerase II ist ein für die Zellteilung und das Zellüberleben essentielles Enzym, das zielgerichtet temporäre DNA-Doppelstrangbrüche ATP-abhängig setzt, um auf die DNA-wirkende Torsionskräfte zu verhindern. Dabei durchläuft das Enzym mehrere Reaktionsschritte, an dessen Ende die Versiegelung der DNA steht. Werden Zellen mit dem Topoisomeraseinhibitor Etoposid inkubiert, kommt es zu einer Interaktion zwischen Etoposid und dem Enzym, das nun fehlerhaft arbeitet und eine Versiegelung der DNA verhindert. Es kommt zu Einzel- und Doppelstrangbrüchen der DNA und nachfolgendem Zelluntergang. Grundsätzlich ist Etoposid in allen Phasen des Zellzyklus toxisch, allerdings ist die Wirkung von Etoposid gerade in der Synthesephase (S-Phase) der DNA verstärkt, da eine vermehrte Aktivität der Topoisomerase II vorliegt [Froelich-Ammon and Osheroff, 1995; Montecucco 
3. Ergebnisse

and Biamonti, 2007]. Im Anschluss an die Etoposidbehandlung wurde die Zytotoxizität über MTT-Assay bestimmt.

Wie Abbildung 3.2 A (Seite 36) zeigt, ist die Dosis-Wirkungskurve nach Zugabe von DMOG deutlich nach rechts verschoben und der Unterschied ist bei jeder gemessenen Konzentration signifikant. Behandlung von HeLa-Zellen mit DMOG führt zu einer Resistenzzunahme gegenüber Etoposid.

Um zu untersuchen, ob die Resistenzzunahme unter DMOG-Zugabe generell und unspezifisch oder Etoposid-spezifisch ist, wurden HeLa-Zellen mit einem weiteren klinisch-relevanten Zytostatikum getestet. Dazu wurden HeLa-Zellen nach einer Inkubationszeit von $24 \mathrm{~h}$ in Anund Abwesenheit von DMOG (1 mM) für $48 \mathrm{~h}$ mit Carboplatin in unterschiedlichen Konzentrationen behandelt. Nach dem Eintritt von Carboplatin in die Zelle kommt es zum Austausch des Oxalation gegen zwei Wassermoleküle. Dieses Molekül reagiert zyklusunspezifisch mit nukleophilen Molekülen wie DNA, RNA und Proteinen. Bevorzugt werden DNA-Pt-Addukte am Atom N7 des Imidazolrings von Guanosin und Adenosin gebildet. Es kommt zu Monoaddukten, Intra- oder Interstrangcrosslinks. Crosslinks führen zu Verdrehungen der DNA und letztlich zu Zelluntergang [Rabik and Dolan, 2007]. Im Anschluss an die Carboplatinbehandlung wurde die Zytotoxizität über MTT-Assay bestimmt.

Die Kurven der Dosis-Wirkbeziehung verlaufen in An- und Abwesenheit von DMOG nach Behandlung mit Carboplatin gleich gerichtet und kreuzen sich (siehe Abbildung 3.2 B, Seite 36). Es konnte keine Resistenzzunahme in Anwesenheit von DMOG gegenüber Carboplatin festgestellt werden. Der oben beschriebene Effekt ist somit Etopoid-spezifisch.

\subsection{Die Resistenzzunahme gegenüber Etoposid in Anwesenheit von DMOG ist HIF-1 $\alpha$-abhängig}

Um weitere Einblicke in die DMOG-vermittelte Resistenz gegenüber Etoposid zu erhalten, wurde die Etoposid-induzierte Zytotoxizität an MEF-Hif- $1 \alpha^{-/-}$- und MEF-Hif- $1 \alpha^{+/+}$-Zellen untersucht. Werden MEF-Hif-1 $\alpha^{-/-}$- und MEF-Hif- $1 \alpha^{+/+}-$Zellen für $24 \mathrm{~h}$ mit DMOG unter normoxischen Bedingungen behandelt, kommt es zur Akkumulation von HIF-1 $\alpha$ in den MEFHif- $1 \alpha^{+/+}$-Zellen, nicht aber in den MEF-Hif-1 $\alpha^{-/-}$-Zellen (siehe Abbildung 3.3, Seite 38. 


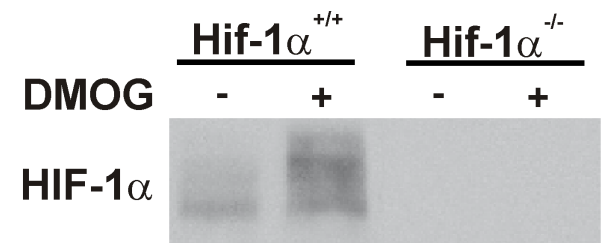

$\beta$-Aktin

\begin{abstract}
Abbildung 3.3: Behandlung mit DMOG führt in MEF-Hif-1 $\alpha^{+/+}$-Zellen zu einer Stabilisierung von HIF$1 \alpha$, nicht aber in MEF-Hif-1 $\alpha^{-/-}$-Zellen. MEF-Hif- $1 \alpha^{+/+}$- und MEF-Hif- $1 \alpha^{-/-}$-Zellen wurden mit DMOG $(1 \mathrm{mM})$ für $24 \mathrm{~h}$ unter normoxischen Bedingungen inkubiert. Anschließend wurden die Zellen lysiert und die Proteinexpression von HIF-1 $\alpha$ und $\beta$-Aktin über Western Blots nachgewiesen.
\end{abstract}

Um zu untersuchen, ob die DMOG-vermittelte Resistenzzunahme gegenüber Etoposid HIF$1 \alpha$-abhängig ist, wurden MEF-Hif- $1 \alpha^{+/+}$- sowie MEF-Hif- $1 \alpha^{-/-}$-Zellen nach einer Inkubationszeit von $24 \mathrm{~h}$ in An- und Abwesenheit von DMOG für $24 \mathrm{~h}$ mit dem Zytostatikum Etoposid behandelt. Im Anschluss wurde die Zytotoxizität über MTT-Assay bestimmt.

Auffällig ist, dass nur die Dosis-Wirkungskurve der MEF-Hif- $1 \alpha^{+/+}$-Zelllinie unter DMOGZugabe nach rechts verschoben ist (siehe Abbildung 3.4 A, Seite 39]. DMOG Zugabe zu MEFHif- $1 \alpha^{-/-}$-Zellen führt hingegen nicht zu einer Verschiebung der Dosis-Wirkungskurve (siehe Abbildung 3.4 B, Seite 39]. Eine erhöhte Resistenz gegenüber dem Zytotstatikum Etoposid in Anwesenheit von DMOG ist nur bei der MEF-Hif- $1 \alpha^{+/+}-$Zelllinie nachweisbar. Zugabe von DMOG zu MEF-Hif-1 $\alpha^{-/-}$-Zellen hat keinen Effekt auf die Etoposid-induzierte Zytotoxizität. Der DMOG-Effekt auf die Etoposid-induzierte Zytotoxizität ist demnach HIF- $1 \alpha$-abhängig.

Um zu untersuchen, ob der Effekt bei dieser Zelllinie ebenfalls Etoposid-spezifisch ist, wurden im nächsten Schritt MEF-Hif- $1 \alpha^{+/+}$- und MEF-Hif-1 $\alpha^{-/-}$-Zellen nach einer Inkubationszeit von $24 \mathrm{~h}$ in An- und Abwesenheit von DMOG für $24 \mathrm{~h}$ mit dem Chemotherapeutikum Carboplatin behandelt. Im Anschluss wurde die Zytotoxizität über MTT-Assay bestimmt.

Abbildungen 3.4 C und D (Seite 39) zeigen, dass der Verlauf der Kurven nahezu identisch ist. Es konnte keine Verschiebung der Dosis-Wirkungskurve in An- und Abwesenheit von DMOG bei MEF-Hif- $1 \alpha^{+/+}$- und MEF-Hif- $1 \alpha^{-/-}$-Zellen festgestellt werden. Die DMOGinduzierte Chemoresistenz bei MEF-Hif- $1 \alpha^{+/+}$-Zellen ist Etoposid-spezifisch. 

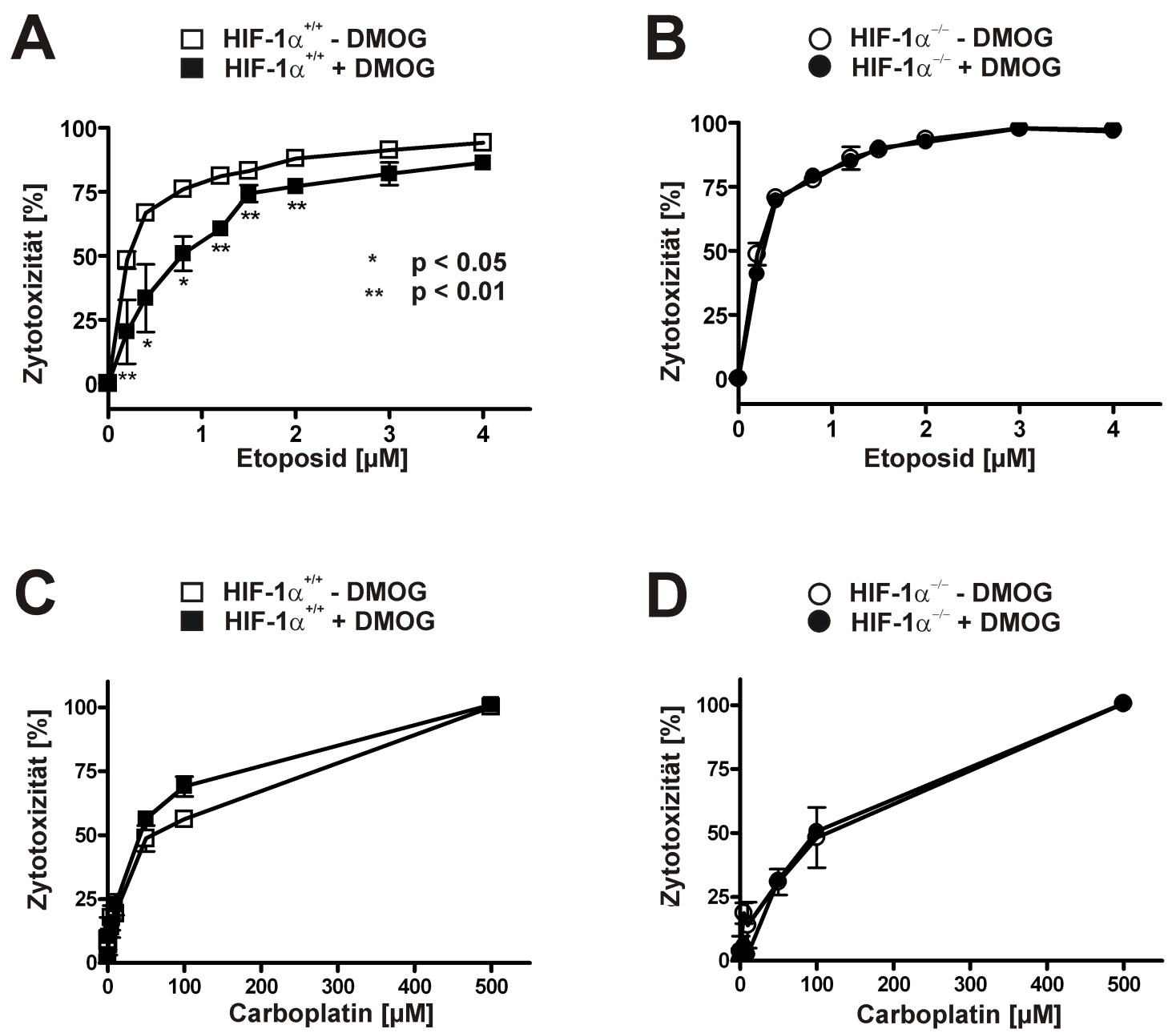

Abbildung 3.4: DMOG beeinflusst die Etoposid-induzierte Zytotoxizität in Abhängigkeit von HIF-1 $\alpha$, hat aber keinen Einfluss auf das Zellüberleben nach Behandlung mit Carboplatin. MEF-Hif$1 \alpha^{+/+}$- und MEF-Hif- $1 \alpha^{+/+}$-Zellen wurden mit der Zielkonzentration von $0,3 \times 10^{5} / \mathrm{ml}$ in $96-$ Lochplatten ausgesät und für 24 Stunden ohne (- DMOG) und mit (+ DMOG) DMOG (1 mM) unter normoxischen Bedingungen inkubiert. Anschließend wurden die Zellen mit Etoposid (A, B) und Carboplatin (C, D) unter Normoxie für $24 \mathrm{~h}$ in den angegebenen Konzentrationen behandelt. Über MTT-Assay wurde die Zytotoxizität bestimmt. $(\mathrm{n}=3 \pm \mathrm{SD}){ }^{*} \mathrm{p} \leq 0,05 ; * * \mathrm{p} \leq$ 0,01 . 


\subsection{Charakterisierung einer PHD2- und PHD3-knock-down-Zelllinie}

Als Substratanalogon inhibiert DMOG unspezifisch unter anderem alle drei Isoformen der PHDs. Um genauere Aussagen zu treffen, welche Isoform der PHDs für die Resistenzzunahme in Anwesenheit von DMOG verantwortlich ist, wurden weitere Untersuchungen durchgeführt.

In der Abteilung Herz-Kreislaufphysiologie wurden eine PHD2 (2.1.1-16)- und eine PHD3 (3.3.3)-induzierbare knock-down-HeLa-Zelllinie etabliert. Zugabe von Tet führt zu einer nachweisbar verminderten Expression von PHD2 (2.1.1-16) unter Normoxie und Hypoxie bzw. PHD3 (3.3.3) unter hypoxischen Bedingungen (siehe Abbildung 2.2, Seite 22). Werden 2.1.116-Zellen für 48 h bzw. $96 \mathrm{~h}$ mit Tet $(10 \mu \mathrm{g} / \mathrm{ml})$ inkubiert, kommt es in den PHD2-knockdown-Zellen zu einer Akkumulation von HIF1 $\alpha$ (siehe Abbildung 3.5).

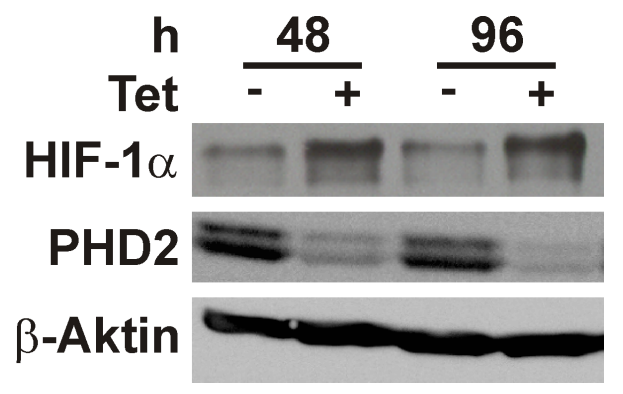

Abbildung 3.5: Behandlung von 2.1.1-16-Zellen mit Tetrazyklin führt zu einer Stabilisierung von HIF-1 $\alpha$. 2.1.1-16-Zellen wurden in An- (+ Tet) und Abwesenheit (- Tet) von Tetrazyklin $(10 \mu \mathrm{g} / \mathrm{ml})$ für 48 $\mathrm{h}$ bzw. $96 \mathrm{~h}$ unter normoxischen Bedingungen inkubiert. Anschließend wurden die Zellen lysiert und die Proteinexpression von HIF-1 $\alpha$, PHD2 und $\beta$-Aktin über Western Blots nachgewiesen.

\subsubsection{Ein PHD2- bzw. PHD3-knock-down hat keinen Einfluss auf die Proliferation}

Die beiden näher betrachteten Chemotherapeutika Etoposid und Carboplatin unterscheiden sich in ihrer Wirkung hinsichtlich des Zellzyklus. Etoposid, als Inhibitor der Topoisomerase II, ist besonders wirksam in der S-Phase der Mitose. Carboplatin, eine alkylierende Substanz, wirkt hingegen zellzyklusunspezifisch. Je nach Proliferationsraten durchlaufen die Zellen die unterschiedlichen Stadien des Zellzyklus mit unterschiedlicher Geschwindigkeit und weisen unterschiedliche Verteilungen auf. Damit ausgeschlossen werden kann, dass unterschiedliche Tet-abhängige Proliferationsraten eine Resistenzbildung vortäuschen, mussten die Zelllinien zunächst genauer charakterisiert werden. 
Dazu wurden T-REx-HeLa- und 2.1.1-16- bzw. 3.3.3-Zellen in An- und Abwesenheit von Tet mit der Zielkonzentration von 2 × $10^{5} / \mathrm{ml}$ ausplattiert und die Zellkonzentration nach angegebener Zeit mikroskopisch gesteuert bestimmt. Mediumwechsel einschließlich Tet wurde alle $48 \mathrm{~h}$ vollzogen.

Auffällig ist, dass der Anstieg der Proliferationskurven der 2.1.1-16- und 3.3.3-Zelllinie im Vergleich zur T-REx-HeLa-Ausgangszellinie geringer ist (siehe Abbildung 3.6 A und 3.6 B). Der Anstieg und Verlauf der Kurven innerhalb der jeweiligen Zelllinien in An- und Abwesenheit von Tet jedoch ist nahezu identisch. Die Proliferation der Zelllinien ist demnach Tet-unabhängig.
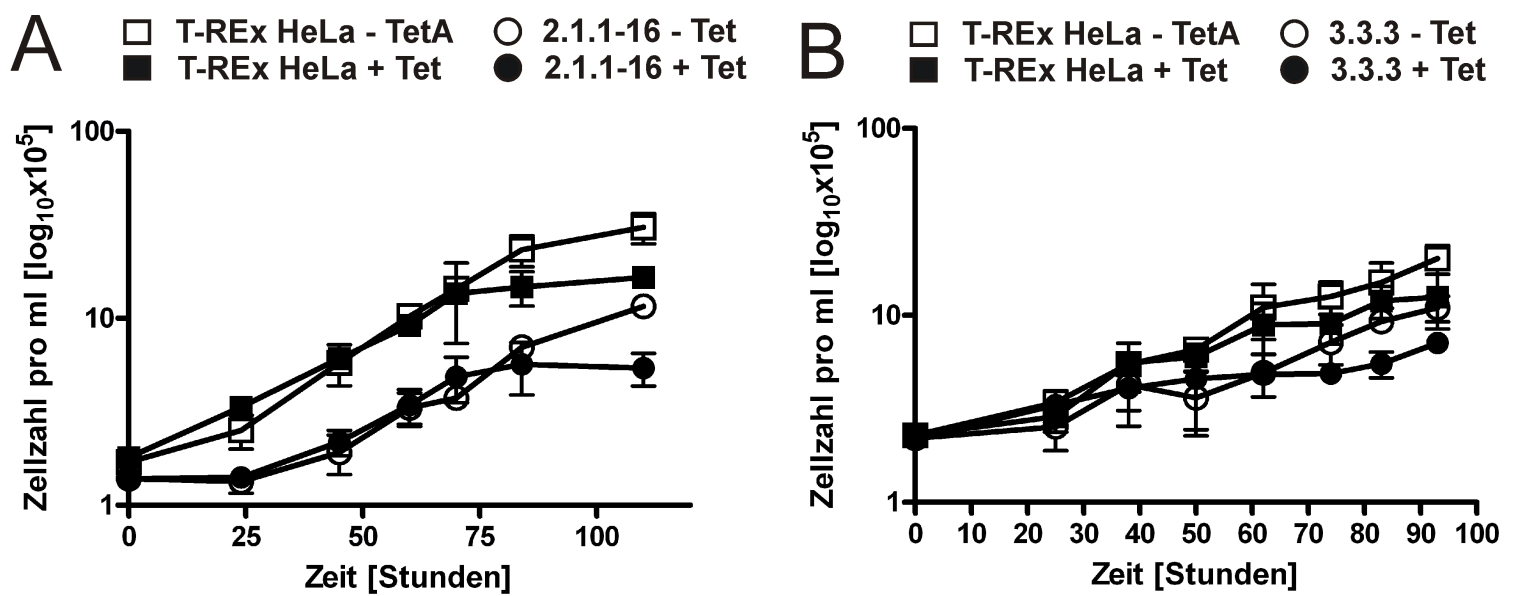

Abbildung 3.6: Die Proliferation der T-REx-HeLa-, 2.1.1-16- und 3.3.3-Zellen ist Tetrazyklin-unabhängig. T-REx-HeLa- und 2.1.1-16- bzw. 3.3.3-Zellen wurden mit der Zielkonzentration 2 x 105/ml in $3 \mathrm{~cm}$ Schalen ausgesät und die Zellzahl nach angegebener Zeit in Abhängigkeit der An- (+ Tet) und Abwesenheit (-Tet) von Tetrazyklin $(10 \mu \mathrm{g} / \mathrm{ml})$ mit dem Cellometer (Nexcelom) bestimmt. Medium und Tet wurden alle $48 \mathrm{~h}$ erneuert. $(\mathrm{n}=3 \pm \mathrm{SD})$.

Wird die Zellkonzentration logarithmisch in Abhängigkeit von der Zeit aufgetragen, so entspricht die Steigung der Kurve in der exponentiellen Phase der Wachstumsrate $\mu$. Die Wachstumsrate $\mu$ ist ein Maß für die spezifische Geschwindigkeit des Zellwachstums. Diese Phase wurde optisch in der logarithmischen Darstellung bestimmt und die Steigung dieses Intervalls über folgende Formel berechnet.

$$
\mu=\left(\log _{10} N_{1}-\log _{10} N_{0}\right) /\left(t_{1}-t_{0}\right)
$$


Die Verdopplungszeit $\mathrm{G}$ steht mit der Wachstumsrate $\mu$ im Verhältnis und kann daher berechnet werden.

$$
G=\left(\log _{10} 2 / \mu\right) \cdot 24
$$

Als Intervallgrenzen wurden gewählt: 2.1.1-16 $\left(\mathrm{t}_{0}=45 \mathrm{~h} ; \mathrm{t}_{1}=70 \mathrm{~h}\right)$ sowie $3.3 .3\left(\mathrm{t}_{0}=25 \mathrm{~h}\right.$; $\left.\mathrm{t}_{1}=50 \mathrm{~h}\right)$.

Die Tabelle 3.1 gibt die Wachstumsrate $\mu$ und die Verdopplungszeit $G$ der Zelllinien wieder. Der zuvor gewonnene optische Eindruck der graphischen Darstellung wird durch die berechnete Wachstumsrate $\mu$ und die Verdoppelungszeit $G$ bestätigt. Innerhalb der jeweiligen Zelllinien sind die Wachstumsraten $\mu$ und Verdoppelungszeiten $\mathrm{G}$ relativ konstant und Tetunabhängig. Zwischen den Zelllinien sind $\mu$ und $\mathrm{G}$ sehr verschieden. Gerade die Auswahl der Intervallgrenzen ist entscheidend für die weitere Berechnung. Dies muss bei der Betrachtung der errechneten Werte berücksichtigt werden.

Tabelle 3.1: Auflistung der zellspezifischen Wachstumsraten und Verdoppelungszeiten

\begin{tabular}{llll}
\hline Zelllinie & Tet & Wachstumsrate $\mu$ & Verdoppelungszeit $\mathrm{l}$ \\
\hline \hline & & & \\
T-REx HeLa & - & $\mu=0,301$ & $\mathrm{G}=24,00 \mathrm{~h}$ \\
T-REx HeLa & + & $\mu=0,326$ & $\mathrm{G}=22,15 \mathrm{~h}$ \\
$2.1 .1-16$ & - & $\mu=0,107$ & $\mathrm{G}=67,51 \mathrm{~h}$ \\
$2.1 .1-16$ & + & $\mu=0,093$ & $\mathrm{G}=77,68 \mathrm{~h}$ \\
& & & \\
\hline \hline & & $\mu=0,241$ & $\mathrm{G}=29,98 \mathrm{~h}$ \\
T-REx HeLa & - & $\mu=0,177$ & $\mathrm{G}=40,81 \mathrm{~h}$ \\
T-REx HeLa & + & $\mu=0,027$ & $\mathrm{G}=267,56 \mathrm{~h}$ \\
3.3 .3 & - & $\mu=0,039$ & $\mathrm{G}=185,23 \mathrm{~h}$ \\
\hline
\end{tabular}




\subsubsection{Ein PHD2-knock-down hat keinen Einfluss auf den Zellzyklus}

Die Betrachtung der Proliferationsrate lässt noch keinen direkten Vergleich der Verteilung der Zellzyklusstadien zu. Um die Verteilung näher zu betrachten und den Einfluss eines PHD2knock-downs zu untersuchen bzw. Tet-abhängige Ungleichheiten bei der Verteilung des Zellzyklus auszuschließen, wurden in den T-REx-HeLa- und 2.1.1-16-Zellen der Einfluss einer Tet- auf den Zellzyklus getestet. Dazu wurde jeweils nach einer Inkubation von 48 h in Anund Abwesenheit von Tet eine Zellzyklusanalyse durchgeführt. Dabei wurde die DNA der Zellen mit PJ angefärbt und im Anschluss der Gehalt der Zellen mittels FACS Analyse an PJ gemessen. Der Gehalt an PJ lässt Rückschlüsse auf das Stadium des Zellzyklus zu $\left(\mathrm{G}_{0} / \mathrm{G}_{1}\right.$ : einfacher DNA-Gehalt; $\mathrm{G}_{2}$ : Doppelter DNA-Gehalt; S: DNA-Gehalt zwischen einfacher und doppelter Menge).

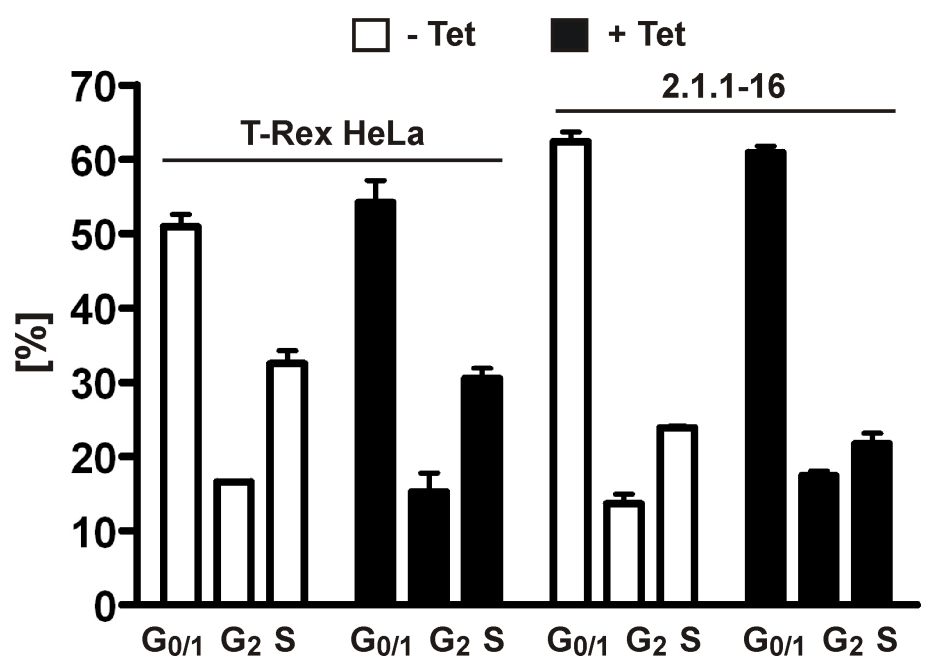

Abbildung 3.7: Ein PHD2-knock-down hat keinen Einfluss auf die Zellzyklusverteilung. Die T-REx-HeLaund 2.1.1-16-Zellen wurden mit der Zielkonzentration von 2 x 10 $/ \mathrm{ml}$ in $10 \mathrm{~cm}$ Schalen ausgesät und in An- und Abwesenheit von Tet (10 $\mu \mathrm{g} / \mathrm{ml})$ für $48 \mathrm{~h}$ unter normoxischen Bedingungene inkubiert. Bei 20000 Zellen wurde über FACS der Popidiumjodidgehalt gemessen, der proportional zum DNA-Gehalt der Zelle ist und so einem Stadium des Zellzykluses zugeordnet werden kann. ( $\mathrm{n}=3 \pm \mathrm{SD})$.

In den unbehandelten 2.1.1-16-Zellen sind geringfügig mehr Zellen in der $\mathrm{G}_{0} / \mathrm{G}_{1}$-Phase und weniger in der S-Phase im Vergleich zu den unbehandelten T-REx-HeLa-Zellen (Abbildung 3.7). Werden T-REx-HeLa-Zellen mit Tet für $48 \mathrm{~h}$ inkubiert, ändert sich die Verteilung des Zellzyklus nicht. Innerhalb der 2.1.1-16-Zelllinie kann in Ab- und Anwesenheit von Tet und 
damit in Abhängigkeit eines PHD2-knock-downs kein Unterschied festgestellt werden. Weder PHD2 noch die Behandlung mit Tet haben einen Einfluss auf die Zellzyklusverteilung.

\subsubsection{Ein PHD2- bzw. PHD3-knock-down hat keinen Einfluss auf die Zellvitalität}

Sollte die Behandlung der Zellen mit Tet Einfluss auf die Zellvitalität nehmen, so würde dies die Betrachtung der Chemotherapeutika-induzierten Zytotoxizität beeinflussen.

Aus diesem Grund wurde die Vitalität der T-REx-HeLa-, 2.1.1-16- und 3.3.3-Zelllinien bestimmt (siehe Abbildung 3.8 A und 3.8 B). Dazu wurden die Zellen für $110 \mathrm{~h}$ (2.1.1-16) bzw. $93 \mathrm{~h}$ (3.3.3) in An- und Abwesenheit von Tet $(10 \mu \mathrm{g} / \mathrm{ml})$ unter normoxischen Bedingungen inkubiert und die Vitalität über Trypan Blau Färbung bestimmt. Bei diesem Test werden abgestorbene Zellen durch den Farbstoff angefärbt, wohingegen vitale Zellen mit intakter Zellmembran nicht angefärbt werden. Im Anschluss wurde das Verhältnis von farblosen zu angefärbten Zellen per automatischer, mikroskopisch-gesteuerter Auswertung bestimmt.
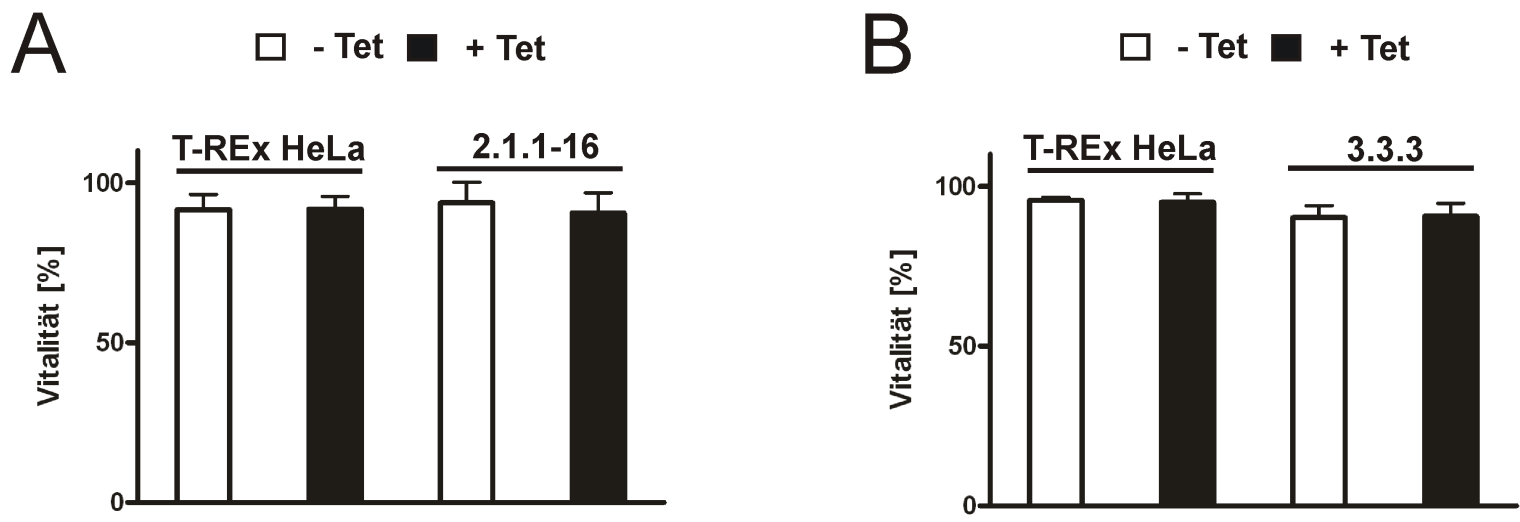

Abbildung 3.8: Die Vitalität der T-REx-HeLa- und der 2.1.1-16- bzw. 3.3.3-Zelllinien sind Tetrazyklinunabhängig. Die T-REx-HeLa- und 2.1.1-16- (A) bzw. 3.3.3-Zellen (B) wurden mit der Konzentration $2 \times 10^{5} / \mathrm{ml}$ in $3 \mathrm{~cm}$ Schalen ausgesät und die Zellvitalität nach $110 \mathrm{~h}$ (2.1.1-16) bzw. $93 \mathrm{~h}$ (3.3.3) in Abhängigkeit der An- (+ Tet) und Abwesenheit (-Tet) von Tetrazyklin (10 $\mu \mathrm{g} / \mathrm{ml})$ mit Trypan Blau Färbung bestimmt. Medium und Tetrazyklin wurde alle 48 h erneuert. $(n=3 \pm$ $\mathrm{SD})$.

Es konnten weder innerhalb der Zelllinien in An- und Abwesenheit von Tet noch im Vergleich der Zelllinien untereinander biologisch-relevante Unterschiede festgestellt werden. Es liegen keine signifikanten Unterschiede der Vitalitäten zwischen den Zelllinien, noch innerhalb einer Zelllinie in Abhängigkeit von Tet vor. 


\subsection{Ein PHD2-knock-down führt zur Resistenzzunahme gegenüber Etoposid, nicht aber Carboplatin}

Die Stabilität des Transkriptionsfaktors HIF-1 $\alpha$ wird über die drei Isoformen der PHDs beeinflusst. Hinsichtlich ihrer relativen Aktivität, ihrer Lokalisation innerhalb der Zelle und ihrer Expressionsstärke unterscheiden sich die Isoformen. PHD2 wird ubiquitär in allen Geweben in unterschiedlichen Stärken exprimiert [Lieb et al., 2002; Cioffi et al., 2003]. Gerade unter normoxischen Bedingungen ist der Einfluss von PHD2 im Vergleich zu den anderen Isoformen bezüglich der Sauerstoffadaptation am größten einzuschätzen [Huang J et al., 2002]. Transgene Mausmodelle haben gezeigt, dass die Funktion von PHD2 in der Embryogenese nicht von PHD1 bzw. PHD3 kompensiert werden kann [Takeda et al., 2006].

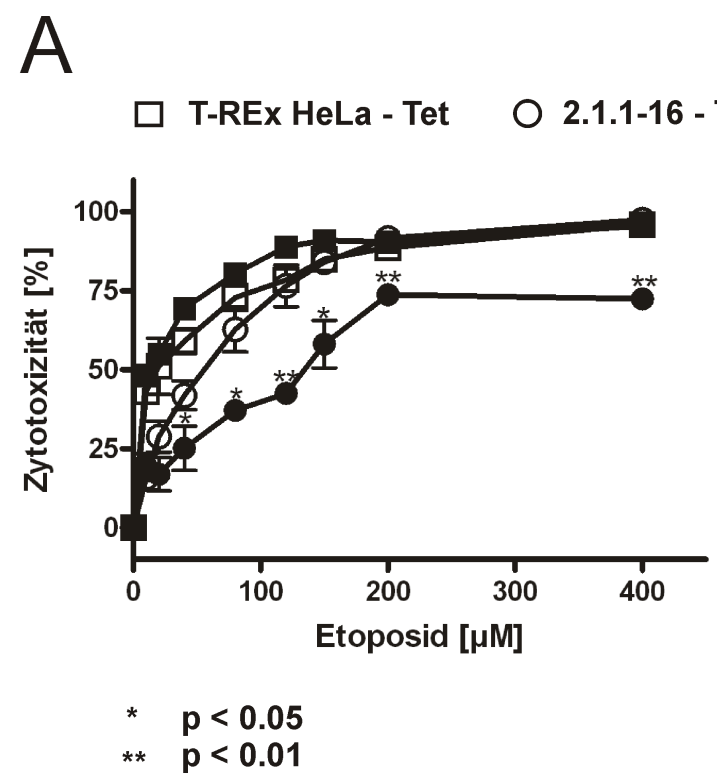

\section{$B$}
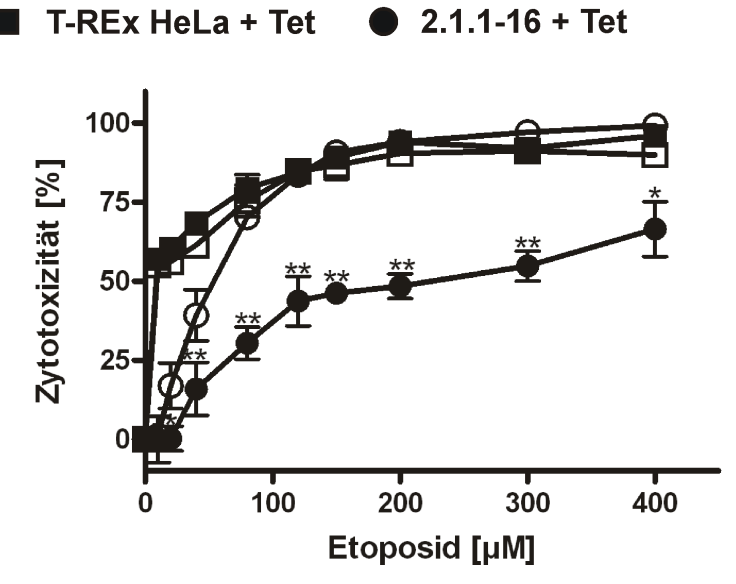

Abbildung 3.9: PHD2 beeinflusst das Zellüberleben nach Gabe von Etoposid in Normoxie und Hypoxie. TREx-HeLa- und 2.1.1-16-Zellen wurden 48 Stunden ohne (- Tet) und mit (+ Tet) Tetrazyklin (10 $\mu \mathrm{g} / \mathrm{ml})$ unter Normoxie $\left(20 \% \mathrm{O}_{2}\right)(\mathbf{A})$ bzw. Hypoxie $\left(1 \% \mathrm{O}_{2}\right)(\mathbf{B})$ inkubiert. Anschließend wurden die Zellen in 96-Lochplatten mit der Zielkonzentration 2 x 10 $/ \mathrm{ml}$ ausgesät (100 $\mu \mathrm{l} /$ Loch) und mit Etoposid für $48 \mathrm{~h}$ in angegebener Konzentration behandelt. Über MTT-Assay wurde die Zytotoxizität bestimmt. ( $\mathrm{n}=3 \pm \mathrm{SD}) ; * \mathrm{p} \leq 0,05 ; * * \mathrm{p} \leq 0,01$.

Um den Einfluss eines spezifischen PHD2-knock-downs auf die Etoposid-induzierte Zytotoxizität unter normoxischen und hypoxischen Bedingungen zu untersuchen, wurden T-RExHeLa- und 2.1.1-16-Zellen in An- und Abwesenheit von Tet $(10 \mu \mathrm{g} / \mathrm{ml})$ für $48 \mathrm{~h}$ unter nor- 
moxischen und hypoxischen Bedingungen inkubiert und anschließend mit Etoposid in verschiedenen Konzentrationen für 48 h behandelt. Die Zytotoxizität wurde über MTT-Assay bestimmt.

Die Kurve der Dosis-Wirkungsbeziehung der 2.1.1-16-Zelllinie unter Tet Zugabe bei normoxischen Bedingungen ist nach rechts verschoben (siehe Abbildung 3.9 A, Seite 45) und die Steigung insgesamt geringer. Ein PHD2-knock-down führt in dieser Zelllinie zu einer Zunahme der Resistenz gegenüber Etoposid. Die Kurven der T-REx-HeLa-Zelllinie in An- und Abwesenheit von Tet verlaufen hingegen gleich und es ist keine Verschiebung zu erkennen. Dies schließt einen Tet-unspezifischen Effekt als Ursache der Resistenz aus.

Abbildung 3.9 B (Seite 45) zeigt, dass auch unter hypoxischen Bedingungen eine Resistenzzunahme gegenüber Etoposid in der 2.1.1-16-Zelllinie unter Tet-Zugabe zu beobachten ist. Die Zugabe von Tet zu T-REx-HeLa-Zellen hat dagegen keinen Einfluss auf die Etoposidinduzierte Zytotoxizität. Im Vergleich zwischen Normoxie und Hypoxie fällt auf, dass die Resistenzzunahme unter hypoxischen Bedinungen bei der 2.1.1-16-Zelllinie in Anwesenheit von Tet deutlicher ausfällt. Der Effekt eines PHD2-knock-downs auf die Zytotoxizität wird unter hypoxischen Bedingungen verstärkt.
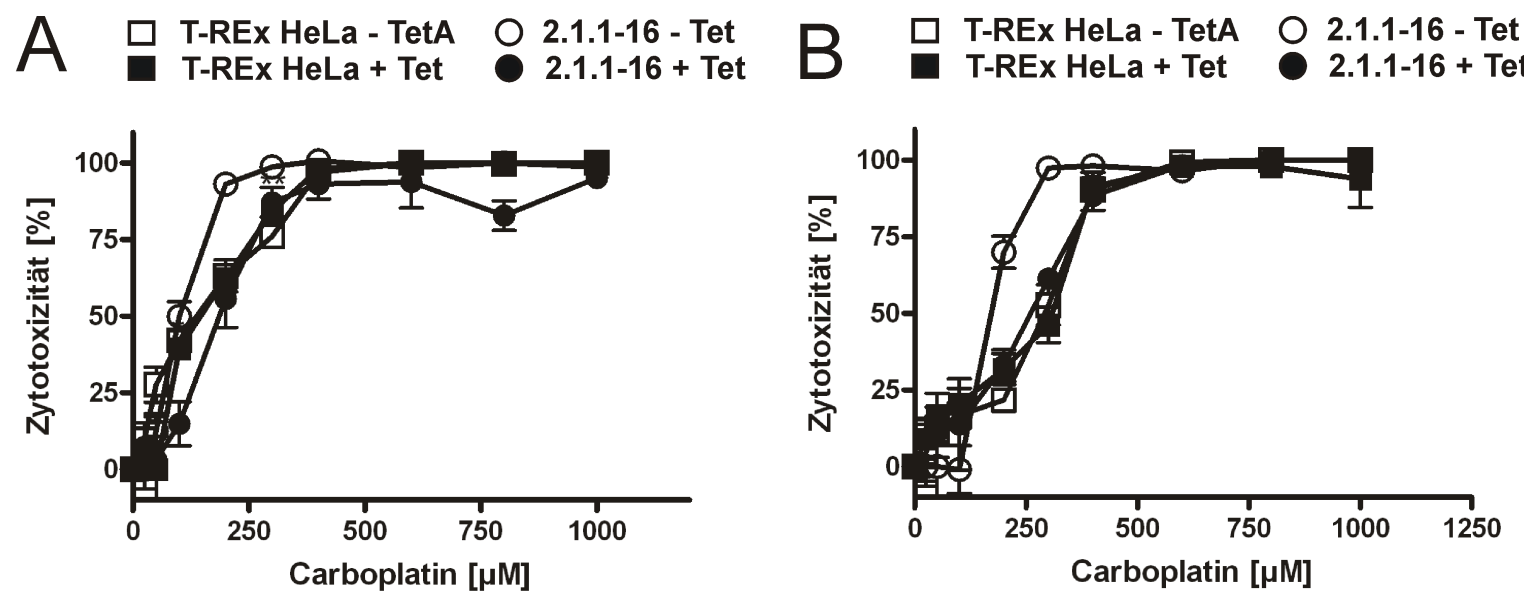

Abbildung 3.10: PHD2 hat keinen Einfluss auf das Zellüberleben nach Gabe von Carboplatin in Normoxie und Hypoxie. T-REx-HeLa- und 2.1.1-16- Zellen wurden 48 Stunden ohne (- Tet) und mit (+ Tet) Tetrazyklin $(10 \mu \mathrm{g} / \mathrm{ml})$ unter Normoxie $\left(20 \% \mathrm{O}_{2}\right) \mathbf{( A )}$ und Hypoxie $\left(1 \% \mathrm{O}_{2}\right)(\mathbf{B})$ inkubiert. Anschließend wurden die Zellen in 96-Lochplatten mit der Zielkonzentration $2 \mathrm{x}$ $10^{5} / \mathrm{ml}$ ausgesät und mit Carboplatin unter Normoxie für $48 \mathrm{~h}$ in angegebener Konzentration behandelt. Über MTT-Assay wurde die Zytotoxizität bestimmt. ( $n=3 \pm S D)$. 
Behandlung von HeLa-Zellen mit DMOG führt zu einer Etoposid-spezifischen Chemoresistenz. Ein DMOG-Effekt auf die Resistenz ist bei Behandlung mit Carboplatin nicht feststellbar. Um zu untersuchen, ob die Chemoresistenz infolge eines PHD2-knock-downs spezifisch ist, wurden T-REx-HeLa- und 2.1.1-16-Zellen nach einer Inkubation für $48 \mathrm{~h}$ in An- und Abwesenheit von Tet $(10 \mu \mathrm{g} / \mathrm{ml})$ für $48 \mathrm{~h}$ mit dem Chemotherapeutikum Carboplatin unter normoxischen und hypoxischen Bedingungen behandelt.

Sowohl unter normoxischen als auch hypoxischen Bedingungen ist kein Effekt von PHD2 auf die Carboplatin-induzierte Zytotoxizität feststellbar (siehe Abbildung 3.10 A und B, Seite 46). Die Kurvenverläufe in An- und Abwesenheit von Tet sind nahezu identisch und es ist kein signifikanter Unterschied erkennbar.

\subsection{Gesteigerte Vitalität nach PHD2-knock-down in Anwesenheit von Etoposid}

Um die Ergebnisse des MTT-Assys durch eine weitere Methode zu verifizieren, wurde die Vitalität der Zellen über den MultiTox-Fluor-Multiplex-Zytotoxizitäts-Assay bestimmt. Im Gegensatz zum MTT-Assay wird hier nicht die Aktivität der Succinat-Dehydrogenase, sondern die einer nur in lebenden Zellen aktiven Protease als Nachweis der Vitalität herangezogen.

Dazu wurden T-REx-HeLa- und 2.1.1-16-Zellen für $48 \mathrm{~h}$ in An- und Abwesenheit von Tet $(10 \mu \mathrm{g} / \mathrm{ml})$ unter normoxischen Bedingungen inkubiert und anschließend für $48 \mathrm{~h}$ mit Etoposid in angegebener Konzentration behandelt. Im Anschluss wurde die Aktivität einer nur in lebenden Zellen aktiven Protease über den Nachweis der Spaltung des GF-AFC-Substrats im Fluorometer bestimmt. Die Aktivität ist proportional zur Anzahl der lebenden Zellen.

Abbildung 3.11 (Seite 48) zeigt den Anteil lebender Zellen nach Behandlung mit Etoposid bei den beiden Zelllinien in An- und Abwesenheit von Tet. Die Kurve der 2.1.1-16Zelllinie unter Tet-Zugabe ist deutlich nach oben verschoben und fällt weniger stark ab. TetAnwesenheit führt bei der 2.1.1-16-Zelllinie zur Resistenzzunahme gegenüber Etoposid. Die Tet-Behandlung bei der T-REx-HeLa-Zelllinie hat keinen Einfluss. 


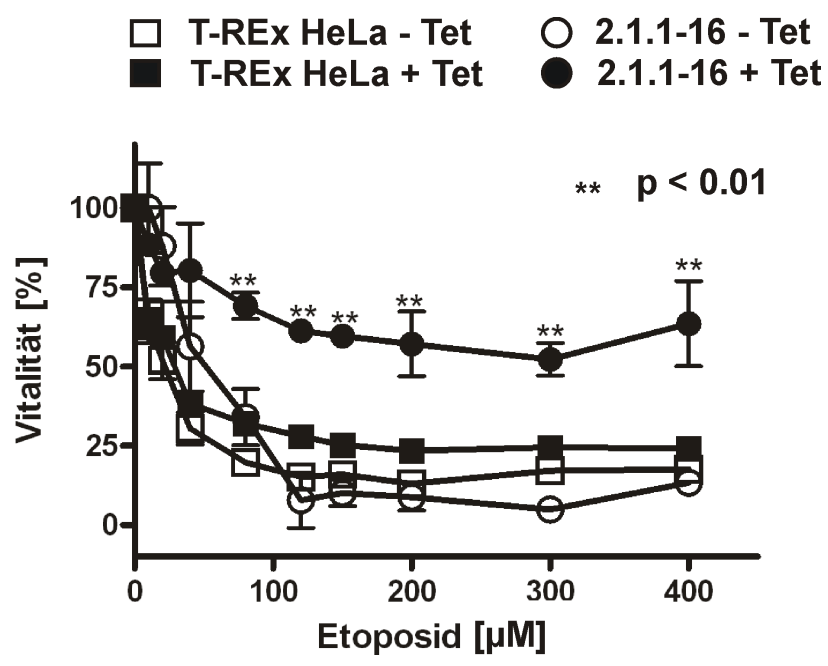

Abbildung 3.11: PHD2 beeinflusst die Vitalität nach Gabe von Etoposid. T-REx-HeLa- und 2.1.1-16-Zellen wurden 48 Stunden ohne (- Tet) und mit (+ Tet) Tetrazyklin $(10 \mu \mathrm{g} / \mathrm{ml})$ unter normoxischen Bedingungen inkubiert. Anschließend wurden die Zellen in 96-Lochplatten mit der Zielkonzentration $2 \times 10^{5} / \mathrm{ml}$ ausgesät und mit Etoposid unter Normoxie für $48 \mathrm{~h}$ in angegebener Konzentration behandelt. Die nur in lebenden Zellen aktive Protease wurde mit dem MultiToxFluor-Multiplex-Zytotoxizitäts-Assay (Promega) bestimmt. $(\mathrm{n}=3 \pm \mathrm{SD}) ; * \mathrm{p} \leq 0,05 ; * * \mathrm{p} \leq$ 0,01 .

\subsection{Ein PHD3-knock-down hat keinen Einfluss auf die Etoposid-induzierte Zytotoxizität}

Während PHD2 ubiquitär exprimiert wird, ist die Verteilung von PHD3 restriktiver und organspezifischer [Lieb et al., 2002]. Auch die Expressionsstärke unterscheidet sich zwischen den beiden Isoformen. PHD3 wird unter normoxischen Bedingungen kaum, unter hypoxischen Bedingungen jedoch stark exprimiert [Appelhoff et al., 2004].

Um den Einfluss eines spezifischen PHD3-knock-downs auf die Etoposid-induzierte Zytotoxizität zu untersuchen, wurden T-REx-HeLa- und 3.3.3-Zellen für $48 \mathrm{~h}$ unter normoxischen und hypoxischen Bedingungen in An- und Abwesenheit von Tet inkubiert und im Anschluss für $48 \mathrm{~h}$ mit unterschiedlichen Konzentrationen Etoposid behandelt.

Sowohl unter normoxischen (siehe Abbildung 3.12 A, Seite 49 als auch hypoxischen Bedingungen (siehe Abbildung 3.12 B, Seite 49) ist kein Einfluss einer Tet-Behandlung auf die Etoposid-induzierte Zytotoxizität feststellbar. Die 3.3.3-Zelllinie zeigt allgemein im Vergleich 
zur T-REx-HeLa-Zelllinie eine gesteigerte Tet-unabhängige Resistenz. Dieser Unterschied kann durch die deutlich geringere Proliferation der 3.3.3-Zelllinie im Vergleich zu den TREx-HeLa-Zellen erklärt werden. Der Einfluss der Proliferationsrate auf die Wirksamkeit von Chemotherapeutika wurde bereits dargelegt.
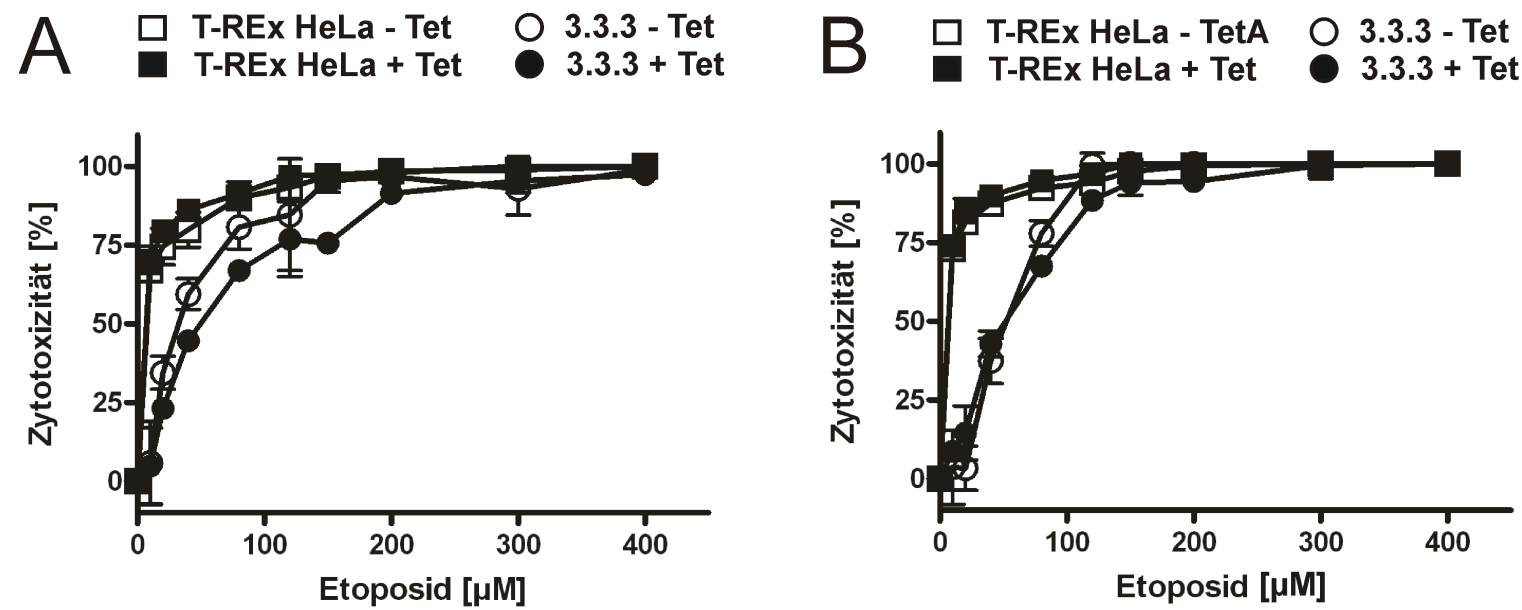

Abbildung 3.12: PHD3 hat keinen Einfluss auf das Zellüberleben nach Gabe von Etoposid in Normoxie und Hypoxie. T-REx-HeLa- und 3.3.3-Zellen wurden 48 Stunden ohne (- Tet) und mit (+ Tet) Tetrazyklin $(10 \mu \mathrm{g} / \mathrm{ml})$ unter Normoxie $\left(20 \% \mathrm{O}_{2}\right)(\mathbf{A})$ und Hypoxie $\left(1 \% \mathrm{O}_{2}\right)(\mathbf{B})$ inkubiert. Anschließend wurden die Zellen in 96-Lochplatten mit der Zielkonzentration 2 x 105/ml ausgesät und mit Etoposid unter Normoxie bzw. Hypoxie für 48 h in angegebener Konzentration behandelt. Über MTT-Assay wurde die Zytotoxizität bestimmt. ( $n=3 \pm S D)$.

\subsection{Der Anstieg der aktiven Caspase 3/7 nach Behandlung mit Etoposid ist PHD2-abhängig}

Die Apoptose ist ein evolutionär konserviertes Selbstmordprogramm der Zellen, bei dem Proteine der Bcl-2- und Caspase-Familie in der Aktivierung, Signaltransduktion und Ausführung des Zelluntergangs eine wichtige Rolle einnehmen [Li J and Yuan, 2008]. Apoptose kann zum einen über den extrinsischen und zum anderen über den intrinsischen Weg induziert werden, wobei die meisten Chemotherapeutika, wie auch Etoposid, Apoptose über den intrinsischen Weg induzieren. Proteine der Bcl-2 Familie kontrollieren die Integrität der äußeren Mitochondrienmembran. Ein intrinsisches Signal, wie zum Beispiel DNA-Schäden, führen über den Transkriptionsfaktor p53 und der Expression von weiteren Faktoren zur Permeabili- 
sierung der Mitochondrienmembran [Vogler et al., 2009]. Proapoptotische Faktoren wie Cytochrom $\mathrm{C}$ gelangen ins Zytosol. Diese aktivieren zunächst die Caspase 9 und eine Kaskade von hintereinandergeschalteten Caspasen wird in Gang gesetzt, an dessen Ende die Effektorcaspasen 3 und 7 stehen. Diese sind einerseits an der Aktivierung von weiteren Zielproteinen beteiligt, aber unterstützen auch den weiteren Ablauf der Apoptose aktiv durch den Abbau von Zellbestandteilen. Es schnüren sich Vesikel von der Zellmembran ab, die jedoch intakt bleibt [Hengartner, 2000]. Der extrinsische Weg wird hingegen über extrazelluläre Faktoren aktiviert, die an spezifische Rezeptoren der Zellmembran binden und ebenfalls die Kaskade von hintereinandergeschalteten Caspasen aktivieren. Die Apoptose verläuft in geregelten Schritten und es kommt im Körper zu keiner Entzündungsreaktion.

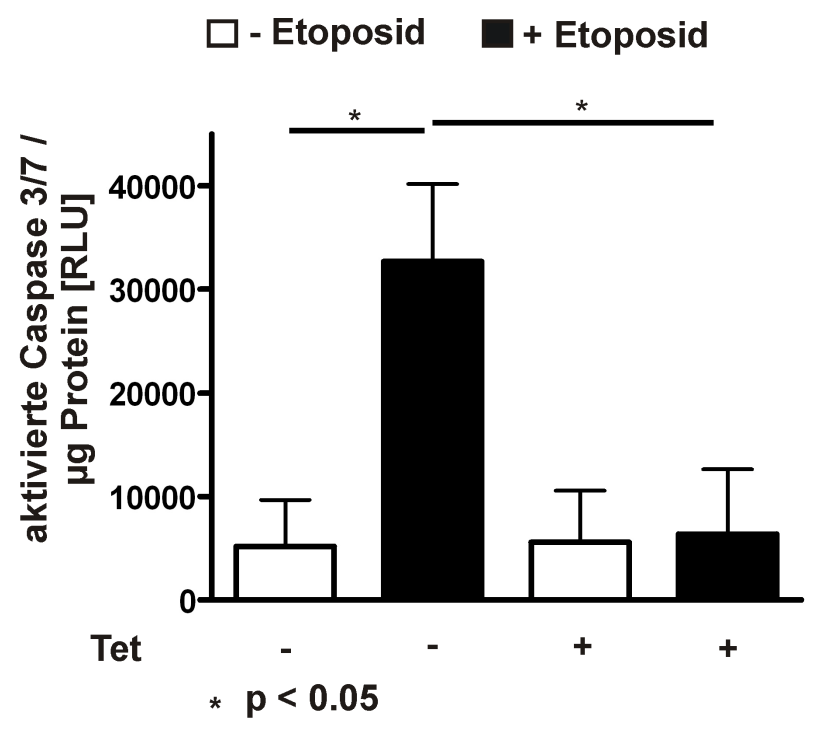

Abbildung 3.13: PHD2 beeinflusst die Konzentration der aktiven Caspase 3/7 nach Gabe von Etoposid. 2.1.1-16-Zellen wurden 48 Stunden ohne (- Tet) und mit (+ Tet) Tetrazyklin $(10 \mu \mathrm{g} / \mathrm{ml})$ unter Normoxie inkubiert. Anschließend wurden die Zellen in 96-Lochplatten mit der Zielkonzentration $2 \times 10^{5} / \mathrm{ml}$ ausgesät und mit und ohne Etoposid $(60 \mu \mathrm{M})$ unter Normoxie für $48 \mathrm{~h}$ behandelt. Die aktive Caspase 3/7 wurde mit dem Caspase-Glo-3/7 Assay (Promega) bestimmt. Im parallelen Ansatz wurde Protein nach Bradford bestimmt und die gemessene Caspase 3/7 auf das $1 \mu \mathrm{g}$ zelluläres Protein bezogen. $(\mathrm{n}=3 \pm \mathrm{SD}) ; * \mathrm{p} \leq 0,05$.

Um zu untersuchen, ob die Behandlung der 2.1.1-16-Zellen mit Tet und Etoposid zu einer Änderung der Grundaktivität der aktiven Caspase 3/7 führt, wurden 2.1.1-16-Zellen bei Normoxie nach einer Inkubationszeit von $48 \mathrm{~h}$ in An- und Abwesenheit von Tet $(10 \mu \mathrm{g} / \mathrm{ml})$ für $48 \mathrm{~h}$ mit $60 \mu \mathrm{M}$ Etoposid behandelt und im Anschluss die Effektorcaspasen 3/7 mithilfe des 
Caspase-Glo Assay bestimmt. Es wurden $60 \mu \mathrm{M}$ Etoposid gewählt, da bei dieser Konzentration $50 \%$ der 2.1.1-16-Zellen tot waren (siehe Abbildung 3.9. Seite 45). Die Bestimmung der aktiven Caspase 3/7 erfolgte über eine Lumineszenzreaktion nach Zelllyse. Zur Bestimmung der Grundaktivität der aktiven Caspase 3/7 wurden die Zellen in Abwesenheit von Etoposid kultiviert. Um die Werte untereinander besser vergleichen zu können, wurde in einem parallelen Ansatz die Proteinkonzentration nach Bradford bestimmt und die gemessene Caspase 3/7 auf $1 \mu \mathrm{g}$ zelluläres Protein bezogen.

Deutlich wird, dass es in An- und Abwesenheit von Tet bei Abwesenheit von Etoposid zu keinem Anstieg der Grundaktivität der Caspase 3/7 kommt (siehe Abbildung 3.13, Seite 50). Ein PHD2-knock-down nimmt demnach keinen Einfluss auf die Grundaktivität. Auffällig ist, dass es zu einem deutlichen Anstieg der Aktivität der Caspase 3/7 in Abwesenheit von Tet bei Behandlung mit Etoposid kommt. Dieser Anstieg ist nicht feststellbar bei Anwesenheit von Tet und Etoposid-Behandlung. Dies bestätigt die Beobachtung, dass es unter Tet zu einer Resistenzbildung gegenüber Etoposid kommt.

\subsection{Charakterisierung der PHD2-abhängigen Transportkapazität}

Von großer klinischer Relevanz ist die Bildung von Chemoresistenzen gegenüber Chemotherapeutika. Sie geht einher mit therapeutischen Konsequenzen und schlechter Prognose. Damit ein Zytostatikum seine Wirkung entfalten kann, muss es in die Zelle gelangen. Für die Resistenzbildung könnte daher eine veränderte Expression verschiedener Transportern verantwortlich sein, die für die Aufnahme und Abgabe des Medikamentes zuständig sind. Eine geringere Expression oder Aktivität von Transportern, die für die Aufnahme (Influx) verantwortlich sind, oder eine gesteigerte Expression oder Aktivität von Transporter, die die Abgabe (Efflux) unterstützen, würden so zu einer geringeren Akkumulation des Medikamentes in der Zelle und somit zu einer geringeren Wirkung.

3.8.1 Ein PHD2-knock-down und eine DMOG-Behandlung haben keinen Einfluss auf die Aufnahme von Etoposid

Die Bildung einer Chemoresistenz kann durch eine geringere Expression oder Aktivität und damit Kapazität von Transportern hervorgerufen werden, die für die Aufnahme des Medikaments verantwortlich sind [Huang Y and Sadee, 2006]. Ein Beispiel für eine transportervermittelte Aufnahme von Zytostatika ist die Interaktion zwischen Cisplatin und dem organic 
cation transporters 2 (OCT 2) [Hayer-Zillgen et al., 2002]. OCTs vermitteln die intrazelluläre Aufnahme diverser strukturell unterschiedlicher organischen Kationen, deren Ursprung endogen (z.B. Kreatinin) oder exogen (z.B. Metformin) sein kann. Die Expression der OCTs konnte für einige Krebszelllinien festgestellt werden [Hayer-Zillgen et al., 2002].

Um zu untersuchen, ob ein PHD2-knock-down zu einer Beeinflussung der Aufnahme von Etoposid führt, wurden HeLa-T-REx- und 2.1.1-16-Zellen für $48 \mathrm{~h}$ in An- und Abwesenheit von Tet $(10 \mu \mathrm{g} / \mathrm{ml})$ unter Normoxie inkubiert. Um den Einfluss einer Inhibition aller PHDs über DMOG zu untersuchen und gegebenenfalls eine HIF-1 $\alpha$-Abhängigkeit festzustellen, wurden MEF-Hif- $1 \alpha^{+/+}$- und MEF-Hif- $1 \alpha^{-/-}$-Zellen für $24 \mathrm{~h}$ in An- und Abwesenheit von DMOG $(1 \mu \mathrm{M})$ bei normoxischen Bedingungen inkubiert.
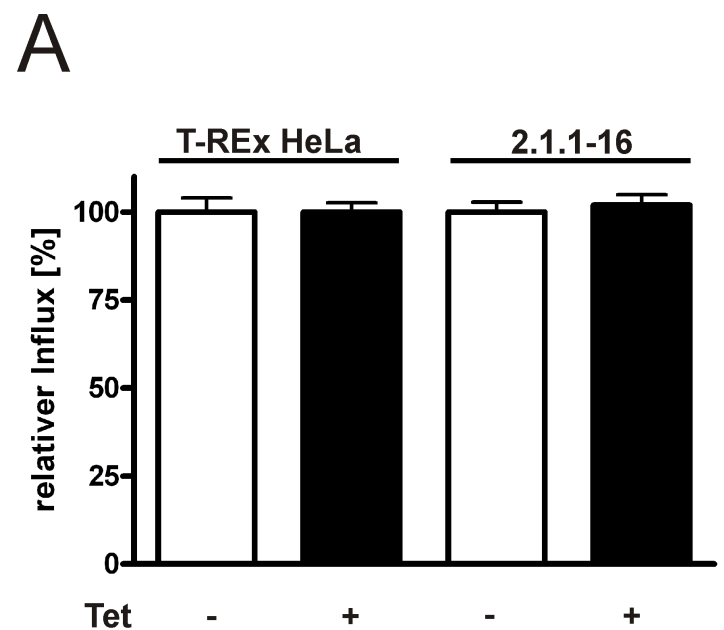
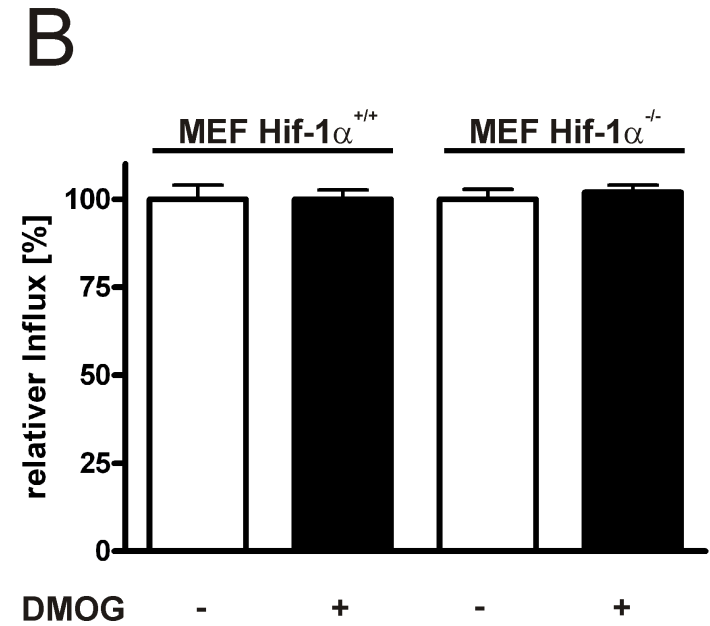

Abbildung 3.14: Die Aufnahme von Etoposid wird nicht beeinflusst durch einen PHD2-knock-down oder DMOG-Behandlung. 2.1.1-16-Zellen (A) wurden 48 Stunden ohne (- Tet) und mit (+ Tet) Tetrazyklin $(10 \mu \mathrm{g} / \mathrm{ml})$ unter normoxischen Bedingungen mit der Zielkonzentration von $2 \mathrm{x}$ $10^{5} / \mathrm{ml}$ in 24-Lochplatten inkubiert. MEF-Hif- $1 \alpha^{+/+}$- und MEF-Hif- $1 \alpha^{-/-}$-Zellen (B) wurden für $24 \mathrm{~h}$ in An-(+ DMOG) und Abwesenheit (- DMOG) von DMOG (1 mM) unter normoxischen Bedingungen mit der Zielkonzentration von $0,3 \times 10^{5} / \mathrm{ml}$ in 24-Lochplatten inkubiert. Anschließend wurden die Zellen gewaschen und fünf min mit Etoposid $\left(1 \mathrm{nM}\left[{ }^{3} \mathrm{H}\right]\right.$ Etoposid, $1 \mu \mathrm{M}$ Etoposid kalt) inkubiert. Die Zellen wurden gewaschen und lysiert. Anschließend wurde über Flüssigkeitsszintillationsmessung die $\left[{ }^{3} \mathrm{H}\right]$ Konzentration bestimmt. Die Werte ohne Behandlung mit Tet bzw. DMOG wurden jeweils als $100 \%$ Influx definiert und die Werte mit Behandlung dazu in Relation gesetzt. $(\mathrm{n}=3 \pm \mathrm{SD})$.

Nach mehreren Waschschritten wurden die Zellen mit dem Transportmedium (Ringerlösung, $\left.10 \mathrm{nM} \mathrm{[}{ }^{3} \mathrm{H}\right]$ Etoposid, $1 \mu \mathrm{M}$ Etoposid kalt) inkubiert. Um die reine Transporter-vermittelte 
Aufnahme festzustellen, wurde als Inkubationszeit fünf min gewählt, da in diesem Intervall die Aufnahme nicht per Diffusion, sondern ausschließlich Transporter-vermittelt abläuft. Nach weiteren Waschschritten und Zelllyse wurde über Flüssigkeitsszintillationsmessung die Aufnahme bestimmt. Die Ergebnisse ohne Behandlung wurden jeweils als $100 \%$ Aufnahme definiert und die Werte mit Behandlung dazu in Relation gesetzt.

Unter allen Bedingungen konnte eine Aufnahme von Etoposid festgestellt werden, die aufgrund der kurzen Inkubationszeit Transporter-vermittelt verläuft (siehe Abbildung 3.14, Seite 52). Die Aufnahme wird jedoch weder durch einen PHD2-knock-down noch durch DMOGBehandlung beinflusst. Eine verminderte Aufnahme als Ursache für die gesteigerte Resistenz gegenüber Etoposid kann somit ausgeschlossen werden.

\subsubsection{Ein PHD2-knock-down führt zu einer Resistenzzunahme gegenüber den MDR-1-Substraten Vinblastin und Doxorubicin}

Tumorzellen können gegenüber Chemotherapeutika Resistenzen bilden, indem der Efflux über eine erhöhte Expression der MDR-Genfamilie gesteigert wird. Zu dieser Genfamilie gehören zwei homologe Mitglieder, wobei MDR-1 am besten charakterisiert ist. Neben MDR-1 werden in der Literatur auch die älteren Namen P-Glykoprotein bzw. ABCB 1 (ATP-binding cassette subfamily $B$ ) homolog verwendet. MDR-1 wird der ABC-Transporterfamilie zugeordnet, die ATP-abhängig diverse Xenobiotika mit unterschiedlichen Konformitäten aus der Zelle über die Zellmembran an die Umgebung abgeben und die Konzentration innerhalb der Zelle auf subtoxische Werte senkt [Fardel et al., 1996]. Die Transporter werden auf den Membranen normaler Zellen gefunden, jedoch konnte eine erhöhte Expression von MDR-1 auf der Zellmembran von Tumorzellen mit einem resistentem Phänotyp nachgewiesen werden und ist assoziiert mit einer schlechten Prognose [Goldstein, 1996; Marie et al., 1996; Legrand et al., 1999]. Etoposid ist ein Substrat der ABC-Transporterfamilie, wohingegen Carboplatin kein Substrat dieser Familie darstellt [Froelich-Ammon and Osheroff, 1995; Rabik and Dolan, 2007]. Neben Etoposid werden noch weitere Chemotherapeutika, wie zum Beispiel Vinblastin und Doxorubicin, MDR-1-vermittelt aus der Zelle befördert [Sharom, 1997].

Um zu untersuchen, ob eine Resistenzzunahme gegenüber weiteren MDR-1-Substraten feststellbar ist, wurden T-REx-HeLa- und 2.1.1-16-Zellen für $48 \mathrm{~h}$ in An- und Abwesenheit von Tet $(10 \mu \mathrm{g} / \mathrm{ml})$ unter normoxischen Bedingungen inkubiert und anschließend mit den Chemotherapeutika Vinblastin und Doxorubicin in angegebener Konzentration für $48 \mathrm{~h}$ inkubiert. Im Anschluss wurde über MTT-Tests die Zytotoxizität bestimmt. 


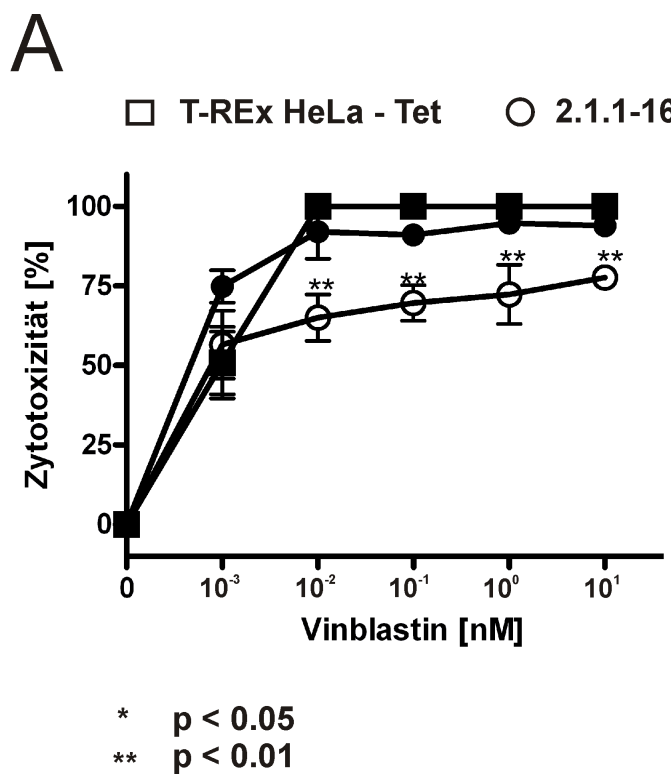

$B$

T-REx HeLa + Tet

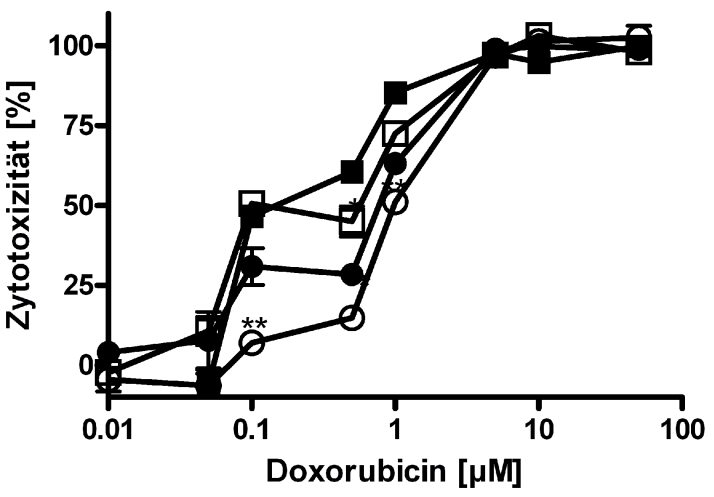

Abbildung 3.15: PHD2 beeinflusst das Zellüberleben nach Behandung mit Vinblastin und Doxorubicin.

T-REx-HeLa- und 2.1.1-16-Zellen wurden 48 Stunden ohne (- Tet) und mit (+ Tet) Tetrazyklin $(10 \mu \mathrm{g} / \mathrm{ml})$ unter normoxischen Bedingungen inkubiert. Anschließend wurden die Zellen in 96Lochplatten mit der Zielkonzentration $2 \times 10^{5} / \mathrm{ml}$ ausgesät und mit Vinblastin (A) und Doxorubicin (B) unter Normoxie für $48 \mathrm{~h}$ in angegebener Konzentration behandelt. Über MTT-Assay wurde die Zytotoxizität bestimmt. ( $\mathrm{n}=3 \pm \mathrm{SD}) ; * \mathrm{p} \leq 0,05 ; * * \mathrm{p} \leq 0,01$.

Abbildung 3.15 zeigt, dass sowohl gegenüber Vinblastin (A) als auch Doxorubicin (B) infolge einer Tet Behandlung bei 2.1.1-16-Zellen eine Resistenzzunahme feststellbar ist. Ein PHD2-knock-down führt somit zu einer verminderten Zytotoxizität gegenüber weiteren MDR1-Substraten. Die Dosis-Wirkungsbeziehung der T-REx-HeLa-Zellen in An- und Abwesenheit von Tet sowie 2.1.1-16-Zellen in Abwesenheit von Tet zeigen, dass Tet keinen PHD2unabhängigen Einfluss auf die Resistenz gegenüber Vinblastin und Doxorubicin ausübt.

\subsubsection{Die Resistenzzunahme infolge eines PHD2-knock-downs ist MDR-1-vermittelt}

Behandlung der T-REx-HeLa-Zellen mit Tet hat keinen Einfluss auf die Vinblastin- und Doxorubicin-induzierte Zytotoxizität. Eine Resistenzzunahme konnte aber bei der 2.1.1-16Zelllinie in Anwesenheit von Tet festgestellt werden. Ein PHD2-knock-down hat demnach auch einen Einfluss auf die von den MDR-1-Substraten Doxorubicin- und Vinblastin-induzierte Zytotoxizität. 
Um weitere Einblicke in die PHD2-vermittelte Chemoresistenz zu erhalten, wurde die Aktivität von MDR-1 durch den in der Literatur beschriebenen Inhibitor Verapamil gehemmt. Behandlung von Zellen mit Verapamil führt über eine kompetitive Inhibition des Transporters zu einem verminderten Efflux anderer Substrate [Yusa and Tsuruo, 1989; Sharom, 1997].

Dazu wurden 2.1.1-16- und T-REx-HeLa-Zellen für $48 \mathrm{~h}$ in An- und Abwesenheit von Tet $(10 \mu \mathrm{g} / \mathrm{ml})$ unter normoxischen Bedingungen inkubiert und anschließend mit Etoposid (60 $\mu \mathrm{M})$ oder Carboplatin $(300 \mu \mathrm{M})$ in An- und Abwesenheit von Verapamil $(10 \mu \mathrm{M})$ behandelt. Im Anschluss wurde die Zytotoxizität über MTT-Test bestimmt. In einem parallelen Ansatz wurden 2.1.1-16-Zellen für $48 \mathrm{~h}$ in An- und Abwesenheit von Tet für $48 \mathrm{~h}$ inkubiert, anschließend lysiert und RNA isoliert. Die Expression von MDR-1 wurde mittels RT-PCR im Verhältnis zum konstitutiv exprimierten L28 analysiert.

Behandlung mit Verapamil hatte keinen Einfluss auf die Etoposid- und Carboplatin-induzierte Zytotoxizität der T-REx-HeLa-Zellen, weder in An- noch in Abwesenheit von Tet (siehe Abbildung 3.16 A, Seite 56). In Anwesenheit von Verapamil konnte aber eine Zunahme der Zytotoxizität gegenüber Etoposid bei der 2.1.1-16-Zelllinie unter Tet-Behandlung festgestellt werden. Dieser Effekt konnte weder in Abwesenheit von Tet, noch bei der Behandlung der 2.1.1-16-Zellen mit Carboplatin festgestellt werden (siehe Abbildung 3.16 B, Seite 56). Die PHD2-vermittelte Resistenzzunahme gegenüber Etoposid scheint daher MDR-1-vermittelt zu sein. In Übereinstimmung mit dieser Beobachtung konnte eine erhöhte Expression von MDR1 auf RNA-Ebene bei der 2.1.1-16-Zelllinie in Anwesenheit von Tet festgestellt werden (siehe Abbildung 3.16C, Seite 56. Dazu wurden 2.1.1-16-Zellen für 48 h in An- und Abwesenheit von Tet behandelt und anschließend RNA isoliert. Die Expression von MDR-1-mRNA wurde mittels RT-PCR analysiert.

In der Literatur wird beschrieben, dass eine Expression des Transporters nicht mit seiner Aktivität korrelieren muss [Sikic et al., 1997]. Für die Resistenzbildung ist neben der Stärke der Expression vor allem die Aktivität entscheidend [Bailly et al., 1995]. Aus diesem Grund wurde die MDR-1-Transportaktivität über den Multidrug Resistance Direct Dye Efflux Assays bestimmt. 


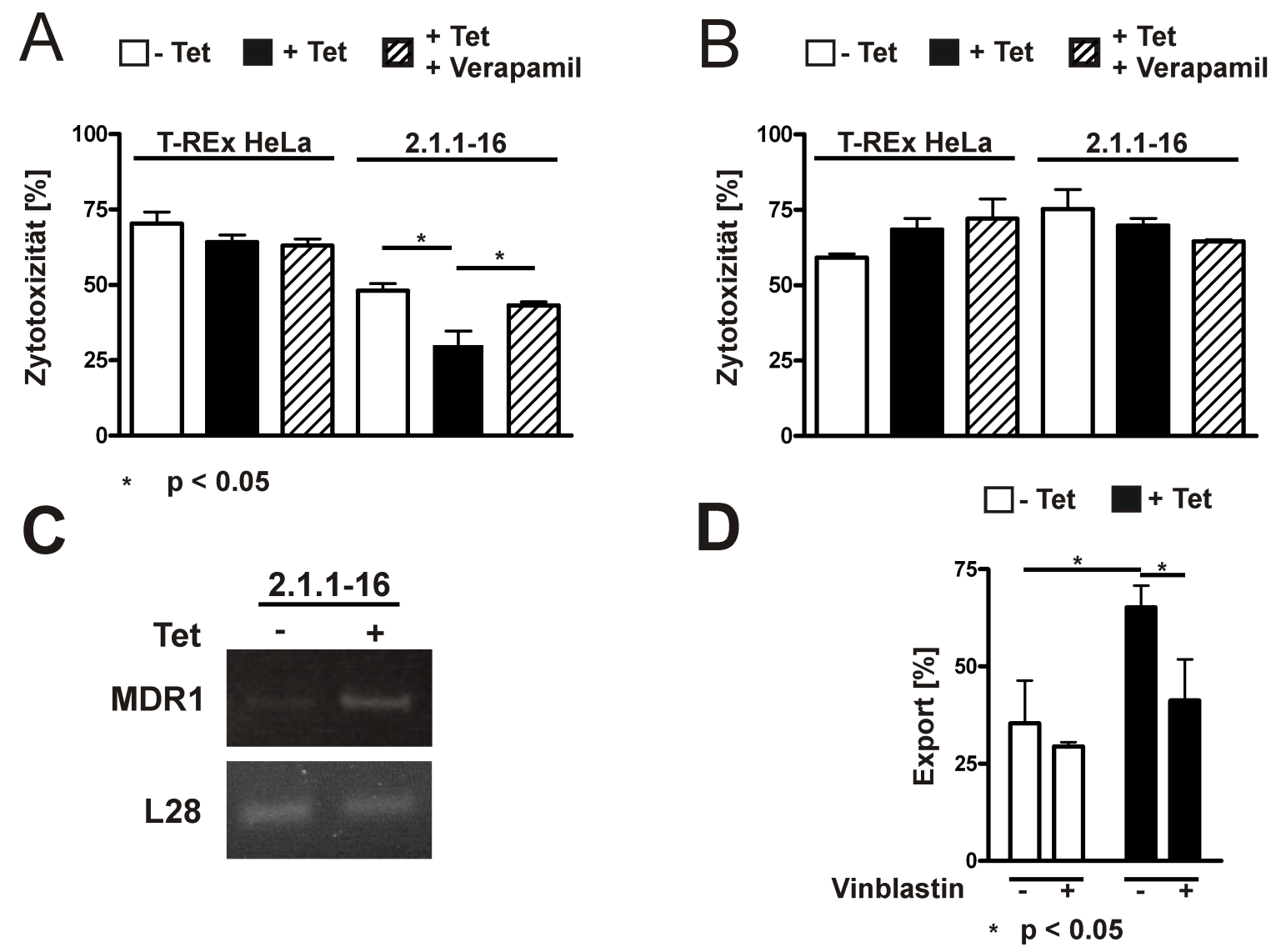

Abbildung 3.16: Verapamilbehandlung beeinflusst die Etoposid-induzierte Zytotoxizität nur bei den PHD2-knock-down-Zellen. T-REx-HeLa- und 2.1.1-16-Zellen wurden 48 Stunden ohne (- Tet) und mit $(+$ Tet) Tetrazyklin $(10 \mu \mathrm{g} / \mathrm{ml})$ unter normoxischen Bedingungen inkubiert. AnschlieBend wurden die Zellen in 96-Lochplatten mit der Zielkonzentration $2 \times 10^{5} / \mathrm{ml}$ ausgesät und mit Etoposid $(60 \mu \mathrm{M})(\mathrm{A})$ und Carboplatin $(300 \mu \mathrm{M})(\mathbf{B})$ in An- oder Abwesenheit von Verapamil $(10 \mu \mathrm{M})$ unter Normoxie für $48 \mathrm{~h}$ in angegebener Konzentration behandelt. Über MTTAssay wurde die Zytotoxizität bestimmt. 2.1.1-16-Zellen (C) wurden 48 Stunden ohne (- Tet) und mit (+ Tet) Tetrazyklin $(10 \mu \mathrm{g} / \mathrm{ml})$ unter Normoxie inkubiert. Die Zellen wurden lysiert und RNA isoliert. Die Expression von MDR-1-mRNA wurde mittels RT-PCR untersucht und im Verhältnis zur L28-mRNA dargestellt. 2.1.1-16-Zellen (D) wurden für $48 \mathrm{~h}$ in An- (+Tet) und Abwesenheit (- Tet) von Tetrazyklin $(10 \mu \mathrm{g} / \mathrm{ml})$ unter normoxischen Bedingungen inkubiert. Die Zellen wurden mit dem Farbstoff $\operatorname{DiOC}_{2}(1 \mu \mathrm{g} / \mathrm{ml})$ für 15 min beladen. Im Anschluss erfolgte die Messung des Exports über Fluoreszenzmessung (siehe Kapitel 2.8.2, Seite 287. In einigen Proben wurden $22 \mu \mathrm{M}$ Vinblastin hinzugefügt. $(\mathrm{n}=3 \pm \mathrm{SD}) ; * \mathrm{p} \leq 0,05$.

Dabei wurden 2.1.1-16-Zellen zunächst für $48 \mathrm{~h}$ in An- und Abwesenheit von Tet $(10 \mu \mathrm{g} / \mathrm{ml})$ bei Normoxie inkubiert und anschließend in Zellkulturmedium aufgenommen. Die Zellen 
wurden mit dem Farbstoff DiOC 2 für 15 min bei $4^{\circ} \mathrm{C}$ beladen. Die Zellen wurden in Zellmedium gewaschen und bei verschiedenen Bedingungen inkubiert. Der Export wurde bestimmt, indem die Fluoreszenz der exportstimulierten Zellen $\left(37^{\circ} \mathrm{C}\right)$ mit der Fluoreszenz der Zellen im Vergleich gesetzt wurde, deren Efflux bei $4^{\circ} \mathrm{C}$ gehemmt wurde. $\mathrm{DiOC}_{2}$ wird sehr spezifisch durch den MDR-1-Transporter über die Zellmembran nach außen transportiert [Mindermann et al., 1996. Bei einigen Proben wurde der Efflux über Vinblastin (10 mM) kompetitiv gehemmt [Sikic et al., 1997].

Konform zu den erhobenen Zytotoxizitätsdaten, konnte eine erhöhte Aktivität des MDR-1Transporters in Anwesenheit von Tet als eine Konsequenz des PHD2-knock-downs festgestellt werden (siehe Abbildung 3.16 D, Seite 56. Dieses Experiment zeigt, dass der gesteigerte Efflux in Anwesenheit von Tet MDR-1-vermittelt ist, da eine Verapamilhemmung zu einer deutlichen Abnahme des Effluxes führt.

\subsection{Behandlung von Zellen mit DMOG führt HIF-1 $\alpha$-abhängig zu einer erhöhten Expression und Aktivität von MDR-1}

In der Literatur konnte gezeigt werden, dass MDR-1 auf RNA- und Proteinebene HIFabhängig unter hypoxischen Bedingungen vermehrt exprimiert wird [Comerford et al., 2002].

Um zu untersuchen, ob eine Inhibition der PHDs mit DMOG HIF-abhängig zu einer vermehrten Expression auf RNA-Ebene von MDR-1 führt, wurden MEF-Hif-1 $\alpha^{+/+}-$, MEF-Hif$1 \alpha^{-/-}$- und HeLa-Zellen für $24 \mathrm{~h}$ mit DMOG (1 mM) inkubiert und im Anschluss ein Nachweis der MDR-1-mRNA mittels RT-PCR durchgeführt. Abbildung 3.17] A (Seite 58) zeigt, dass DMOG-Behandlung in den MEF-Hif- $1 \alpha^{+/+}$-Zellen zu einem Anstieg der MDR-1-Expression auf RNA-Ebene führt. Ein solcher Anstieg kann bei MEF-Hif- $1 \alpha^{-/-}$-Zellen nicht festgestellt werden. Eine Induktion der MDR-1-Expression konnte auch durch DMOG-Zugabe bei HeLaZellen nachgewiesen werden (siehe Abbildung 3.17 B, Seite 58).

Um die vermehrte Expression von MDR-1 durch DMOG-Zugabe auf Proteinebene nachzuweisen, wurden MEF-Hif- $1 \alpha^{+/+}$- sowie MEF-Hif-1 $\alpha^{-/-}$-Zellen für maximal $24 \mathrm{~h}$ in An- und Abwesenheit von DMOG (1 mM) inkubiert und zu verschiedenen Zeitpunkten die Expression auf Proteinebene von MDR-1 untersucht. Bei den MEF-Hif- $1 \alpha^{+/+}$-Zellen kommt es im Zeitverlauf zu einer Zunahme der Expression von MDR-1 unter DMOG-Behandlung. Dieser Effekt ist nicht bei den MEF-Hif-1 $\alpha^{-/-}$-Zellen feststellbar. Die Induktion der MDR-1-Expression auf Proteinebene unter DMOG-Behandlung ist somit HIF-abhängig. 
Um den Einfluss einer erhöhten Expression auf die Transportrate zu bestimmen, wurde der Efflux über den Multidrug Resistance Direct Dye Efflux Assay bestimmt. Dabei wurden HeLa-, MEF-Hif- $1 \alpha^{+/+}$- sowie MEF-Hif-1 $\alpha^{-/-}$-Zellen mit dem Farbstoffen DiOC 2 für 15 min bei $4^{\circ} \mathrm{C}$ beladen. Die Zellen wurden mit Zellmedium gewaschen und bei verschiedenen Bedingungen inkubiert. Der Export wurde bestimmt, indem die Fluoreszenz der exportstimulierten Zellen $\left(37^{\circ} \mathrm{C}\right)$ mit der Fluoreszenz der Zellen im Vergleich gesetzt wurde, deren Efflux bei $4^{\circ} \mathrm{C}$ gehemmt wurde. Bei einigen Proben wurde der Efflux über Vinblastin (10 mM) kompetitiv gehemmt.
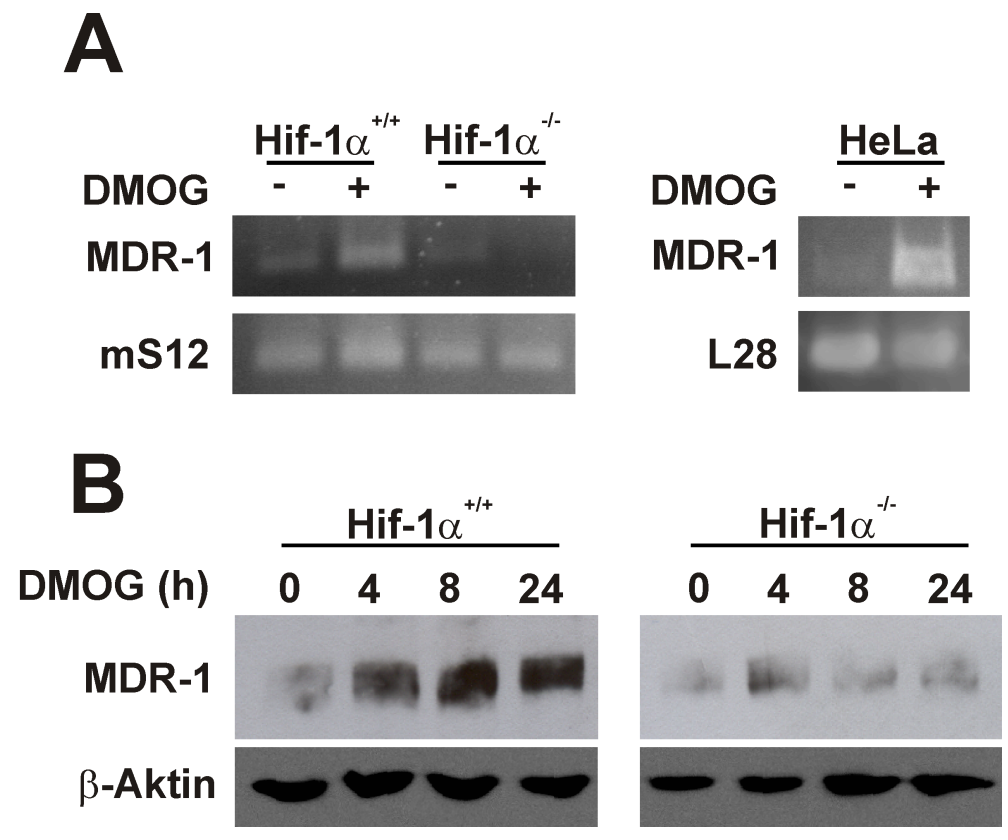

Abbildung 3.17: DMOG induziert die Expression von MDR-1 auf RNA- und Proteinebene HIF-1 $\alpha$ abhängig. MEF-Hif-1 $\alpha^{+/+}$, MEF-Hif-1 $\alpha^{-/-}$- und HeLa-Zellen wurden für bis zu $24 \mathrm{~h}$ in Anund Abwesenheit von DMOG (1 mM) inkubiert. Die Zellen wurden lysiert und Protein und RNA isoliert. Die Expression von MDR-1-mRNA wurde mittels RT-PCR bei den MEF-Hif$1 \alpha^{+/+}-$, MEF-Hif-1 $\alpha^{-/-}$-Zellen und HeLa-Zellen nach $24 \mathrm{~h}$ untersucht und im Verhältnis zu mS12- bzw. L28-mRNA angegeben (A). Über Western Blots wurde die Proteinexpression von MDR-1 bei den MEF-Hif-1 $\alpha^{+/+}$-, MEF -Hif-1 $\alpha^{-/-}$-Zellen für vier Zeitpunkte nachgewiesen (B).

Die Effluxkapazität der unbehandelten MEF-Hif-1 $\alpha^{+/+}$- sowie MEF-Hif- $1 \alpha^{-/-}$-Zellen weist keinen signifikanten Unterschied auf (siehe Abbildung 3.18, Seite 59]. Eine erhöhte Transporterkapazität ist bei Vorbehandlung mit DMOG festzustellen bei den MEF-Hif- $1 \alpha^{+/+}$- und den HeLa-Zellen, nicht aber bei den MEF-Hif-1 $\alpha^{-/-}$-Zellen. In Anwesenheit von Vinblastin 
kommt es bei allen Proben zu einer Abnahme der Transporterkapazität. Die Versuche zeigen zusammengenommen, dass die DMOG-induzierte MDR-1-Aktivität durch HIF-1 $\alpha$ vermittelt wird.

A

$\square$ - DMOG

+ DMOG

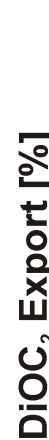

Vinblastin

100

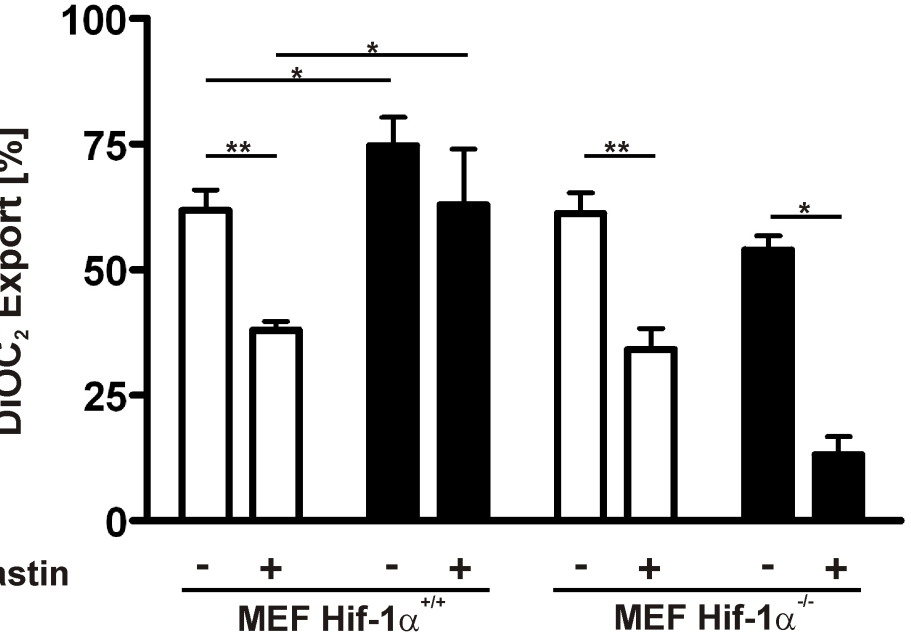

* $p<0.05$

** $p<0.01$
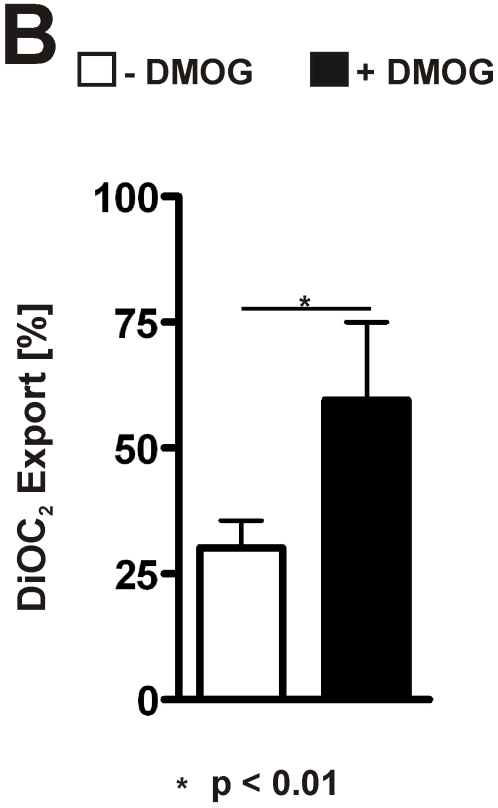

Abbildung 3.18: Gesteigerte Aktivität des MDR-1-Transporters durch DMOG-Behandlung. MEF-Hif$1 \alpha^{+/+}-$, MEF-Hif-1 $\alpha^{-/-_{-}}$(A) und HeLa-Zellen (B) wurden für bis zu $24 \mathrm{~h}$ in An- und Abwesenheit von DMOG (1 $\mathrm{mM})$ unter normoxischen Bedingungen inkubiert. Die Zellen wurden mit dem Farbstoff DiOC $_{2}(1 \mu \mathrm{g} / \mathrm{ml})$ für 15 min beladen. Im Anschluss erfolgte die Messung des $\mathrm{DiOC}_{2}$ Export über Fluoreszenzmessung, In einigen Proben wurden $22 \mu \mathrm{M}$ Vinblastin hinzugefügt. $(\mathrm{n}=3 \pm \mathrm{SD})$ 


\section{Diskussion}

HIF-1 ist ein essentieller Transkriptionsfaktor, der die sauerstoffabhängige Expression von mehr als 100 Zielgenen reguliert. Entscheidende Anpassungsvorgänge, wie metabolische Adaptation, pH-Regulation und Angiogenese werden HIF-1-vermittelt eingeleitet [Wenger. 2002]. Solide Tumoren weisen 50 - $60 \%$ hypoxische oder anoxische Bereiche auf, in denen es im Zuge des geringeren Sauerstoffangebots zu einer Stabilisierung von HIF-1 $\alpha$ kommt [Talks] et al., 2000; Vaupel and Mayer, 2007]. Als Folge kommt es zur Akkumulation von HIF-1 mit Tumorprogression, anti-Tumor-Resistenzbildung und schlechterer Prognose für den Patienten [Semenza, 2002]. Für die sauerstoffabhängige Regulation von HIF-1 $\alpha$ sind die PHDs verantwortlich, die zunehmend als Ziel einer spezifischen Therapie gesehen werden [Frais] et al., 2009]. Darum hat das Wissen über deren Einfluss auf die Chemoresistenz an Bedeutung gewonnen.

Die Inhibition der PHDs führt sowohl in vitro als auch in vivo zu einer Aktivierung des HIF-1-Signalweges [Warnecke et al., 2003]. Über eine PHD-Inhibition kann somit unter normoxischen Bedingungen direkt Einfluss auf die HIF-1-abhängige Expression über eine Stabilisierung von HIF-1 $\alpha$ und Stimulation der Expression der Zielgene genommen werden. In vitro kann eine Inhibition über das Oxoglutaratanalogon DMOG erfolgen. In vivo hingegen ist eine Behandlung mit DMOG aufgrund der zahlreichen Nebenwirkungen nicht optimal. Aus diesem Grund sind spezifische PHD-Inhibitoren für in-vivo-Experimente in Entwicklung. Einige werden bereits in Phase-II-Studien eingesetzt werden. Über eine medikamentöse Inhibition der PHDs soll die endogene EPO-Produktion bei Patienten, die im Zuge von chronischer Niereninsuffizienz, anti-Tumor-Therapie oder chronischem Entzündungsleiden anämisch wurden, angeregt werden. Daneben nimmt die Inhibition der PHDs über die daraus resultierende Stabilisierung von HIF-1 $\alpha$ und anschließender HIF-1-vermittelter Geneexpression Einfluss auf die Zytoprotektion, die im Kontext von Gewebsschäden der Niere, des zentralen Nervensystems und der Herz-Kreislaufsystems aufgrund Sauerstoffmangels bedeutend ist. Zahlreiche Arbeitsgruppen konnten bereits einen Effekt der PHD-Inhibition auf die EPO-Produktion sowie auf die Zytoprotektion während ischämischer Phasen am Tiermodell nachweisen [Bernhardt et al., 2006; Kim W et al., 2006]. 
Problematisch ist die zur Zeit vorhandenen geringe Spezifität der Inhibitoren. Eine Anwendung führt zur unspezifischen Inhibition alle drei Isoformen. Die einzelnen Isoformen unterscheiden sich in ihrer Aktivität gegenüber den spezifischen HIF $\alpha$-Isoformen, die sich neben der Struktur auch in ihren induzierten Zielgenen unterscheiden. Die ubiquitäre Expression der PHDs und die zahlreichen HIF-1-abhängigen Gene führen zu einer Reihe an ungewollten Nebenwirkungen. Selektive Inhibition einer einzelnen Isoform der PHDs und daraus resultierende spezifische Einflussnahme auf die Stabilität einer bestimmten HIF $\alpha$-Isoform und damit verbunden die Begrenzung an Nebenwirkungen kann in Zukunft neue Chancen für eine spezifische Therapie bieten. Die zunehmende Bedeutung der einzelnen PHDs als mögliches Ziel einer spezifischen Therapie muss unweigerlich zu einer genaueren Betrachtung deren zellulären Auswirkungen im Falle der spezifischen Inhibition einer einzelnen Isoform führen.

Wie aus vorangegangenen Studien schon bekannt, kommt es nach Behandlung mit DMOG zu einer starken Stabilisierung des Transkriptionsfaktors HIF-1 $\alpha$ [Köditz et al., 2007]. In Abhängigkeit von der Inkubationszeit nimmt die Stabilisierung zu. Eine Inkubation für 24 Stunden führt im Vergleich zu einer Inkubation von 4 Stunden zu einer deutlicheren Zunahme des Transkriptionsfaktors (siehe Abbildung 3.1, Seite 35).

Im Rahmen dieser Arbeit kommt es im Zuge der unspezifischen Inhibition der PHDs durch die DMOG-Behandlung gegenüber Etoposid zu einer signifikant gesteigerten Chemoresistenz. Werden diese Zellen mit dem ebenfalls klinisch-relevanten Zytostatikum Carboplatin behandelt, konnte kein Einfluss auf die Chemoresistenz festgestellt werden. Interessanterweise scheint die gesteigerte Chemoresistenz Etoposid-spezifisch zu sein.

Infolge der Stabilisierung von HIF-1 $\alpha$ kommt es zu einer HIF-1-vermittelten Induktion zahlreicher Gene. HIF-1-abhängig werden entscheidende Anpassungsvorgänge eingeleitet, die im Rahmen der Tumorbildung, wie Tumorangiogenese, pH-Regulation und metabolische Adaptation, entscheidend sind [Wenger et al., 2005]. Darüber hinaus werden zahlreiche Gene HIF-1-abhängig exprimiert, die auf zellulärer Ebene involviert sind in Zellüberleben und Resistenz gegenüber Chemotherapeutika [Semenza, 2002]. Verantwortlich für eine gesteigerte Resistenz kann eine Veränderung der Genexpression auf mehreren Ebenen sein, für die bereits eine HIF-1-Abhängigkeit gezeigt werden konnte: Influx und Efflux, DNA-Reparatur oder Veränderung des apoptotisches Potential [Wartenberg et al., 2001; Erler et al., 2004; Schnitzer et al., 2006; Sermeus et al., 2008; Sullivan et al., 2008; Wirthner et al., 2008].

In weiteren Experimenten konnte gezeigt werden, dass die Zunahme der Resistenz infolge der Inhibition der PHDs nach DMOG-Behandlung gegenüber Etoposid abhängig von der $\alpha$-Untereinheit ist. Werden MEF-Hif- $1 \alpha^{-/-}$- und MEF-Hif- $1 \alpha^{+/+}-$Zellen mit DMOG be- 
handelt, kommt es nur in MEF-Hif- $1 \alpha^{+/+}$-Zellen zu einer Stabilisierung der $\alpha$-Untereinheit (siehe Abbildung 3.3, Seite 38). Im Zuge dieser Stabilisierung kommt es zu einer gesteigerten Resistenz gegenüber Etoposid. Interessanterweise handelt es sich auch bei den MEFHif- $1 \alpha^{+/+}$-Zellen um eine Etoposid-spezifische Chemoresistenz. HeLa-Zellen zeigten nach DMOG-Behandlung eine gesteigerte Resistenz gegenüber Etoposid, nicht aber Carboplatin. Eine HIF- $1 \alpha$-abhängige gesteigerte Chemoresistenz deckt sich mit den Ergebnissen anderer Arbeitsgruppen [Wirthner et al., 2008].

Im Rahmen einer DMOG-induzierten unspezifischen Inhibition der PHDs konnte eine gesteigerte Chemoresistenz gegenüber Etoposid festgestellt werden. Es konnte gezeigt werden, dass die Entwicklung der Resistenz HIF- $1 \alpha$-abhängig ist. Vorangegangene Studien haben gezeigt, dass die Zytotoxizität von Etoposid unter normoxischen und hypoxischen Bedingungen keine signifikanten Unterschiede aufweist. Allenfalls kommt es zu einem kleinen Anstieg des $\mathrm{IC}_{50}$ unter hypoxischen Bedingungen [Unruh et al., 2003]. Diese Beobachtung scheint im Widerspruch zu den in dieser Arbeit beschriebenen Ergebnissen zu stehen, schließlich führt die Inhibition der PHDs, vergleichbar mit hypoxischen Bedingungen, zu einer Stabilisierung der $\alpha$-Untereinheit mit anschließender HIF-1-abhängigen Genexpression. Entscheidend ist, dass eine DMOG-abhängige PHD-Inhibition nur ungenau hypoxische Bedingungen widerspiegelt. Neben der HIF-abhängigen Genexpression führt Hypoxie zur weiteren Aktivierung zahlreicher anderer Signalwege. Die PHDs modulieren sehr spezifisch den HIF-Signalweg, weitere Wege werden bei dieser Inhibition nicht betrachtet. Darüber hinaus unterscheidet sich die HIF-Antwort nach DMOG-Inhibition der PHDs und während Sauerstoffmangelbedingungen. Im Zuge der hypoxischen Stabilisierung von HIF-1 $\alpha$ kommt es im Sinne eines negativen Feedbacks zur Induktion der Genexpression von PHD2 und PHD3 [Stiehl et al., 2006]. So führt eine gesteigerte Expression unter hypoxischen Bedingungen von PHD2 und 3 zu einer Limitierung der HIF-Antwort. Die gesteigerte Expression nach DMOG-Behandlung führt allerdings nicht zu einer Limitierung der HIF-Antwort aufgrund der andauernden Hemmung der PHDs. Behandlung von Zellen mit einem PHD-Inhibitor führt demnach zu einer chronischen Aktivierung des Signalwegs und unterscheidet sich von der physiologischen, hypoxischen Antwort. Die genaue Einstellung der Inhibition, sodass die Situation der physiologischen Antwort ähnelt, ist schwer möglich. Dies muss bei der zukünftigen Anwendung beachtet werden. Darüber hinaus führt DMOG neben einer unspezifischen Hemmung der PHDs zu einer Hemmung aller Enzyme der Oxoglutarat-abhängigen Dioxygenasenfamilie. Somit ist nicht auszuschließen, dass die Behandlung mit DMOG zu weiteren zellulären Effekten führt, die eine spezifische Resistenzzunahme fördern. 
DMOG führt als Substratanalogon zu einer unselektiven Inhibition aller Isoformen der PHDs. Um den Einfluss der einzelnen Isoformen der PHDs auf die Entwicklung einer Chemoresistenz beurteilen zu können, wurden weitere Experimente an spezifischen PHD2- bzw. PHD3-induzierbarer knock-down-Zelllinien durchgeführt. Zugabe von Tet zum Zellkulturmedium führt bei diesen Zelllinien zu einem messbaren PHD2- bzw. PHD3-knock-down (siehe Abbildung 2.2, Seite 22). Die Experimente wurden an induzierbaren knock-down-Zelllinien durchgeführt, da dies mehrere Vorteile gegenüber transienten Transfektionen von siRNA bzw. shRNA oder nicht-induzierbaren, stabil transfizierten shRNA-Zelllinien hat. Gegenüber transienten Zelllinien bietet die Verwendung induzierbaren knock-down-Zelllinien den Vorteil, dass reproduzierbare Bedingungen zur Verfügung stehen. Die Effizienz einer transienten Transfektion unterliegt möglicherweise einer gewissen Schwankung, wohingegen induzierbare knockdown-Zelllinien relativ konstante knock-down-Effizienzen aufweisen. Die Ergebnisse sind damit besser vergleichbar. Darüber hinaus hat die Verwendung induzierbarer Zelllinien gegenüber stabil nicht-induzierten Zelllinien den Vorteil, dass auftretende Effekte im zeitlichen Zusammenhang des knock-downs betrachtet werden können. Außerdem wird bei Verwendung einer induzierbaren knock-down-Zelllinie im Vergleich zu einem stabilen knock-down eine mögliche Kompensation des knock-downs verhindert, da die Zeitintervalle für diesen Vorgang zu kurz sind. Allerdings bleibt unklar, ob sich die Behandlung mit Tet, neben dem gewünschten knock-down, ungewünscht auf die zellulären Funktionen auswirkt und die Effekte fälschlicherweise als Folge des knock-downs interpretiert werden. Aus diesem Grund wurde zur Kontrolle eine untransfizierten HeLa-T-REx-Zelllinie mit und ohne Tet behandelt, um unspezifische Tet-Effekte zu demaskieren.

Transiente Transfektion von siRNA gegen PHD2 führen nahezu zu einem vollständigen PHD2-knock-down [Stiehl et al., 2006]. Nach diesem effizienten knock-down kann eine HIF$1 \alpha$-Stabilisierung unter normoxischen Bedingungen beobachtet werden [Stiehl et al., 2006; Köditz et al., 2007]. Der PHD2-knock-down innerhalb der induzierbaren 2.1.1-16-Zellen ist weniger effizient, jedoch kommt es auch hier unter normoxischen Bedingungen zu einer HIF$1 \alpha$-Stabilisierung und einer erhöhten Aktivität des Transkriptionsfaktors. PHD3 ist unter normoxischen Bedingungen in den Zellen kaum und lediglich unter hypoxischen Bedingungen nachweisbar. Behandlung der 3.3.3-Zellen mit Tet hingegen führt nur unter hypoxischen Bedingungen zu einem im Western Blot detektierbaren PHD3-knock-down.

Um den Einfluss eines spezifischen knock-downs der einzelnen Isoformen PHD2 und 3 auf die Entwicklung einer Chemoresistenz zu untersuchen, erfolgte unter normoxischen und hypoxischen Bedingungen die Behandlung mit Etoposid und Carboplatin. 
Nach Behandlung der 2.1.1-16-Zelllinie mit Tet kommt es gegenüber Etoposid zu einer Zunahme der Resistenz unter normoxischen sowie hypoxischen Bedingungen. Ein PHD2knock-down und die damit verbundene Stabilisierung von HIF-1 $\alpha$ führten zu einer Steigerung der Chemoresistenz. Im Vergleich zur Normoxie fällt die Zunahme der Chemoresistenz unter hypoxischen Bedingungen deutlicher aus. Wahrscheinlich führt die weitere Hypoxieinduzierte Stabilisierung von HIF-1 zu einer Zunahme der Gesamtaktivität von HIF-1 unter diesen Bedingungen. Wird davon ausgegangen, dass es HIF-1-abhängig zu einer Zunahme der Chemoresistenz kommt, fällt auf, dass im Widerspruch dazu kein Einfluss der Sauerstoffkonzentration auf die Chemoresistenz bei den T-REx-HeLa-Zellen sowie den 2.1.1-16-Zellen in Abwesenheit von Tet festgestellt werden kann. Hypoxische Bedingungen nehmen nur Einfluss im Rahmen eines PHD2-knock-downs.

Normalerweise führt Hypoxie zu einer starken Aktivierung des Transkriptionsfaktors HIF1 [Jewell et al., 2001], wobei Dauer und Schwere der Hypoxie dabei einen Einfluss auf die Ausprägung nehmen. Vermutlich reichen die vorliegenden Bedingungen für die Ausbildung einer HIF-1-induzierten Chemoresistenz gegenüber Etoposid nicht aus. Aus vorangegangene Studien ist bereits bekannt, dass hypoxische Bedigungen bei anderen Zelllinien keinen Einfluss auf die Etoposid-induzierte Zytotoxizität haben [Unruh et al., 2003]. Erst im Zuge eines PHD2-knock-downs kann die Sauerstoffkonzentration einen Einfluss auf die Chemoresistenz ausüben. Ursächlich dafür kann auch hier der zelluläre, negative Rückkoppelungsmechanismus sein: Die vermehrte Stabilisierung von HIF-1 führt physiologisch zu einer vermehrten Expression von PHD2 und PHD3, die wiederum vermehrt die $\alpha$-Untereinheit für den weiteren Abbau markieren. Dieser Rückkopplungsmechanismus wird unter einem knock-down, vergleichbar mit Zustand einer DMOG-Behandlung, nahezu ausgeschaltet, da die Expression der Sauerstoffsensoren durch den knock-down gehemmt werden. Was resultiert ist eine erhöhte Stabilisierung von HIF-1 $\alpha$ und eine Zunahme der Expression der HIF-Zielgene. Dies erklärt, warum allein im Rahmen eines PHD2-knock-downs die Sauerstoffkonzentration einen Einfluss nehmen kann.

Ein PHD3-knock-down hat, im Gegensatz zu einem PHD2-knock-down, keinen Einfluss auf die Chemoresistenz. Weder unter normoxischen noch unter hypoxischen Bedingungen kann ein Einfluss auf die Etoposid-induzierte Zytotoxizität festgestellt werden. PHD3 unterscheidet sich hinsichtlich seines Expressionsprofils und seiner Bedeutung für die Regulation von HIF$1 \alpha$ von PHD2. Der Einfluss von PHD3 im Vergleich zu PHD2 auf die Regulation von HIF-1 $\alpha$ ist insgesamt deutlich geringer [Berra et al., 2003]. Unter normoxischen Bedingungen ist eine PHD3-Expression kaum feststellbar. Erst durch die HIF-1-abhängige Geninduktion unter 
4. Diskussion

hypoxischen Bedingungen kommt es zu einer deutlichen Zunahme der Expression, die nun im Western Blot nachgewiesen werden kann [Appelhoff et al., 2004]. Ein PHD3-knock-down macht sich dementsprechend nur unter hypoxischen Bedingungen bemerkbar (siehe Abbildung 2.2. Seite 22). Insofern ist es nicht verwunderlich, dass kein signifikanter Einfluss eines PHD3-knock-downs unter normoxischen Bedingungen auf die Chemoresistenz festgestellt werden kann.

Allerdings hat auch der PHD3-knock-down unter hypoxischen Bedingungen kein Einfluss auf die Chemoresistenz. PHD3 weist eine höhere Aktivität gegenüber HIF-2 $\alpha$ auf. Obwohl HIF- $1 \alpha$ und HIF- $2 \alpha$ in ihrer Sequenz große Ähnlichkeiten aufweisen, sind sie in ihrer Funktion unterschiedlich. Die Expression von HIF- $2 \alpha$ ist, im Gegensatz zu der Expression von HIF$1 \alpha$, restriktiver und organspezifischer. Hohe Proteinlevel konnten physiologisch für Plazenta, Lunge und Herz nachgewiesen werden. Darüber hinaus konnte gezeigt werden, dass diverse Gene existieren, die spezifisch nach erfolgter Dimierisierung mit der $\beta$-Untereinheit nur von HIF-1 $\alpha$ oder HIF-2 $\alpha$ induziert werden [ Hu et al., 2003; Raval et al., 2005; Wang V et al., 2005; Kim W et al., 2006; Hu et al., 2007]. Die Bedeutung des Transkriptionsfaktors HIF für die Tumorgenese ist anhand des Nierenzellkarzinoms gut charakterisiert, bei dem HIF- $2 \alpha$ eine spezielle Funktion einnimmt [Kim W and Kaelin, 2004]. VHL ${ }^{-1-}$-Nierenzellkarzinomzellen weisen eine erhöhte Expression von HIF-2 $\alpha$ auf, die in Verbindung mit erhöhter Dysplasieund Atypieneigung gebracht wird und für das Tumorwachstum essentiell ist [Maxwell et al. 1999; Mandriota et al., 2002; Kondo et al., 2003]. Neben dem Nierenzellkarzinom konnte eine erhöhte Expression von HIF-2 $\alpha$ in Bronchialkarzinomzellen festgestellt werden, die mit der Tumorgröße und der Prognose des Patienten signifikant korreliert [Giatromanolaki et al., 2001; Kim W et al., 2009]. Der Einfluss von HIF-2 $\alpha$ auf die Ausbildung einer Resistenz gegenüber einer anti-Tumor-Therapie hingegen ist bisher nicht geklärt. Es kann vermutet werden, dass vor allem die Akkumulation von HIF-1 $\alpha$ für die Ausbildung der Chemoresistenz verantwortlich und der Einfluss von HIF-2 $\alpha$ marginal ist. Der PHD3-knock-down führt nur zu einer leichten Stabilisierung des Transkriptionsfaktors HIF-1 $\alpha$. Dieser Einfluss ist als gering einzuschätzen, als dass er zu einer signifikanten Beeinflussung der Chemoresistenz führt. Darüber hinaus ist das Expressionsprofil von HIF-2 $\alpha$ organspezifischer und möglicherweise in den T-REx-HeLa-Zellen, die aus humanen Zervix-Adenokarzinomzellen gewonnen wurden, für die Sauerstoffadaptation kaum bedeutend.

Es erfolgte die weitere Charakterisierung der 2.1.1-16-Zelllinien, damit ausgeschlossen werden kann, dass ein PHD2-knock-down Einfluss auf Proliferationsrate, Vitalität oder eine unterschiedliche Verteilung des Zellzyklus und damit der Chemoresistenz nimmt. 
Insgesamt konnte für die transfizierten Zelllinien eine geringere Proliferation festgestellt werden, die aber Tet-unabhängig zu beobachten ist. Allein die durchgeführte stabile Transfektion des jeweiligen Plasmids führt bei diesen Zellen zu einer Abnahme der Proliferationspotentials (siehe Abbildung 3.6. Seite 41). Da diese Änderung unabhängig von einer Tet-Behandlung und somit von dem PHD2-knock-down zu beobachten ist, kann ein Einfluss der Tet-Behandlung bzw. des PHD2-knock-downs auf die Chemoresistenz über unterschiedliche Proliferationspotentiale ausgeschlossen werden. Ebenfalls wirkt sich eine unterschiedliche Verteilung des Zellzyklus auf die Chemoresistenz aus. Bei den 2.1.1-16-Zellen konnte im Vergleich zu HeLa-T-REx-Zellen eine andere Verteilung festgestellt werden, die ebenfalls Tet-unabhängig und somit auch unabhängig von einem PHD2-knock-down zu beobachten ist. Es befinden sich bei der 2.1.1-16-Zelllinie mehr Zellen in der $\mathrm{G}_{0} / \mathrm{G}_{1}$-Phase als bei der HeLa-TREx-Zelllinie. Diese Beobachtung steht im Einklang mit den gemachten Proliferationsstudien, da höhere Proliferationsraten unweigerlich zu einem größeren Anteil der Zellen in der S- oder $\mathrm{G}_{2}$-Phase führen. Es konnte ebenfalls kein Unterschied der Vitalität zwischen den Zelllinien festgestellt werden, noch hat die Tet-Behandlung einen Einfluss auf die Vitalität.

Die Behandlung mit Tet und der daraus folgende PHD2-knock-down haben keinen Einfluss auf Proliferation, Zellzyklus und Vitalität. Die Zelllinien eignen sich für die weitere Betrachtung der Chemoresistenz in Abhängigkeit von einem spezifischen PHD-knock-down.

Aufgrund Interferenzen zwischen Substraten und dem MTT-Salz kann es bei der Untersuchung der Zytotoxizität mit dem MTT-Assay zu falschen Ergebnissen kommen [Vellonen et al. [2004]. Um dieses zu verhindern, wurde unter Verwendung des MultiTox-FluorMultiplex-Zytotoxizitäts-Assay das Ergebnis verifiziert. In Abhängigkeit eines PHD2-knockdowns konnte eine Zunahme der Vitalität nach Behandlung mit Etoposid beobachtet werden (siehe Abbildung 3.11, 48). Somit kann ausgeschlossen werden, dass es aufgrund möglicher Interferenzen zwischen Etoposid und dem MTT-Substrat zu falschen Ergebnissen gekommen ist.

Die Effektorcaspasen 3 und 7 sind verantwortlich für den apoptotischen Zelluntergang. Mittels des Caspase-Glo Assays konnte gezeigt werden, dass die Tet-Behandlung und damit zusammenhängend der PHD2-knock-down keinen Einfluss auf die Grundaktivität der Caspasen nimmt. Es kann demnach ausgeschlossen werden, dass für eine Resistenzbildung die PHD2abhängige Veränderung der Grundaktivität der Effektorcaspasen 3/7 verantwortlich ist. Nach einer Behandlung der Zellen mit Etoposid kam es lediglich bei den 2.1.1-16-Zellen in Abwesenheit von Tet zu einem deutlichen Anstieg der Effektorcaspasen 3/7 (siehe Abbildung 3.13, Seite 50). Eine Zunahme der Aktivität kann in Anwesenheit von Tet nach Behandlung 
mit Etoposid nicht festgestellt werden. Dies deutet darauf hin, dass der Zelluntergang nach der Behandlung mit Etoposid über eine Aktivierung des zellulären Selbstmordprogramms abläuft. Durch den PHD2-knock-down kommt es bei gleicher Konzentration des Zytostatikums Etoposid im Medium zu einer geringeren zellulären Antwort der Caspasekaskade.

Die Behandlung von HeLa- und MEF-Hif- $1 \alpha^{+/+}$-Zellen mit dem Substatanalogon DMOG führten zur Ausbildung einer spezifischen Chemoresistenz gegenüber Etoposid. Diese Spezifität konnte für die 2.1.1-16-Zelllinie ebenfalls nachgewiesen werden. Im Zuge eines PHD2knock-downs kommt es nur zur spezifischen Resistenzzunahme gegenüber Etoposid, nicht aber gegenüber Carboplatin.

Ein fester Bestandteil einer anti-Tumor-Therapie ist die Behandlung mit Zytostatika. Eine im Rahmen der Therapie ausgebildete Chemoresistenz führt zu einem Versagen der Therapie und mitunter zur Verschlechterung der Prognose des Patienten. Verantwortlich für die Ausbildung einer Chemoresistenz kann die Verringerung der intrazellulären Konzentration des Zytostatikums über eine verminderte Aufnahme oder eine gesteigerte Abgabe sein. Für die Aufnahme diverser endogene und exogene organische Kationen sind die OCTs verantwortlich. Für einige Zytostatika konnte bereits eine transportervermittelte Aufnahme via OCTs gezeigt werden [Hayer-Zillgen et al., 2002]. Kommt es im Rahmen der Therapie zu einer verminderten Expression, führt dies zu einer geringeren intrazellulären Akkumulation des Zytostatikums und zur Ausbildung einer Chemoresistenz. Die Aktivität der OCTs wird auf der Ebene der Transkription sowie posttranslationalen Modifikation reguliert [Choi and Song, 2008]. Es konnte bisher keine HIF-1-abhängige Beeinflussung der Aufnahme von Chemotherapeutika gezeigt werden.

Um die Influxrate von Etoposid in Abhängigkeit eines PHD2-knock-downs bzw. eines HIF$1 \alpha$-knock-outs zu untersuchen, wurden Zellen für fünf min mit $\left[{ }^{3} \mathrm{H}\right]$-Etoposid inkubiert und dessen intrazelluläre Konzentration nach Zelllyse und mehreren Waschschritten über Flüssigkeitsszintillationsmessung bestimmt. Innerhalb dieses kurzen Intervalls kann ausgeschlossen werden, dass Etoposid per Diffusion die Zelle penetriert. Es wird ausschließlich die Transportervermittelte Aufnahme betrachtet.

Ein PHD2-knock-down sowie ein HIF-1 $\alpha$-knock-out zeigten keinen Einfluss auf die Aufnahme des radioaktiv markierten Etoposids, obwohl es innerhalb der relativ kurzen Inkubationszeit zu einer Akkumulation von Etoposid in den Zellen kam. Die Aufnahme von Etoposid erfolgt demnach Transporter-assoziiert, ist aber PHD2- bzw. HIF-1 $\alpha$-unabhängig.

Viele Tumoren sind gegenüber einer zytostatischen Therapie sensibel, bilden aber mit der Dauer der Therapie Resistenzen aus. Ob eine längerfristige Behandlung mit Etoposid in Kom- 
4. Diskussion

bination mit einem PHD2-knock-down bzw. einem HIF-1 $\alpha$-knock-out zu einer verminderten Expression von Transportern führt, die für den Influx verantwortlich sind, kann unter diesen Versuchsbedingungen nicht beantwortet werden. Der Transkriptionsfaktor HIF-1 ist involviert in die Expression zahlreicher Gene, die auf zellulärer Ebene für das Zellüberleben und die Resistenz verantwortlich sind. Neben der Änderung der Genexpression auf Ebene des Influxes kann eine geänderte Genexpression auf weiteren Stufen verantwortlich für eine gesteigerte Chemoresistenz sein, wie Efflux, DNA-Reparatur oder Veränderung des apoptotisches Potential [Wartenberg et al., 2001; Erler et al., 2004; Schnitzer et al., 2006; Sermeus et al., 2008; Sullivan et al., 2008; Wirthner et al., 2008].

Im Rahmen des Medikamenteneffluxes spielen Transporter der ATP-binding cassette-superfamily $(\mathrm{ABC})$ eine entscheidende Rolle. Deren Expression korreliert mit einer geringeren zellulären Akkumulation von hydrophoben Chemotherapeutika, die entlang des Konzentrationsgradienten die Zellmembran penetrieren [Huang Y, 2007]. Transporter der ABC-Familie sind charakterisiert durch eine zytoplasmatische ATP-Bindungsdomäne. Die Hydrolyse von ATP und die damit verbundene Energiegewinnung wird eingesetzt, um Substanzen entgegen ihrem Konzentrationsgefälle aus der Zelle über die Membran zu transportieren. Daneben existieren mit der Nukleotidbindungsdomäne und der transmembranären Domäne zwei weitere Domänen. Transporter der ABC-Familie sind je nach Organisation der Domänen in sieben Subfamilien (A bis G) gegliedert. Insgesamt existieren 49 unterschiedliche Proteine, von denen bis heute drei in Verbindung mit Chemoresistenz gebracht werden konnten [Stavrovskaya and Stromskaya, 2008]. Neben dem MDR-associated protein (MRP-1) und dem breast cancer resistance protein (BCRP) ist das multi drug resistance protein (MDR-1) für den Transport zahlreicher Medikamente und der damit verbundenen Chemoresistenz verantwortlich. In der Literatur werden neben der Bezeichnung MDR-1 auch die älteren Namen P-Glykoprotein sowie ABCB 1 verwendet. MRP-1, BCRP sowie MDR-1 sind involviert in den Efflux diverser Zytostatika, die im Rahmen einer anti-Tumor-Therapie genutzt werden. Neben Gemeinsamkeiten in der Substratspezifität existieren auch zahlreiche Unterschiede. Für alle drei Transporter konnte der Transport von Etoposid nachgewiesen werden [Mao and Unadkat, 2005; Liu, 2009]. Die genannten Transporter werden physiologisch auf normalen Zellen exprimiert. Aus vorangegangenen Studien ist bekannt, dass Tumorzellen oft eine erhöhte Expression aufweisen, die mit einem resistenten Phänotyp sowie schlechter Prognose assoziiert ist [Goldstein, 1996; Marie et al., 1996; Legrand et al., 1999].

Innerhalb dieser Gruppe nimmt MDR-1 eine klinisch-relevante Stellung ein, dessen Hemmung zu einer Steigerung der Zytotoxizität diverser Chemotherapeutika führt Ambudkar 
et al., 2003; Fojo and Bates, 2003; Schinkel and Jonker, 2003]. Die Expression und Aktivität von MDR-1 wird durch diverse Faktoren reguliert, wie Zytokine, Wachstumsfaktoren (u. a. NFkB und c-Fos) und p53 [Li Z et al., 1997; Yang et al., 1997; Ogretmen and Safa, 1999; Lee G and Piguette-Miller, 2003]. Daneben konnte eine gesteigerte Expression unter hypoxischen Bedingungen festgestellt werden. Im Zuge der HIF-1 $\alpha$-Stabilisierung und HIF1-Akkumulation kommt es zur Bindung am HRE des MDR-1-Promotors und gesteigerten Expression des MDR-1-Proteins [Comerford et al., 2002].

Neben Etoposid werden weitere Chemotherapeutika MDR-1-vermittelt transportiert, darunter Doxorubicin und Vinblastin. Doxorubicin gehört zur Gruppe der Anthrazykline und wirkt über eine DNA-Interkalation. Vinblastin, ein Alkaloid, wirkt als Inhibitor der Zellteilung, indem es durch eine Tubulin-Vinblastin-Interaktion zu einer Hemmung der Mitose kommt. Es konnte gezeigt werden, dass es infolge eines PHD2-knock-downs zu einer Zunahme der Resistenz gegenüber Doxorubicin und Vinblastin kommt (siehe Abbildung 3.15, Seite 54). Wie bereits erwähnt, sind die unterschiedlichen Transporter der ABC-Familie substratspezifisch. Doxorubicin wird von MDR-1, MRP-1 sowie BCRP transportiert, wohingegen Vinblastin lediglich von MDR-1 und MRP-1 aus der Zelle befördert wird [Litman et al., 2000; Mao and Unadkat, 2005; Liu, 2009].

Verapamil führt über eine kompetitive Inhibition zu einer Hemmung der Transporter MDR1 und MRP-1. Werden 2.1.1-16-Zellen mit Etoposid behandelt, kommt es in Abhängigkeit von einem PHD2-knock-down zu einer Verminderung der Zytotoxizität. Dieser Effekt wird durch die Behandlung mit dem Inhibitor Verpamil aufgehoben. Die Zytotoxizität von Carboplatin hingegen wird durch die Verapamilhemmung nicht beeinflusst.

Die Ergebnisse lassen vermuten, dass für Entwicklung der Chemoresistenz eine Beeinflussung der Transportkapazität von MDR-1 und MRP-1 verantwortlich ist. Die Transportkapazität ist dabei abhängig von mehreren Faktoren. Neben der Aktivität der einzelnen Proteine spielen die Expression und die Rekrutierung von präformierten Transportern aus Vesikeln eine Rolle [Kim H et al., 1997; Ferrao et al., 2001]. Auf RNA-Ebene konnte eine erhöhte Expression von MDR-1 in Abhängigkeit von einem PHD2-knock-down bei der 2.1.1-16-Zelllinie festgestellt werden. Aufgrund dessen und der Tatsache, dass für MDR-1 eine hypoxische Induktion gezeigt werden konnte [Comerford et al., 2002], wurde nun MDR-1 näher betrachtet, wohlwissend, dass auf zellulärer Ebene die Aktivität mehrerer Transporter entscheidend ist.

Die Kapazität eines bestimmten Transporterproteins korreliert nur ungenügend mit der Expression, vielmehr ist die Aktivität der einzelnen Proteine entscheidend [Bailly et al., 1995; Sikic et al., 1997]. Der Farbstoff $\mathrm{DiOC}_{2}$ ist als spezifisches Substrat von MDR-1 beschrie- 
ben und wird spezifisch entgegen dem Konzentrationsgradienten MDR-1-vermittelt aus der Zelle befördert. Über eine Fluoreszenzreaktion kann nach erfolgten Inkubationszeiten die intrazelluläre Konzentration des Farbstoffes ermittelt und so indirekt auf die Transportkapazität geschlossen werden. Im Zuge eines PHD2-knock-downs kann bei der 2.1.1-16-Zelllinie eine signifikant erhöhte Exportrate von $\mathrm{DiOC}_{2}$ festgestellt werden (siehe Abbildung 3.16, Seite 56). Nach Zugabe von Vinblastin, das neben MRP-1 vor allem die Aktivität von MDR-1 hemmt, kommt es nur nach einem PHD2-knock-down zu einer signifikanten Abnahme der Exportkapazität. Diese Beobachtungen lassen vermuten, dass für die Steigerung der Chemoresistenz gegenüber Etoposid vor allem eine PHD2-vermittelte Zunahme der Transporterkapazität von MDR-1 verantwortlich ist.

Auf Proteinebene konnte gezeigt werden, dass es nach DMOG-Behandlung zu einer vermehrten MDR-1-Expression in HeLa- und MEF-Hif- $1 \alpha^{+/+}$-Zellen kommt (siehe Abbildung 3.17, Seite 58,. Für MEF-Hif-1 $\alpha^{-/-}$-Zellen konnte keine vermehrte Expression festgestellt werden. Die Expression von MDR-1 nimmt im Zeitverlauf nach Behandlung mit DMOG in MEF-Hif- $1 \alpha^{+/+}$-Zellen zu. Für HeLa- und MEF-Hif- $1 \alpha^{+/+}$-Zellen konnte nach Behandlung mit DMOG ein erhöhter $\mathrm{DiOC}_{2}$-Efflux nachgewiesen werden (siehe Abbildung 3.18, Seite 59). Diese Zunahme blieb bei MEF-Hif-1 $\alpha^{-/-}$-Zellen nach DMOG-Behandlung aus. Diese Ergebnisse lassen vermuten, dass es durch die Behandlung mit DMOG HIF- $1 \alpha$-abhängig zu einer vermehrten Expression von MDR-1 kommt und infolge dessen die Transporterkapazität zunimmt. Denkbar wäre eine Zunahme der Kapazität als Folge einer erhöhten Expression sowie Steigerung der Aktivität. Ob die Inhibition der PHDs zusätzlich die Aktivität des einzelnen Transporters beeinflusst, kann unter diesen Versuchsbedingungen nicht gezeigt werden.

Für MDR-1 konnte bereits ein Einfluss von Hypoxie [Comerford et al., 2002], Glukosemangel [Ledoux et al., 2003] sowie reaktiver Sauerstoffradikale [Wartenberg et al., 2005] gezeigt werden. Aktuelle Daten zeigen einen Einfluss des extrazellulären pH-Wertes auf [Thews et al., 2006]. Nach einer Ansäuerung des Zellkulturmediums konnte eine gesteigerte Aktivität von MDR-1 und infolge dessen eine Zunahme der Chemoresistenz gegenüber dem MDR-1Substrat Daunorubicin beobachtet werden. Die Expression von MDR-1 blieb nach Ansäuerung jedoch konstant. Kommt es innerhalb eines soliden Tumors zu Sauerstoffmangelbedingungen, wird HIF-abhängig der Abbau von Glukose über anaerobe Glukolyse gefördert. Es kommt durch die vermehrte Entstehung von Laktat zu einem Abfall des pHs und Steigerung der Transportkapazität von MDR-1. Die Steigerung der Aktivität von MDR-1 als Folge des Abfalls des pH-Wertes ist für die in dieser Arbeit vorgestellten Daten unwahrscheinlich. Durch die Verwendung von gepuffertem Zellkulturmedium und durch den regelmäßigen Wechsel 
können große $\mathrm{pH}-\mathrm{Sch}$ ankungen ausgeschlossen werden. Zudem konnten bei pH-Messungen keine Unterschiede zwischen den Versuchsbedingungen festgestellt werden. Die DMOG- bzw. PHD2-induzierte Zunahme der Transportkapazität ist somit sicher auf die erhöhte Expression zurückzuführen.

Den Daten nach zu urteilen, führt eine starke Aktivierung des HIF-Systems durch eine Inhibition der PHD-Aktivität zu einer gesteigerten Chemoresistenz gegenüber bestimmten Zytostatika über eine Zunahme der Transportkapazität von MDR-1. Carboplatin ist, im Gegensatz zu Etoposid, Vinblastin und Doxorubicin, kein Substrat von MDR-1 [Rabik and Dolan, 2007]. Dementsprechend beeinflusst eine Inhibition der PHD-Aktivität nicht die Zytotoxizität von Carboplatin. Der zytotoxische Effekt einer Behandlung mit Carboplatin wurde nicht von PHD2, HIF-1 $\alpha$ oder einer Behandlung der Zellen mit DMOG beeinflusst. Zudem konnte kein Effekt einer Verapamil-vermittelten Inhibition von MDR-1 und MRP-1 auf die Carboplatin-induzierte Zytotoxizität festgestellt werden. In der Zusammenschau der Datenlage ist die Spezifität der ausgebildeten Chemoresistenz vor allem durch den unterschiedlichen MDR-1-Transport von Etoposid und Carboplatin hervorgerufen.

Neuere Studien zeigen, dass die HIF-1-abhängige Chemoresistenz durch DNA-DoppelstrangReparatur hervorgerufen wird [Wirthner et al., 2008]. Infolge der Behandlung mit Etoposid konnte es in MEF-Hif-1 $\alpha^{+/+}$-Zellen im Vergleich zu MEF-Hif- $1 \alpha^{-/-}$-Zellen eine geringere Anzahl an DNA-Doppelstrang-Brüchen festgestellt werden. Ursächlich für diesen Effekt scheint die Involvierung dreier Mitglieder der DNA-abhängigen Proteinkinasen (DNA-PK) Komplexes zu sein (DNA-PKc, Ku70 sowie Ku80). Mitglieder der DNA-PK sind involviert in die Nicht-homologe-End-zu-End-Verknüpfung der DNA nach Doppelstrang-Brüchen. Durch die HIF-1 $\alpha$-Defizienz kommt es zur DNA-PK-Dysregulation und zum vermehrten Auftreten von DNA-Doppelstrang-Brüchen. Dieser Mechanismus der Resistenzausbildung müsste Einfluss auf die Zytotoxizität von Carboplatin haben und steht damit im Widerspruch zu den in dieser Arbeit gemachten Aussagen. Allerdings konnte in der zitierten Studie keine Induktion der Mitglieder des DNA-PK Komplexes unter hypoxischen Bedingungen oder nach DMOGBehandlung beobachtet werden. Dies steht im Kontrast zur Hypoxie- und DMOG-induzierten Chemoresistenz in Abhängigkeit der Expression von MDR-1.

In der Arbeit konnten Ergebnisse präsentiert werden, die eine DMOG-induzierte, HIF-1 $\alpha$ abhängige MDR-1-Expression vermuten lassen. Natürlich können weitere Mechanismen, wie pH-Pufferung und Änderung des apoptotischen Potentials, an der PHD-abhängigen Chemoresistenz beteiligt sein. Obwohl diverse Arbeitsgruppen bereits eine HIF-1 $\alpha$-abhängige Chemoresistenz zeigen konnten und der Einfluss der PHD-Aktivität auf dessen Stabilisierung bekannt 
ist, war der direkte Einfluss der PHDs auf die Entwicklung einer Chemoresistenz bisher unklar. Inhibition der PHDs führt, wie hier gezeigt, zu einer vermehrten Stabilisierung von HIF-1 $\alpha$ mit allen negativen Konsequenzen in Hinblick auf Chemoresistenz. Die verminderte Expression von PHD2 in Endothelzellen des Tumorgewebes hingegen führt über die Normalisierung der Gefäßarchitektur, neben der Hemmung der Invasion, Intravasation und Metastasenbildung, eventuell zu einer besseren Zugänglichkeit der Chemotherapeutika [Mazzone et al., 2009]. So existiert derzeit eine widersprüchliche Datenlage für den Einsatz von Inhibitoren der PHDs als Krebstherapie. Die Ergebnisse müssen, gerade bei der Behandlung von Anämie bei Krebspatienten, beachtet werden. Um weiter Einblick zu erhalten und möglicherweise in Zukunft eine optimale Therapie zu gestalten, sind weitere Studien erforderlich. Führt die Behandlung mit PHD-Inhibitoren über die bessere Zugänglichkeit für Chemotherapeutika zu einem Tumorregress, oder aber wird auf zellulärem Level die Chemoresistenz induziert? Gerade Ergebnisse aus in-vivo-Studien sind für die weitere Diskussion wertvoll und notwendig.

Zusammenfassend zeigen die hier präsentierten Daten, dass die Inhibition der PHDs HIFabhängig zu einem MDR-1-vermittelten Phänotyp in Tumorzellen führt. Diese Erkenntnisse müssen bei der klinischen Anwendung von PHD-Inhibitoren beachtet werden. 


\section{Zusammenfassung}

Der Transkriptionsfaktor Hypoxie-induzierbarer Faktor (HIF) ist für die sauerstoffabhängige Genexpression von entscheidender Bedeutung. Es sind mehr als 100 Zielgene bekannt, die HIF-1-abhängig exprimiert werden und für eine Adaption an die Sauerstoffverhältnisse sorgen. Über eine Inhibition der Prolyl-4-Hydroxylase-Domäne-Enzyme (PHD), die die Aktivität der $\alpha$-Untereinheit regulieren, kann Einfluss auf den HIF-Signaltransduktionsweg genommen werden. In dieser Arbeit wurde der Einfluss einer Inhibition der PHDs auf die Chemoresistenz untersucht.

Werden die PHDs unspezifisch mit dem 3-Oxoglutaratanalogon Dimethyloxalylglycin (DMOG) inhibiert, kommt es in HeLa-Zellen zu einer gesteigerten Chemoresistenz gegenüber Etoposid, nicht aber Carboplatin. In Tetrazyklin-induzierbaren PHD2-knock-down-HeLa-Zellen konnte ebenfalls eine Zunahme der Etoposid-spezifischen Chemoresistenz festgestellt werden. Dass die Etoposid-spezifische gesteigerte Chemoresistenz HIF-1-abhängig ist, konnte an Maus-embryonalen Fibroblasten (MEF-Hif- $1 \alpha^{+/+}$- und MEF-Hif- $1 \alpha^{-/-}$-Zellen) gezeigt werden. Die verminderte zelluläre Zytotoxizität gegenüber Etoposid korreliert invers mit einer DMOG-induzierbaren, HIF-1 $\alpha$-abhängigen vermehrten MDR-1-Expression und gesteigerten Transportkapazität, die über RT-PCR, Immunoblots und Aktivitätsmessungen bestimmt wurden.

Zusammenfassend zeigen die Daten, dass PHD-Inhibitoren HIF- $1 \alpha$-abhängig zu einer MDR1-vermittelten gesteigerten Chemoresistenz führen. 


\section{Literaturverzeichnis}

Ambudkar SV, Kimchi-Sarfaty C, Sauna ZE and Gottesman M (2003): P-glycoprotein: from genomics to mechanism. Oncogene $\underline{47}, 7468-85$

Appelhoff RJ, Tian YM, Raval RR, Turley H, Harris AL, Pugh CW, Ratcliffe PJ and Gleadle JM (2004): Differential function of the prolyl hydroxylases phd1, phd2, and phd3 in the regulation of hypoxia-inducible factor. J Biol Chem 279, 38458-65

Aprelikova O, Chandramouli G, Wood M, Vasselli J, Riss J, Maranchie J, Linehan W and Barrett J (2004): Regulation of hif prolyl hydroxylases by hypoxia-inducible factors. J Biol Chem 92, 491-501

Aragonés J, Schneider M, Van Geyte K, Fraisl P, Dresselaers T, Mazzone M, Dirkx R, Zacchigna S, Lemieux H, Jeoung NH et al. (2008): Deficiency or inhibition of oxygen sensor phd1 induces hypoxia tolerance by reprogramming basal metabolism. Nat Genet $\underline{40}, 170-80$

Arany Z, Huang LE, Eckner R, Bhattacharya S, Jiang C, Goldberg MA, Bunn HF and Livingston DM (1996): An essential role for $\mathrm{p} 300 / \mathrm{cbp}$ in the cellular response to hypoxia. Proc Natl Acad Sci U S A 93, 12969-73

Bailly JD, Muller C, Jaffrézou J, Demur C, Gassar G, C B and Laurent G (1995): Lack of correlation between expression and function of p-glycoprotein in acute myeloid leukemia cell lines. Leukemia $\underline{9}$, 799-807.

Barth S, Nesper J, Hasgall P, Wirthner R, Nytko K, Edlich F, Katschinski D, Stiehl D, Wenger $\mathrm{R}$ and Camenisch $\mathrm{G}$ (2007): The peptidyl prolyl cis/trans isomerase fkbp38 determines hypoxia-inducible transcription factor prolyl-4-hydroxylase phd 2 protein stability. Mol Cell Biol 27, 3758-68

Bernhardt W, Câmpean V, Kany S, Jürgensen J, Weidemann A, Warnecke C, Arend M, Klaus S, Günzler V, Amann K et al. (2006): Preconditional activation of hypoxia-inducible factors ameliorates ischemic acute renal failure. J Am Soc Nephrol 17, 1970 - 1978

Berra E, Benizri E, Ginouvès A, Volmat V, Roux D and Pouysségur J (2003): Hif prolylhydroxylase 2 is the key oxygen sensor setting low steady-state levels of hif-1alpha in normoxia. EMBO J 22, 4082-90

Bishop T, Gallagher D, Pascual A, Lygate CA, de Bono JP, Nicholls LG, Ortega-Saenz P, Oster H, Wijeyekoon B, Sutherland AI et al. (2008): Abnormal sympathoadrenal development and systemic hypotension in phd3-/- mice. Mol Cell Biol 28, 3386-400 
Brown JM (2002): Tumor microenvironment and the response to anticancer therapy. Cancer Biol Ther $\underline{1}, 453-8$

Bruick RK and McKnight SL (2001): A conserved family of prolyl-4-hydroxylases that modify hif. Science 294, 1337-40

Casadevall N, Nataf J, Viron B, Kolta A, Kiladjian J, Martin-Dupont P, Michaud P, Papo T, Ugo V, Teyssandier I et al. (2002): Pure red-cell aplasia and antierythropoietin antibodies in patients treated with recombinant erythropoietin. N Engl J Med 346, 469-75

Cervera AM, Apostolova N, Luna-Crespo F, Sanjuan-Pla A, Garcia-Bou R and McCreath KJ (2006): An alternatively spliced transcript of the phd3 gene retains prolyl hydroxylase activity. Cancer Lett 233, 131-8

Chan DA, Sutphin PD, Yen SE and Giaccia AJ (2005): Coordinate regulation of the oxygendependent degradation domains of hypoxia-inducible factor 1 alpha. Mol Cell Biol $\underline{25}$, 6415-26

Choi M and Song I (2008): Organic cation transporters and their pharmacokinetic and pharmacodynamic consequences. Drug Metab Pharmacokinet 23, 243-53

Cioffi C, Liu X, Kosinski P, Garay M and Bowen B (2003): Differential regulation of hif1 alpha prolyl-4-hydroxylase genes by hypoxia in human cardiovascular cells. Biochem Biophys Res Commun 303, 947-53

Comerford KM, Wallace TJ, Karhausen J, Louis N, Montalto M and Colgan S (2002): Hypoxia-inducible factor-1-dependent regulation of the multidrug resistance (mdr1) gene. Cancer Res $\underline{62}, 3387-94$

Dalgard C, Lu H, Mohyeldin A and Verma A (2004): Endogenous 2-oxoacids differentially regulate expression of oxygen sensors. Biochem J $\underline{380}$, 419-24

Durand RE (1994): The influence of microenvironmental factors during cancer therapy. In Vivo $\underline{8}, 691-702$

Elvidge G, Glenny L, Appelhoff R, Ratcliffe P, Ragoussis J and Gleadle J (2006): Concordant regulation of gene expression by hypoxia and 2-oxoglutarate-dependent dioxygenase inhibition: the role of hif-1alpha, hif-2alpha, and other pathways. J Biol Chem $\underline{281}$, 15215-26

Ema M, Taya S, Yokotani N, Sogawa K, Matsuda Y and Fujii-Kuriyama Y (1997): A novel bhlh-pas factor with close sequence similarity to hypoxia-inducible factor 1alpha regulates the vegf expression and is potentially involved in lung and vascular development. Proc Natl Acad Sci U S A 94, 4273-8 
Epstein AC, Gleadle JM, McNeill LA, Hewitson KS, O’Rourke J, Mole DR, Mukherji M, Metzen E, Wilson MI, Dhanda A et al. (2001): C. elegans egl-9 and mammalian homologs define a family of dioxygenases that regulate hif by prolyl hydroxylation. Cell $\underline{107}, 43-54$

Erler JT, Cawthorne C, Williams K, Koritzinsky M, Wouters B, Wilson C, Miller C, Demonacos C, Stratford I and Dive C (2004): Hypoxia-mediated down-regulation of bid and bax in tumors occurs via hypoxia-inducible factor 1-dependent and -independent mechanisms and contributes to drug resistance. Mol Cell Biol 24, 2875-89

Erler JT, Bennewith KL, Nicolau M, Dornhöfer N, Kong C, Le QT, Chi JTA, Jeffrey SS and Giaccia AJ (2006): Lysyl oxidase is essential for hypoxia-induced metastasis. Nature 440 , $1222-6$

Evans AJ, Russell RC, Roche O, Burry TN, Fish JE, Chow VWK, Kim WY, Saravanan A, Maynard MA, Gervais ML et al. (2007): Vhl promotes e2 box-dependent e-cadherin transcription by hif-mediated regulation of sip1 and snail. Mol Cell Biol 27, 157-69

Fardel O, Lecureur V and Guillouzo A (1996): The p-glycoprotein multidrug transporter. Gen Pharmacol 27, 1283-91

Ferrao P, Sincock P, Cole S and Ashmann L (2001): Intracellular p-gp contributes to functional drug efflux and resistance in acute myeloid leukaemia. Leuk Res $\underline{25}$, 395-405

Ferrara N and Davis-Smyth T (1997): The biology of vascular endothelial growth factor. Endocr Rev $\underline{18}, 4-25$

Fojo T and Bates S (2003): Strategies for reversing drug resistance. Oncogene 47, 7512-23

Fraisl P, Aragones J and Carmeliet P (2009): Inhibition of oxygen sensors as a therapeutic strategy for ischaemic and inflammatory disease. Nat Rev Drug Discov $\underline{8}, 139-52$

Froelich-Ammon SJ and Osheroff N (1995): Topoisomerase poisons: harnessing the dark side of enzyme mechanism. J Biol Chem 270, 21429-32

Gerald D, Berra E, Frapart Y, Chan D, Giaccia A, Mansuy D, Pouysségur J, Yaniv M and Mechta-Grigoriou F (2004): Jund reduces tumor angiogenesis by protecting cells from oxidative stress. Cell 118, 781-94

Giatromanolaki A, Koukourakis M, Sivridis E, Turley H, Talks K, Pezzella F, Gatter K and AL H (2001): Relation of hypoxia inducible factor 1 alpha and 2 alpha in operable non-small cell lung cancer to angiogenic/molecular profile of tumours and survival. Br J Cancer $\underline{85}$, $881-90$

Goldstein LJ (1996): Mdr1 gene expression in solid tumours. Eur J Cancer 32A, 1039-50 
Gordeuk V, Sergueeva A, Miasnikova G, Okhotin D, Voloshin Y, Choyke P, Butman J, Jedlickova K, Prchal J and Polyakova L (2004): Congenital disorder of oxygen sensing: association of the homozygous chuvash polycythemia vhl mutation with thrombosis and vascular abnormalities but not tumors. Blood 103, 3924-32

Graeber TG, Osmanian C, Jacks T, Housman DE, Koch CJ, Lowe SW and Giaccia AJ (1996): Hypoxia-mediated selection of cells with diminished apoptotic potential in solid tumours. Nature 379, 88-91

Gray LH, Conger AD, Ebert M, Hornsey S and Scott OC (1953): The concentration of oxygen dissolved in tissues at the time of irradiation as a factor in radiotherapy. $\mathrm{Br} \mathrm{J}$ Radiol 26, 63848

Gu YZ, Moran SM, Hogenesch JB, Wartman L and Bradfield CA (1998): Molecular characterization and chromosomal localization of a third alpha-class hypoxia inducible factor subunit, hif3alpha. Gene Expr 7, 205-13

Hanahan D and Weinberg RA (2000): The hallmarks of cancer. Cell $\underline{100}, 57-70$

Hansen M, Nielsen S and Berg K (1989): Re-examination and further development of a precise and rapid dye method for measuring cell growth/cell kill. J Immunol Methods 119, 203-10

Hayer-Zillgen M, Brüss M and Bönisch H (2002): Expression and pharmacological profile of the human organic cation transporters hoct1, hoct2 and hoct3. Br J Pharmacol 136, 829-36

Hengartner MO (2000): The biochemistry of apoptosis. Nature $\underline{6850}, 770-6$

Hirsilä M, Koivunen P, Günzler V, Kivirikko KI and Myllyharju J (2003): Characterization of the human prolyl 4-hydroxylases that modify the hypoxia-inducible factor. J Biol Chem $\underline{278}, 30772-80$

Hoffman EC, Reyes H, Chu FF, Sander F, Conley LH, Brooks BA and Hankinson O (1991): Cloning of a factor required for activity of the ah (dioxin) receptor. Science 252, 954-8

Hu C, Wang L, Chodosh L, Keith B and Simon M (2003): Differential roles of hypoxiainducible factor 1alpha (hif-1alpha) and hif-2alpha in hypoxic gene regulation. Mol Cell Biol 23, 9361-74

Hu C, Sataur A, Wang L, Chen H and Simon M (2007): The n-terminal transactivation domain confers target gene specificity of hypoxia-inducible factors hif-1alpha and hif-2alpha. Mol Biol Cell $\underline{18}, 4528-42$

Huang J, Zhao Q, Mooney S and Lee F (2002): Sequence determinants in hypoxia-inducible factor-1alpha for hydroxylation by the prolyl hydroxylases phd1, phd2, and phd3. J Biol Chem 277, 39792-800 
Huang Y (2007): Pharmacogenetics/genomics of membrane transporters in cancer chemotherapy. Cancer Metastasis Rev 26, 183-201

Huang Y and Sadee W (2006): Membrane transporters and channels in chemoresistance and -sensitivity of tumor cells. Cancer Lett 239, 168-82

Iliopoulos O, Levy AP, Jiang C, Kaelin WG Jr and Goldberg MA (1996): Negative regulation of hypoxia-inducible genes by the von hippel-lindau protein. Proc Natl Acad Sci U S A $\underline{93}$, 10595-9

Isaacs JS, Jung YJ, Mole DR, Lee S, Torres-Cabala C, Chung YL, Merino M, Trepel J, Zbar B, Toro J et al. (2005): Hif overexpression correlates with biallelic loss of fumarate hydratase in renal cancer: novel role of fumarate in regulation of hif stability. Cancer Cell $\underline{8}, 143-53$

Ivan M, Kondo K, Yang H, Kim W, Valiando J, Ohh M, Salic A, Asara JM, Lane WS and Kaelin WG Jr (2001): Hifalpha targeted for vhl-mediated destruction by proline hydroxylation: implications for 02 sensing. Science $292,464-8$

Iyer NV, Kotch LE, Agani F, Leung SW, Laughner E, Wenger RH, Gassmann M, Gearhart JD, Lawler AM, Yu AY et al. (1998): Cellular and developmental control of o2 homeostasis by hypoxia-inducible factor 1 alpha. Genes Dev 12, 149-62

Jaakkola P, Mole DR, Tian YM, Wilson MI, Gielbert J, Gaskell SJ, Av K, Hebestreit HF, Mukherji M, Schofield CJ et al. (2001): Targeting of hif-alpha to the von hippel-lindau ubiquitylation complex by o2-regulated prolyl hydroxylation. Science 292, 468-72

Jewell U, Kvietikova I, Scheid A, Bauer C, Wenger R and Gassmann M (2001): Induction of hif-1alpha in response to hypoxia is instantaneous. FASEB J $\underline{15}, 1312-4$

Jokilehto T, Rantanen K, Luukkaa M, Heikkinen P, Grenman R, Minn H, Kronqvist P and Jaakkola PM (2006): Overexpression and nuclear translocation of hypoxia-inducible factor prolyl hydroxylase phd 2 in head and neck squamous cell carcinoma is associated with tumor aggressiveness. Clin Cancer Res $\underline{12}, 1080-7$

Kallio PJ, Wilson WJ, O'Brien S, Makino Y and Poellinger L (1999): Regulation of the hypoxia-inducible transcription factor 1alpha by the ubiquitin-proteasome pathway. J Biol Chem $\underline{274}, 6519-25$

Kim H, Barroso M, Samanta R, Greenberger L and Sztul E (1997): Experimentally induced changes in the endocytic traffic of p-glycoprotein alter drug resistance of cancer cells. Am J Physiol 273, C687-702

Kim W and Kaelin W (2004): Role of vhl gene mutation in human cancer. J Clin Oncol 22, 4991-5004 
Kim W, Safran M, Buckley M, Ebert B, Glickman J, Bosenberg M, Regan M and Kaelin WJ (2006): Failure to prolyl hydroxylate hypoxia-inducible factor alpha phenocopies vhl inactivation in vivo. EMBO J $25,4650-62$

Kim W, Perera S, Zhou B, Carretero J, Yeh J, Heathcote S, Jackson A, Nikolinakos P, Ospina B, Naumov G et al. (2009): Hif2alpha cooperates with ras to promote lung tumorigenesis in mice. J Clin Invest 119, 2160-70

Knowles H, Raval R, Harris A and Ratcliffe P (2003): Effect of ascorbate on the activity of hypoxia-inducible factor in cancer cells. Cancer Res $\underline{63}, 1764-1768$

Köditz J, Nesper J, Wottawa M, Stiehl DP, Camenisch G, Franke C, Myllyharju J, Wenger RH and Katschinski DM (2007): Oxygen-dependent atf-4 stability is mediated by the phd3 oxygen sensor. Blood $\underline{110}, 3610-7$

Koivunen P, Hirsilä M, Günzler V, Kivirikko KI and Myllyharju J (2004): Catalytic properties of the asparaginyl hydroxylase (fih) in the oxygen sensing pathway are distinct from those of its prolyl 4-hydroxylases. J Biol Chem 279, 9899-904

Kondo K, Kim W, Lechpammer M and Kaelin WJ (2003): Inhibition of hif2alpha is sufficient to suppress pvhl-defective tumor growth. PLos Biol $\underline{3}$, E83

Konerding MA, Miodonski AJ and Lametschwandtner A (1995): Microvascular corrosion casting in the study of tumor vascularity: a review. Scanning Microsc 9, 1233-43; discussion $1243-4$

Lando D, Peet DJ, Gorman JJ, Whelan DA, Whitelaw ML and Bruick RK (2002a): Fih-1 is an asparaginyl hydroxylase enzyme that regulates the transcriptional activity of hypoxiainducible factor. Genes Dev $\underline{16}, 1466-71$

Lando D, Peet DJ, Whelan DA, Gorman JJ and Whitelaw ML (2002b): Asparagine hydroxylation of the hif transactivation domain a hypoxic switch. Science 295, 858-61

Latif F, Tory K, Gnarra J, Yao M, Duh FM, Orcutt ML, Stackhouse T, Kuzmin I, Modi W and Geil L (1993): Identification of the von hippel-lindau disease tumor suppressor gene. Science $\underline{260}, 1317-20$

Ledoux S, Yang R, Friedlander G and Laouari D (2003): Glucose depletion enhances pglycoprotein expression in hepatoma cells: role of endoplasmic reticulum stress response. Cancer Res $\underline{63}, 7284-90$

Lee G and Piguette-Miller M (2003): Cytokines alter the expression and activity of the multidrug resistance transporters in human hepatoma cell lines; analysis using rt-pcr and cdna microarrays. J Pharm Sci 92, 2152-63 
Lee K, Lynd JD, O'Reilly S, Kiupel M, McCormick JJ and LaPres JJ (2008): The biphasic role of the hypoxia-inducible factor prolyl-4-hydroxylase, phd2, in modulating tumor-forming potential. Mol Cancer Res $\underline{6}, 829-42$

Lee S, Nakamura E, Yang H, Wei W, Linggi MS, Sajan MP, Farese RV, Freeman RS, Carter BD, Kaelin WG Jr et al. (2005): Neuronal apoptosis linked to egln3 prolyl hydroxylase and familial pheochromocytoma genes: developmental culling and cancer. Cancer Cell $\underline{8}$, $155-67$

Legrand O, Zompi S, Perrot J, Faussat A, Benderra Z, Chaoui D and Marie J (1999): Role of mrp1 in multidrug resistance in acute myeloid leukemia. Leukemia $\underline{13}, 578-84$

Le-Huu S: Etablierung und Charakterisierung einer Tetrazyklin-induzierbaren PHD2Knockdown-HeLa-Zelllinie. Med. Diss. Göttingen 2009

Li J and Yuan J (2008): Caspases in apoptosis and beyond. Oncogene $\underline{48}$, 6194-206

Li Z, Zhu Y and Lit X (1997): Wild-type p53 gene increases mdr1 gene expression but decreases drug resistance in an mdr cell line kbv200. Cancer Lett 119, 177-82

Lieb M, Menzies K, Moschella M, Ni R and Taubman M (2002): Mammalian egln genes have distinct patterns of mrna expression and regulation. Biochem Cell Biol $\underline{80}, 421-6$

Lipscomb EA, Sarmiere PD and Freeman RS (2001): Sm-20 is a novel mitochondrial protein that causes caspase-dependent cell death in nerve growth factor-dependent neurons. J Biol Chem 276, 5085-92

Lisy K and Peet DJ (2008): Turn me on: regulating hif transcriptional activity. Cell Death Differ 15, 642-9

Litman T, Brangi M, Hudson E, Fetsch P, Abati A, Ross D, Miyake K, Resau J and Bates S (2000): The multidrug-resistant phenotype associated with overexpression of the new abc half-transporter, mxr (abcg2). J Cell Sci 113, 2011-21

Liu F (2009): Mechanisms of chemotherapeutic drug resistance in cancer therapy-a quick review. Taiwan J Obstet Gynecol 48, 239-44

Mahon PC, Hirota K and Semenza GL (2001): Fih-1: a novel protein that interacts with hif1alpha and vhl to mediate repression of hif-1 transcriptional activity. Genes Dev 15, 267586

Manalo DJ, Rowan A, Lavoie T, Natarajan L, Kelly BD, Ye SQ, Garcia JGN and Semenza GL (2005): Transcriptional regulation of vascular endothelial cell responses to hypoxia by hif-1. Blood 105, 659-69 
Mandriota S, Turner K, Davies D, Murray P, Morgan N, Sowter H, Wykoff C, Maher E, Harris A, Ratcliffe P et al. (2002): "hif activation identifies early lesions in vhl kidneys: evidence for site-specific tumor suppressor function in the nephron. Cancer Cell $\underline{5}$, 459-68

Mao Q and Unadkat JD (2005): Role of the breast cancer resistance protein (abcg2) in drug transport. AAPS J $\underline{7}$, E118-33

Marie J, Zhou D, Gurbuxani S, Legrand O and Zittoun R (1996): Mdr1/p-glycoprotein in haematological neoplasms. Eur J Cancer $\underline{32 \mathrm{~A}}, 1034-8$

Masson N, Willam C, Maxwell PH, Pugh CW and Ratcliffe PJ (2001): Independent function of two destruction domains in hypoxia-inducible factor-alpha chains activated by prolyl hydroxylation. EMBO J 20, 5197-206

Masson N, Appelhoff R, Tuckerman J, Tian Y, Demol H, Puype M, Vandekerckhove J, Ratcliffe P and Pugh C (2004): The hif prolyl hydroxylase phd3 is a potential substrate of the tric chaperonin. FEBS Lett $\underline{570}$, 166-70

Maxwell PH, Wiesener MS, Chang GW, Clifford SC, Vaux EC, Cockman ME, Wykoff CC, Pugh CW, Maher ER and Ratcliffe PJ (1999): The tumour suppressor protein vhl targets hypoxia-inducible factors for oxygen-dependent proteolysis. Nature $\underline{399}, 271-5$

Maynard MA and Ohh M (2007): The role of hypoxia-inducible factors in cancer. Cell Mol Life Sci $\underline{64}, 2170-80$

Maynard MA, Qi H, Chung J, Lee EHL, Kondo Y, Hara S, Conaway RC, Conaway JW and Ohh M (2003): Multiple splice variants of the human hif-3 alpha locus are targets of the von hippel-lindau e3 ubiquitin ligase complex. J Biol Chem $\underline{278}$, 11032-40

Mazzone M, Dettori D, Leite de Oliveira R, Loges S, Schmidt T, Jonckx B, Tian Y, Lanahan A, Pollard P, Ruiz de Almodovar C et al. (2009): Heterozygous deficiency of phd 2 restores tumor oxygenation and inhibits metastasis via endothelial normalization. Cell $\underline{136}, 839-51$

Metzen E, Berchner-Pfannschmidt U, Stengel P, Marxsen JH, Stolze I, Klinger M, Huang WQ, Wotzlaw C, Hellwig-Bürgel T, Jelkmann W et al. (2003a): Intracellular localisation of human hif-1 alpha hydroxylases: implications for oxygen sensing. J Cell Sci 116, 1319-26

Metzen E, Zhou J, Jelkmann W, Fandrey J and Brüne B (2003b): Nitric oxide impairs normoxic degradation of hif-1alpha by inhibition of prolyl hydroxylases. Mol Biol Cell 14, $3470-81$

Metzen E, Stiehl DP, Doege K, Marxsen JH, Hellwig-Bürgel T and Jelkmann W (2005): Regulation of the prolyl hydroxylase domain protein 2 (phd2/egln-1) gene: identification of a functional hypoxia-responsive element. Biochem J $\underline{387}$, 711-7 
Minamishima YA, Moslehi J, Bardeesy N, Cullen D, Bronson RT and Kaelin WG Jr (2008): Somatic inactivation of the phd 2 prolyl hydroxylase causes polycythemia and congestive heart failure. Blood 111, 3236-44

Mindermann H, Vanhoefer U, Toth K, Yin M, Minderman M, Wrzosek C, Slovak M and Rustum Y (1996): Dioc2(3) is not a substrate for multidrug resistance protein (mrp)-mediated drug efflux. Cytometry $\underline{25}, 14-20$

Moeller BJ, Cao Y, Li CY and Dewhirst MW (2004): Radiation activates hif-1 to regulate vascular radiosensitivity in tumors: role of reoxygenation, free radicals, and stress granules. Cancer Cell $\underline{5}, 429-41$

Montecucco A and Biamonti G (2007): Cellular response to etoposide treatment. Cancer Lett $\underline{25}, 9-18$

Myllyharju J and Kivirikko KI (1997): Characterization of the iron- and 2-oxoglutaratebinding sites of human prolyl 4-hydroxylase. EMBO J $\underline{16}$, 1173-80

Nakayama K, Frew I, Hagensen M, Skals M, H H, Bhoumik A, Kadoya T, ErdjumentBromage H, Tempst P, Frappell P et al. (2004): Siah2 regulates stability of prolylhydroxylases, controls hiflalpha abundance, and modulates physiological responses to hypoxia. Cell $\underline{117}, 941-952$

Nytko K, Spielmann P, Camenisch G, Wenger R and Stiehl D (2007): Regulated function of the prolyl-4-hydroxylase domain (phd) oxygen sensor proteins. Antioxid Redox Signal $\underline{9}$, $1329-38$

Oehme F, Ellinghaus P, Kolkhof P, Smith TJ, Ramakrishnan S, Hütter J, Schramm M and Flamme I (2002): Overexpression of ph-4, a novel putative proline 4-hydroxylase, modulates activity of hypoxia-inducible transcription factors. Biochem Biophys Res Commun 296, 343-9

Ogretmen B and Safa AR (1999): Negative regulation of mdr1 promoter activity in mcf-7, but not in multidrug resistant mcf-7/adr, cells by cross-coupled nf-kappa b/p65 and c-fos transcription factors and their interaction with the caat region. Biochemistry $\underline{38}, 2189-99$

Overgaard J (1994): Clinical evaluation of nitroimidazoles as modifiers of hypoxia in solid tumors. Oncol Res $\underline{6}, 509-18$

Overgaard J and Horsman MR (1996): Modification of hypoxia-induced radioresistance in tumors by the use of oxygen and sensitizers. Semin Radiat Oncol $\underline{6}, 10-21$

del Peso L, Castellanos M, Temes E, Martin-Puig S, Cuevas Y, Olmos G and Landazuri M (2003): The von hippel lindau/hypoxia-inducible factor (hif) pathway regulates the transcription of the hif-proline hydroxylase genes in response to low oxygen. J Biol Chem 278 , 48690-48695 
Pollard PJ, Wortham NC and Tomlinson IPM (2003): The tca cycle and tumorigenesis: the examples of fumarate hydratase and succinate dehydrogenase. Ann Med 35, 632-9

Pouysségur J, Dayan F and Mazure NM (2006): Hypoxia signalling in cancer and approaches to enforce tumour regression. Nature $\underline{441}, 437-43$

Prabhakar NR and Kline DD (2002): Ventilatory changes during intermittent hypoxia: importance of pattern and duration. High Alt Med Biol 3, 195-204

Pugh CW, Tan CC, Jones RW and Ratcliffe PJ (1991): Functional analysis of an oxygenregulated transcriptional enhancer lying 3' to the mouse erythropoietin gene. Proc Natl Acad Sci U S A 88, 10553-7

Rabik CA and Dolan ME (2007): Molecular mechanisms of resistance and toxicity associated with platinating agents. Cancer Treat Rev 33, 9-23

Raval R, Lau K, Tran M, Sowter H, Mandriota S, Li J, Pugh C, Maxwell P, Harris A and PJ R (2005): Contrasting properties of hypoxia-inducible factor 1 (hif-1) and hif-2 in von hippel-lindau-associated renal cell carcinoma. Mol Cell Biol 25, 5675-86

Rocha S (2007): Gene regulation under low oxygen: holding your breath for transcription. Trends Biochem Sci 32, 389-97

Ryan HE, Lo J and Johnson RS (1998): Hif-1 alpha is required for solid tumor formation and embryonic vascularization. EMBO J $\underline{17}, 3005-15$

Ryan HE, Poloni M, McNulty W, Elson D, Gassmann M, Arbeit J and Johnson RS (2000): Hypoxia-inducible factor-1alpha is a positive factor in solid tumor growth. Cancer Res $\underline{60}$, $4010-5$

Salnikow K, Donald S, Bruick R, Zhitkovich A, Phang J and Kasprzak K (2004): Depletion of intracellular ascorbate by the carcinogenic metals nickel and cobalt results in the induction of hypoxic stress. J Biol Chem $\underline{279}, 319-330$

Schiltz RL, Mizzen CA, Vassilev A, Cook RG, Allis CD and Nakatani Y (1999): Overlapping but distinct patterns of histone acetylation by the human coactivators p300 and pcaf within nucleosomal substrates. J Biol Chem 274, 1189-92

Schinkel AH and Jonker W (2003): Mammalian drug efflux transporters of the atp binding cassette (abc) family: an overview. Adv Drug Deliv Rev 55, 3-29

Schlisio S, Kenchappa RS, Vredeveld LCW, George RE, Stewart R, Greulich H, Shahriari K, Nguyen NV, Pigny P, Dahia PL et al. (2008): The kinesin kif1bbeta acts downstream from egln3 to induce apoptosis and is a potential 1p36 tumor suppressor. Genes Dev 22, 884-93 
Schnitzer S, Schmid T, Zhou J and Brüne B (2006): Hypoxia and hif-1alpha protect a549 cells from drug-induced apoptosis. Cell Death Differ $\underline{13}, 1611-3$

Schofield CJ and Ratcliffe PJ (2004): Oxygen sensing by hif hydroxylases. Nat Rev Mol Cell Biol 5, 343-54

Selak MA, Armour SM, MacKenzie ED, Boulahbel H, Watson DG, Mansfield KD, Pan Y, Simon MC, Thompson CB and Gottlieb E (2005): Succinate links tca cycle dysfunction to oncogenesis by inhibiting hif-alpha prolyl hydroxylase. Cancer Cell $\underline{7}, 77-85$

Semenza GL (2002): Hif-1 and tumor progression: pathophysiology and therapeutics. Trends Mol Med $\underline{8}$, S62-7

Semenza GL, Nejfelt MK, Chi SM and Antonarakis SE (1991): Hypoxia-inducible nuclear factors bind to an enhancer element located 3' to the human erythropoietin gene. Proc Natl Acad Sci U S A $\underline{88}, 5680-4$

Sermeus A, Cosse J, Crespin M, Mainfroid V, de Longueville F, Ninane N, Raes M, Remacle $\mathrm{J}$ and Michiels C (2008): Hypoxia induces protection against etoposide-induced apoptosis: molecular profiling of changes in gene expression and transcription factor activity. Mol Cancer 27, 27

Sharom FJ (1997): The p-glycoprotein efflux pump: how does it transport drugs? J Membr Biol 160, 161-75

Sikic B, Fisher G, Lum B, Halsey J, Beketic-Oreskovic L and Chen G (1997): Modulation and prevention of multidrug resistance by inhibitors of p-glycoprotein. Cancer Chemother Pharmacol 40, S13-9

Stavrovskaya A and Stromskaya T (2008): Transport proteins of the abc family and multidrug resistance of tumor cells. Biochemistry $\underline{73}, 592-604$

Stiehl D, Wirthner R, Köditz J, Spielmann P, Camenisch G and Wenger R (2006): Increased prolyl 4-hydroxylase domain proteins compensate for decreased oxygen levels. evidence for an autoregulatory oxygen-sensing system. J Biol Chem 281, 23482-91

Stolze IP, Tian YM, Appelhoff RJ, Turley H, Wykoff CC, Gleadle JM and Ratcliffe PJ (2004): Genetic analysis of the role of the asparaginyl hydroxylase factor inhibiting hypoxiainducible factor (hif) in regulating hif transcriptional target genes. J Biol Chem 279, 4271925

Sullivan R, Paré G, Frederiksen L, Semenza G and Graham C (2008): Hypoxia-induced resistance to anticancer drugs is associated with decreased senescence and requires hypoxiainducible factor-1 activity. Mol Cancer Ther $\underline{7}, 1961-73$ 
Sutter CH, Laughner E and Semenza GL (2000): Hypoxia-inducible factor 1alpha protein expression is controlled by oxygen-regulated ubiquitination that is disrupted by deletions and missense mutations. Proc Natl Acad Sci U S A 97, 4748-53

Takeda K, Ho VC, Takeda H, Duan LJ, Nagy A and Fong GH (2006): Placental but not heart defects are associated with elevated hypoxia-inducible factor alpha levels in mice lacking prolyl hydroxylase domain protein 2. Mol Cell Biol 26, 8336-46

Takeda K, Aguila HL, Parikh NS, Li X, Lamothe K, Duan LJ, Takeda H, Lee FS and Fong GH (2008): Regulation of adult erythropoiesis by prolyl hydroxylase domain proteins. Blood 111, 3229-35

Talks KL, Turley H, Gatter KC, Maxwell PH, Pugh CW, Ratcliffe PJ and Harris AL (2000): The expression and distribution of the hypoxia-inducible factors hif-1alpha and hif-2alpha in normal human tissues, cancers, and tumor-associated macrophages. Am J Pathol 157, $411-21$

Taylor BL and Zhulin IB (1999): Pas domains: internal sensors of oxygen, redox potential, and light. Microbiol Mol Biol Rev $\underline{63}$, 479-506

Thews O, Gassner B, Kelleher D, Schwerdt G and Gekle M (2006): Impact of extracellular acidity on the activity of p-glycoprotein and the cytotoxicity of chemotherapeutic drugs. Neoplasia $\underline{8}, 143-52$

Tian YM, Mole DR, Ratcliffe PJ and Gleadle JM (2006): Characterization of different isoforms of the hif prolyl hydroxylase phd1 generated by alternative initiation. Biochem $\mathbf{J}$ $\underline{397}, 179-86$

Unruh A, Ressel A, Mohamed HG, Johnson RS, Nadrowitz R, Richter E, Katschinski DM and Wenger RH (2003): The hypoxia-inducible factor-1 alpha is a negative factor for tumor therapy. Oncogene $\underline{22}, 3213-20$

Vaupel P and Mayer A (2007): Hypoxia in cancer: significance and impact on clinical outcome. Cancer Metastasis Rev 26, 225-39

Vaupel P, Thews O and Hoeckel M (2001): Treatment resistance of solid tumors: role of hypoxia and anemia. Med Oncol $\underline{18}, 243-59$

Vellonen K, Honkakoski P and Urtti A (2004): Substrates and inhibitors of efflux proteins interfere with the mtt assay in cells and may lead to underestimation of drug toxicity. Eur $\mathbf{J}$ Pharm Sci $\underline{23}, 181-8$

Vogler M, Dinsdale D, Dyer M and Cohen G (2009): Bcl-2 inhibitors: small molecules with a big impact on cancer therapy. Cell Death Differ 16, 360-7 
Wang GL and Semenza GL (1993): Characterization of hypoxia-inducible factor 1 and regulation of dna binding activity by hypoxia. J Biol Chem $\underline{268}, 21513-8$

Wang GL, Jiang BH, Rue EA and Semenza GL (1995): Hypoxia-inducible factor 1 is a basichelix-loop-helix-pas heterodimer regulated by cellular o2 tension. Proc Natl Acad Sci U S A $\underline{92}, 5510-4$

Wang V, Davis D, Haque M, Huang L and Yarchoan R (2005): Differential gene up-regulation by hypoxia-inducible factor-1alpha and hypoxia-inducible factor-2alpha in hek293t cells. Cancer Res 65, 3299-306

Warburg O (1956): On the origin of cancer cells. Science 123, 309-14

Warnecke C, Griethe W, Weidemann A, Jürgensen J, Willam C, Bachmann S, Ivashchenko Y, Wagner I, Frei U, Wiesener M et al. (2003): Activation of the hypoxia-inducible factorpathway and stimulation of angiogenesis by application of prolyl hydroxylase inhibitors. FASEB J $17,1186-8$

Wartenberg M, Dönmez F, Ling F, Acker H, Hescheler J and Sauer H (2001): Tumor-induced angiogenesis studied in confrontation cultures of multicellular tumor spheroids and embryoid bodies grown from pluripotent embryonic stem cells. FASEB J 15, 995-1005

Wartenberg M, Gronczynska S, Bekhite M, Saric T, Niedermeier W, Hescheler J and Sauer $\mathrm{H}$ (2005): Regulation of the multidrug resistance transporter p-glycoprotein in multicellular prostate tumor spheroids by hyperthermia and reactive oxygen species. Int J Cancer $\underline{113}$, 229-40

Wenger RH (2002): Cellular adaptation to hypoxia: O2-sensing protein hydroxylases, hypoxia-inducible transcription factors, and o2-regulated gene expression. FASEB J 16, $1151-62$

Wenger RH, Stiehl DP and Camenisch G (2005): Integration of oxygen signaling at the consensus hre. Sci STKE $\underline{2005}$, re12

Willam C, Maxwell PH, Nichols L, Lygate C, Tian YM, Bernhardt W, Wiesener M, Ratcliffe PJ, Eckardt KU and Pugh CW (2006): Hif prolyl hydroxylases in the rat; organ distribution and changes in expression following hypoxia and coronary artery ligation. J Mol Cell Cardiol $\underline{41}, 68-77$

Wirthner R, Wrann S, Balamurugan K, Wenger R and Stiehl D (2008): Impaired dna doublestrand break repair contributes to chemoresistance in hif-1 alpha-deficient mouse embryonic fibroblasts. Carcinogenesis $\underline{29}, 2306-16$

Wykoff CC, Beasley NJ, Watson PH, Turner KJ, Pastorek J, Sibtain A, Wilson GD, Turley H, Talks KL, Maxwell PH et al. (2000): Hypoxia-inducible expression of tumor-associated carbonic anhydrases. Cancer Res $\underline{60}$, 7075-83 
Yang J, Sullivan G and Hait W (1997): Regulation of the function of p-glycoprotein by epidermal growth factor through phospholipase c. Biochem Pharmacol $\underline{53}$, 1597-604

Yang J, Zhang L, Erbel PJA, Gardner KH, Ding K, Garcia JA and Bruick RK (2005): Functions of the per/arnt/sim domains of the hypoxia-inducible factor. J Biol Chem 280, 36047-54

Yu F, White SB, Zhao Q and Lee FS (2001): Hif-1alpha binding to vhl is regulated by stimulussensitive proline hydroxylation. Proc Natl Acad Sci U S A $\underline{98}, 9630-5$

Yusa K and Tsuruo T (1989): Reversal mechanism of multidrug resistance by verapamil: direct binding of verapamil to p-glycoprotein on specific sites and transport of verapamil outward across the plasma membrane of k562/adm cells. Cancer Res $\underline{49}, 5002-6$ 


\section{Publikation}

Die Ergebnisse dieser Arbeit wurden publiziert in Cancer Science (2009 Sep. 14):

\section{Increased chemoresistance induced by inhibition of HIF-prolyl-hydroxylase} domain enzymes.

Brökers N, Le-Huu S, Vogel S, Hagos Y, Katschinski DM, Kleinschmidt M.

Department of Cardiovascular Physiology, Georg August University Göttingen, Göttingen, Germany. 


\section{Lebenslauf}

Am 30.11.1984 wurde ich, Nils Brökers, als Sohn von Johann Brökers und Cornelia Brökers, geb. Hövel, in Mettingen geboren. Aufgewachsen bin ich in Wolfenbüttel (Niedersachsen), wo ich ebenfalls meine schulische Laufbahn absolvierte. Dort bestand ich am 22. Juni 2004 mein Abitur mit den Leistungskursen Biologie und Chemie mit der Note 1,8. Meinen Zivildienst leistete ich im Marienkrankenhaus Hamburg ab.

Im April 2005 begann ich mein Studium der Humanmedizin an der Georg-August-Universität Göttingen. Den ersten Abschnitt der Ärztlichen Prüfung bestand ich am 12. April 2007 mit der Note sehr gut.

Meine Dissertation in der Abteilung Herz-Kreislaufphysiologie der Universität Göttingen unter der Leitung von Frau Prof. Dr. med. DM Katschinski begann ich im Okober 2007. Im Rahmen eines Freisemesters in der Zeit von April 2008 - August 2008 konnte ich einen Großteil der Experimente abschließen. In den folgenden beiden Semestern führte ich die Arbeit im Labor semesterbegleitend fort. Die Niederschrift der Dissertation erfolgte anschließend ebenfalls semesterbegleitend.

Ein Teil der Ergebnisse konnte auf der Tagung der Deutschen Physiologischen Gesellschaft 2009 in Gießen innerhalb eines Vortrages vorgestellt werden. Die Deutsche Physiologische Gesellschaft förderte mich mit einem Reisestipendium. Als Erstautor konnte ich die Ergebnisse im September 2009 in dem Journal Cancer Science publizieren.

Finanziell gefördert wurde ich während der Ausarbeitung meiner Doktorarbeit durch das fakultätsinterne Stipendienprogramm Gö4med der Universitätsmedizin Göttingen. Zudem bin ich Stipendiat der bischöflichen Studienförderung Cusanuswerk.

Für meine praktische Ausbildung konnte ich wertvolle Erfahrungen während meiner Famulaturen sammeln, von denen ich eine in Uganda verbracht habe. Voraussichtlich werde ich den zweiten Abschnitt der Ärztlichen Prüfung im Oktober 2011 ablegen.

Im Februar 2010 